\title{
How entomopathogenic endophytic fungi modulate plant-insect interactions
}

\author{
Dissertation \\ to obtain the Ph. D. degree in Entomology \\ in the International Ph.D. Program for Agricultural Sciences in Göttingen (IPAG) \\ at the Faculty of Agricultural Sciences, \\ Georg-August-University Göttingen, Germany
}

Presented by

Sandra Milena Aragón Rodríguez

Born in Armenia, Colombia

Göttingen, July 2016 
1. Name of supervisor: $\quad$ Prof. Dr. Stefan Vidal

2. Name of co-supervisor: Prof. Dr. Stefan Schütz

3. Name of co-supervisor: Assoc. Prof. Dariusz Piesik

Date of dissertation: $\quad 8^{\text {th }}$ of July 2016 
Summary. 1

General introduction

Chapter 1. PCR based method for fungal endophytes detection in tomato plant tissues

1 Introduction

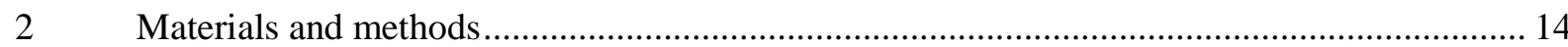

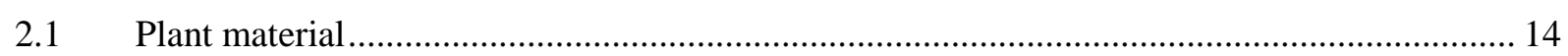

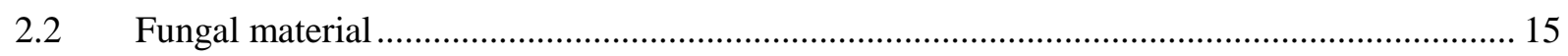

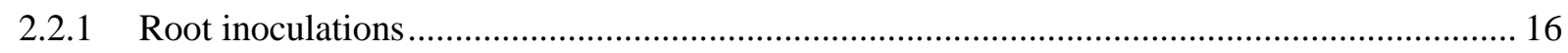

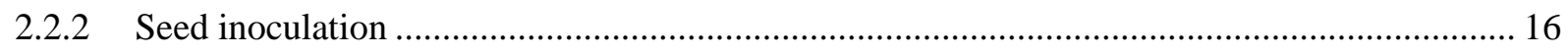

2.3 Determination of endophytic colonization of tomato plant tissues via re-isolation in selective

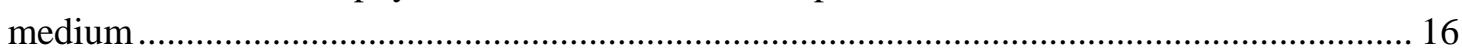

2.4 Determination of endophytic fungal colonization of tomato plant tissues via real time PCR.. 17

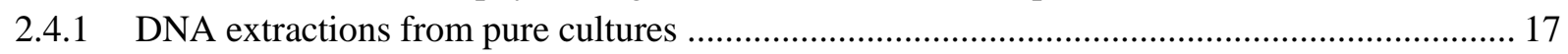

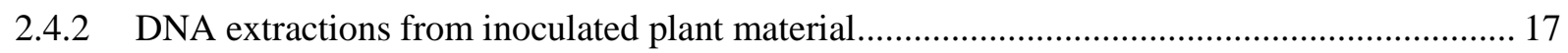

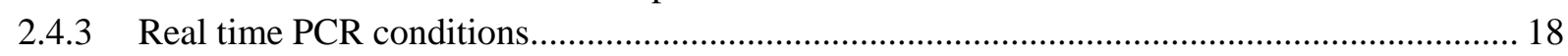

2.5 Effect of fungal endophytic colonization in plant length .................................................... 19

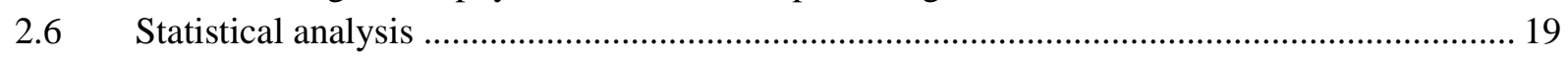

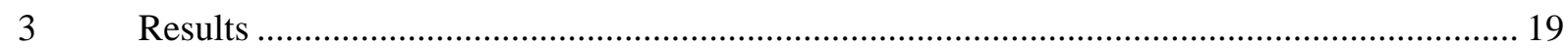

3.1 Determination of endophytic colonization of tomato plant tissues via re-isolation in selective

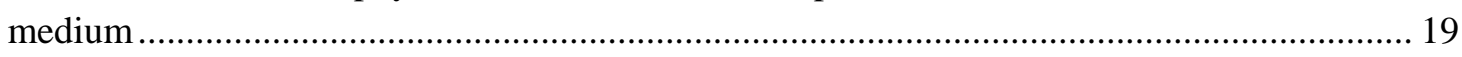

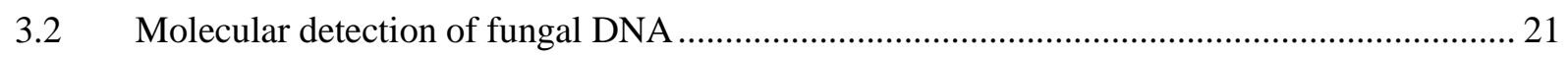

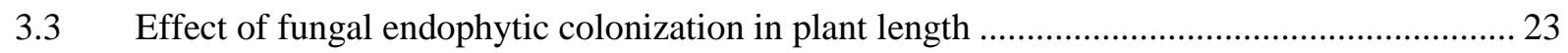

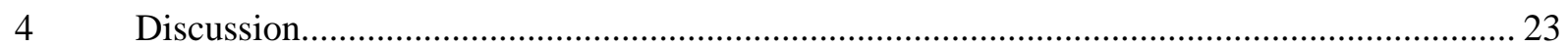

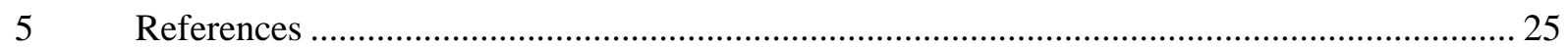

Chapter 2. Fungal endophytic colonization influences tomato plant volatile emissions and aphid

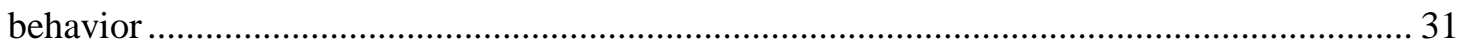

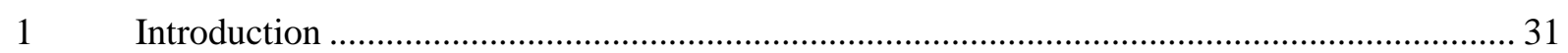

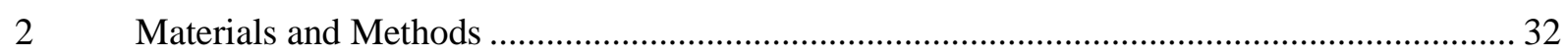

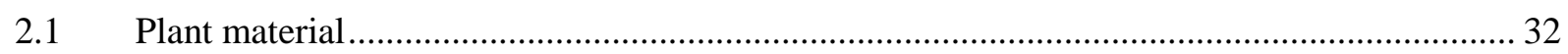

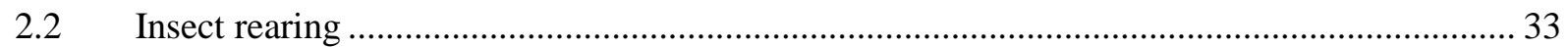

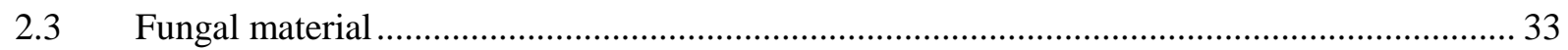

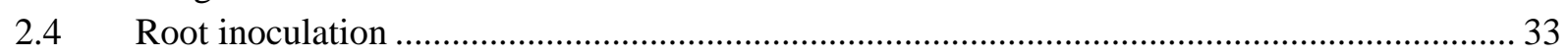

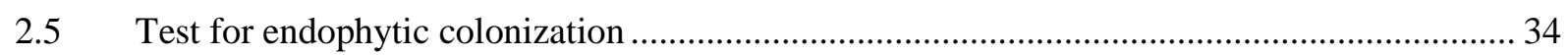

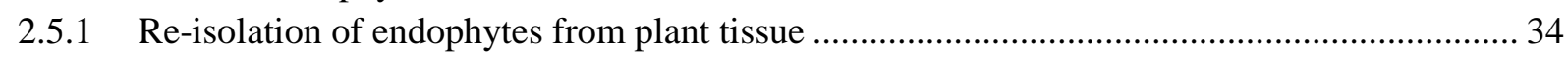

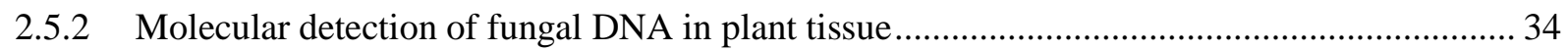

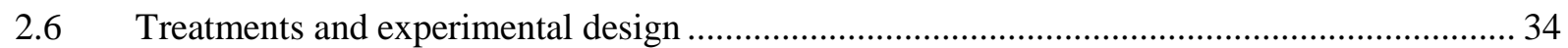

2.7 Experiment I: Plant volatile profiles in response to fungal endophytic inoculation.................. 34

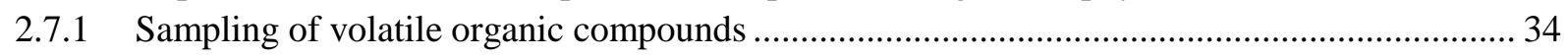

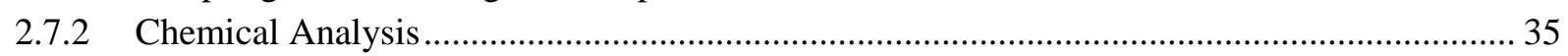

2.8 Experiment II: Effect of endophytic fungal inoculations on Myzus persicae attraction........... 38

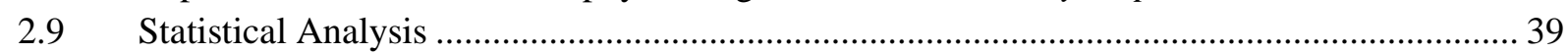




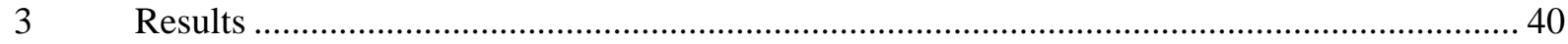

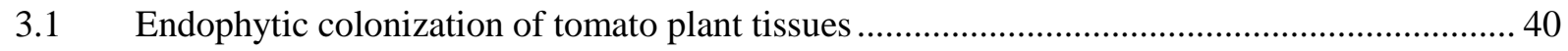

3.2 Effect of inoculation by fungal endophytes on the volatile profile of tomato plants ............... 40

3.3 Effect of fungal inoculations on host plant selection by the herbivorous insect Myzus persicae41

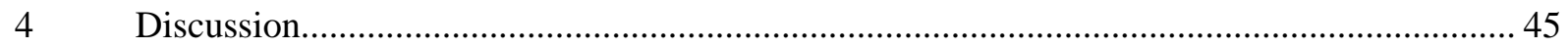

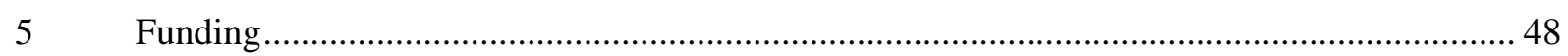

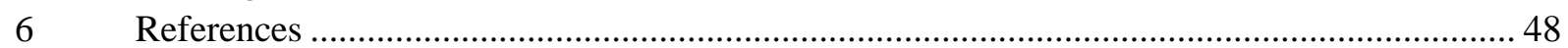

Chapter 3. Endophyte-mediated host plant selection by Helicoverpa armigera.................................. 541

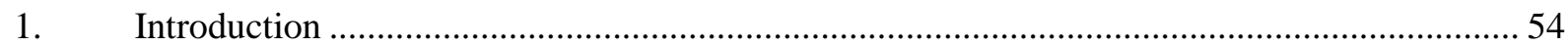

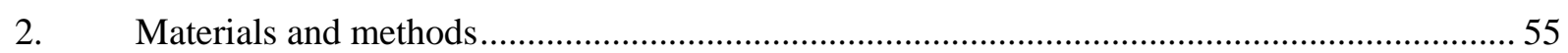

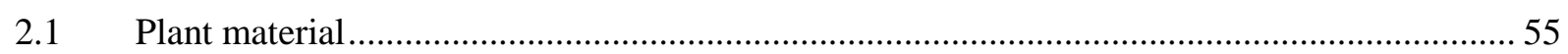

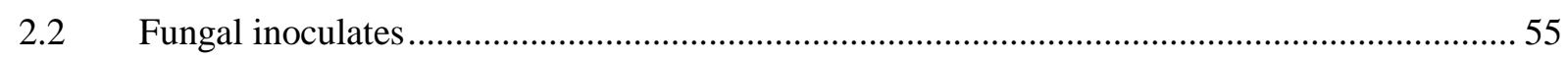

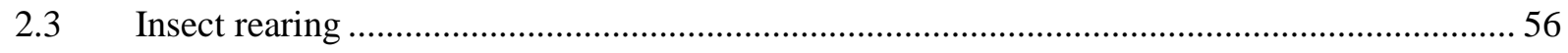

2.4 Detection of fungal endophytic colonization by real-time polymerase chain reaction ............ 56

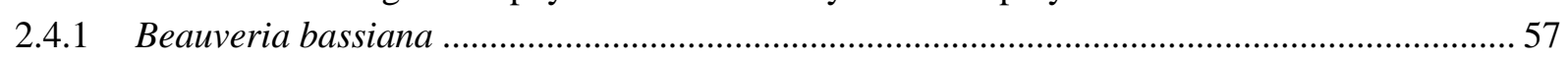

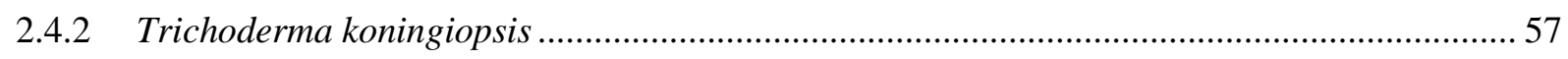

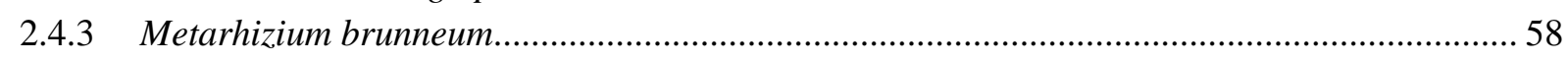

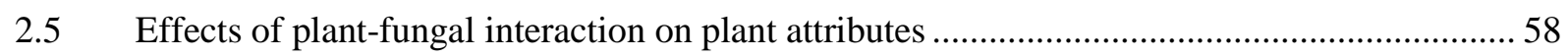

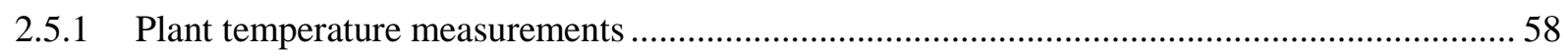

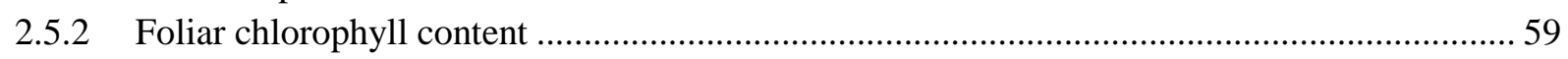

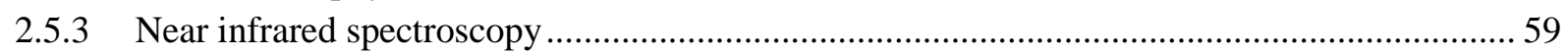

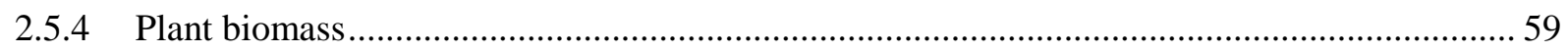

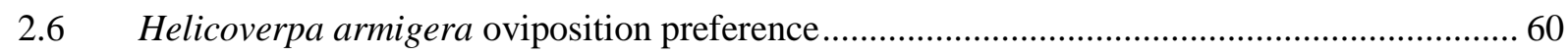

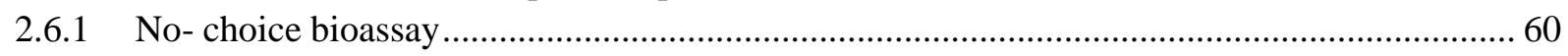

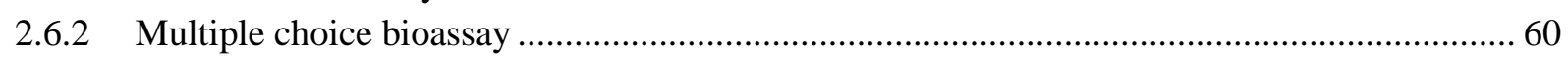

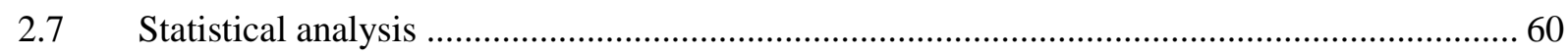

2.7.1 Detection of fungal endophytic colonization by real-time polymerase chain reaction ............. 60

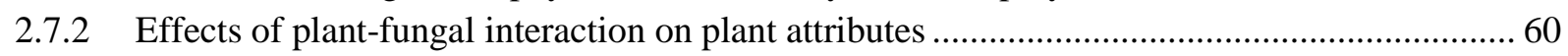

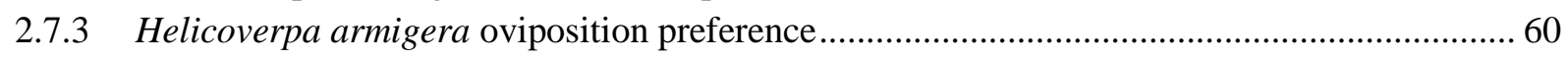

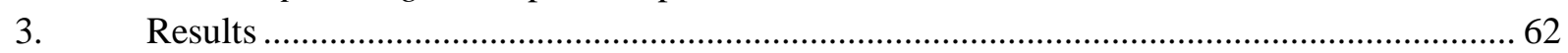

3.1 Detection of fungal endophytic colonization by real-time polymerase chain reaction ........... 62

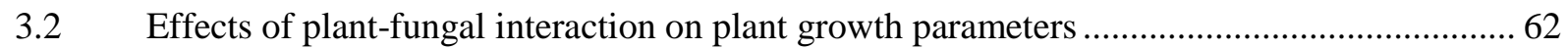

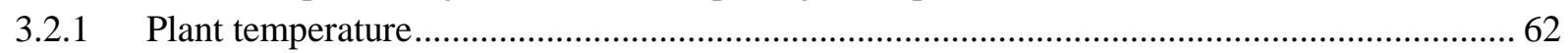

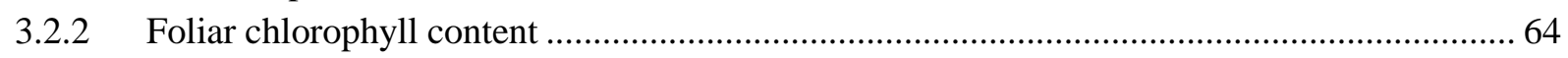

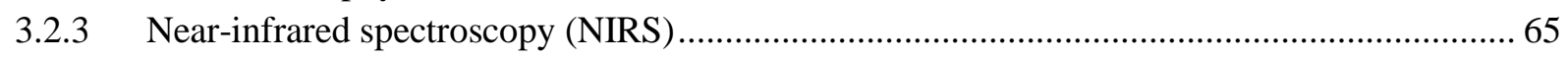

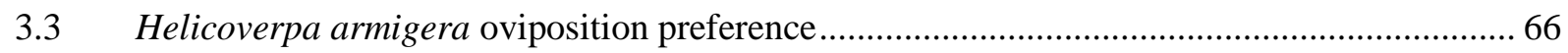

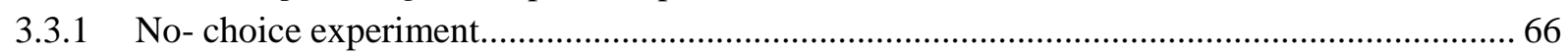

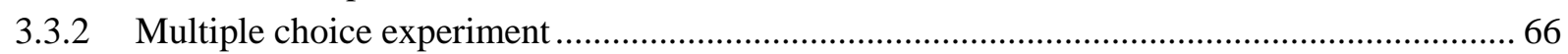

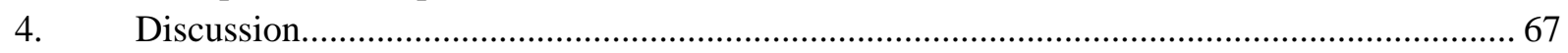

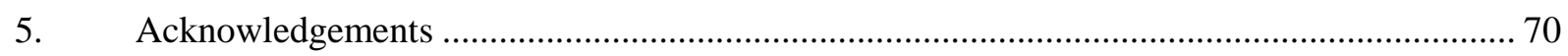

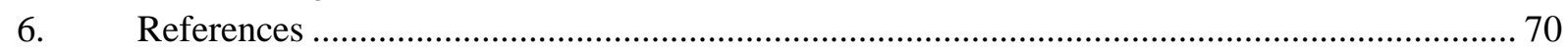

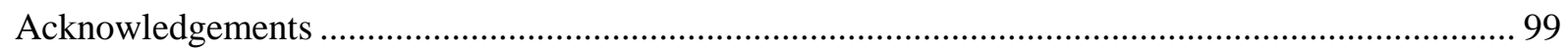

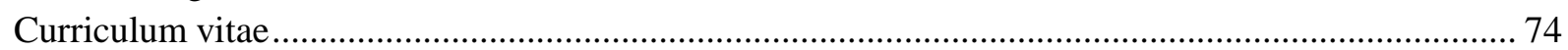




\section{Summary}

Tomato plants host multiple microbes able to colonize plant tissues endophytically without causing symptoms of infections. Whether these microorganisms living inside the plants co-exist completely undetected by the plant metabolism remains to be explored in detail. A more detailed understanding of these interactions may help in developing new strategies for plant nutrition and crop protection programs.

This research contributes to the understanding of the multitrophic interaction among tomato plants, fungal endophytes and the insect herbivores. We focused on three main topics (i) whether the studied fungi are able to colonize endophytically tomato tissues, (ii) which parameters are influenced by an endophytic colonization of the plants and (iii) whether endophytes are able to modulate the behavior of the insect herbivores on endophyte treated plants. We hypothesize that i) endophytic fungi manipulate plant metabolism affecting different plant attributes such as plant volatile organic compounds profiles, plant temperature, leaf chlorophyll content or biomass allocation, ii) insect herbivores can discriminate between endophytically colonized plants and endophyte-free plants and iii) that differences in plant attributes may influence insect attraction and also the oviposition preference.

The model evaluated here was composed by the three fungal endophytes Beauveria bassiana, Trichoderma koningiopsis and Metarhizium brunneum, the tomato plant Solanum lycopersicon (Mill.) as the host and two different insect herbivores, the aphid Myzus persicae and the polyphagous moth Helicoverpa armigera.

\section{Detection of fungal endophytic colonization by real-time polymerase chain reaction}

Our aim was to evaluate the potential of three fungal species, B. bassiana, T. koningiopsis and $M$. brunneum to colonize endophytically plant tissues. In our research we successfully achieved the establishment of the fungal entomopathogens B. bassiana and M. brunneum as well as the biocontrol agent $T$. koningiopsis in tomato plants with two different inoculation methods, seed and root inoculation. 
- The colonization of plant parts by B. bassiana when root inoculated was found to be higher in the leaves than in the stems, and almost no positive records were found in the roots. While seed inoculated plants, showed a higher colonization frequency in the roots than in leaves and stems. (Chapter 1)

- The colonization frequency observed in the plants treated with T. koningiopsis, was higher in the roots, than in the stems and leaves. (Chapter 1)

- M. brunneum was successful in colonizing root tissues, but the colonization of aboveground plant organs stem and leaves was achieved only in few samples. (Chapter 3)

\section{Effects of plant-fungal interaction on plant attributes}

The effect of colonization with fungal endophytes on plant attributes was evaluated by i) by comparing the headspace volatiles emitted by tomato plants (Solanum lycopersicon Mill) colonized with the endophytic fungi B. bassiana and T. koningiopsis with those from nontreated plants, and those from plants with a dual application of an endophytic fungus and an insect attack caused by the aphid $M$. persicae, ii) by comparing the plant biomass, temperature and leaf chlorophyll content from tomato plants inoculated with B. bassiana, T.koningiopsis or M. brunneum compared to non-treated plants.

- On the basis of the tentative identifications and semi-quantitative assessments of compound amounts by the relative peak-area of the Total Ion Current (TIC), preliminary assignments of indicator compounds are suggested. For endophyte-free plant volatile profiles, one of the indicator compounds is the p-cymene. Endophytically inoculated tomato plant volatile profile is characterized by the release of $\alpha$-pinene as the major indicator compound and the volatile profile of plants treated with endophyte and aphid attack is characterized by compounds such as $\beta$ - caryophyllene, ascaridole and $\alpha$ thujone.

- We observed that the Total Ion Current (TIC) peak area ratios of several sesquiterpenes, changed according to the treatment applied.

- The total plant biomass was significantly higher in those plants inoculated with $T$. koningiopsis while the total plant biomass of B. bassiana treated plants remains similar to control plants. 
- The compounds p-cymene and $\alpha$-pinene significantly reduced their TIC peak area when the plant was inoculated by the entomopathogenic fungi Beauveria bassiana

- Thermal imaging captured with a heat-sensing camera revealed no significant differences in temperature profiles of leaves among treatments compared to the control plants.

- The leaf chlorophyll content measured in SPAD units showed that plants treated with B. bassiana had significant less chlorophyll content compared to non-treated plants and those treated with T. koningiopsis or M. brunneum.

\section{Behavioral experiments to determine endophyte modulation of plant - insect interactions}

To determine if there is an endophyte modulation of plant-insect interactions, we evaluated i) the attraction of the aphid $M$. persicae towards tomato plants treated with the endophytes $B$. bassiana and T. koningiopsis compared to non-treated plants and, ii) the oviposition preference of the polyphagous moth $H$. armigera when offered tomato plants inoculated with B. bassiana, T. koningiopsis or M. brunneum simultaneously.

- With the aphid M. persicae, the host plant selection was tested in multiple choice experiments under laboratory and greenhouse conditions, using five different odor sources (i.e. B. bassiana strains EAB 04/01 Tip $\left(\mathrm{Bb}^{1}\right), \mathrm{Bv} 061\left(\mathrm{Bb}^{2}\right)$ and Bb1022 $\left(\mathrm{Bb}^{3}\right)$; T. koningiopsis strain Th003 and non-treated plants) simultaneously.

- We observed that winged aphids can discriminate between treated and non-treated tomato plants with more specimens attracted to blends emitted by tomato plants treated with the entomopathogenic endophytic fungi B. bassiana $\mathrm{Bb}^{l}$ compared to the untreated plants under laboratory and greenhouse conditions.

- In a multiple choice set up, we offered one plant from each of the six different treatments (i.e., B. bassiana $\mathrm{Bb}^{1}, \mathrm{Bb}^{2}$ and $\mathrm{Bb}^{3}$; T. koningiopsis $\mathrm{Th} 003$, M. brunneum and untreated plants) to one female of $H$. armigera for oviposition preference, and the number of eggs laid on the plant surface was registered after 24 hours.

- We observed that $H$. armigera had less preference to oviposit on those plants treated with $\mathrm{Bb}^{1}$. While no significant differences were found in the other treatments compared with the control. 


\title{
General Introduction
}

\author{
Aragón, S. ${ }^{1,2 *}$ \\ ${ }^{1}$ Colombian Corporation for Agricultural Research. Biological Control Laboratory. Mosquera, \\ Colombia.
}

${ }^{2}$ University of Göttingen. Department of Crop Sciences, Göttingen, Germany 


\title{
General Introduction
}

\author{
Aragón, S. ${ }^{1,2 *}$ \\ ${ }^{1}$ Colombian Corporation for Agricultural Research. Biological Control Laboratory. Mosquera, \\ Colombia.
}

${ }^{2}$ University of Göttingen. Department of Crop Sciences, Göttingen, Germany

Endophytic microbes cause inconspicuous infections that are symptomless and occur inside the plant tissue (Stone et al., 2000). Fungal endophytes can be distinguished from mycorrhizae by the absence of fungal structures such as external hyphae or mantels (Saikkonen et al., 1998). A fungal endophyte is able to exploit different nutrition resources (Ownley et al., 2010). For instance, a survey of entomopathogenic fungal endophytes made in coffee plants showed that Beauveria bassiana and Clonostachys rosea were able to exploit two different nutritional sources. Despite being isolated from plant tissues, these endophytes were also able to be pathogenic against the coffee borer Hypothenemus hampei (Vega et al., 2008).

The entomopathogenic fungi Beauveria bassiana has so far been reported to successfully colonize plant tissues from leaves, roots and stems of bean plants Phaseolus vulgaris artificially infected by spraying the leaves or soil drenching (Parsa et al., 2013), in the stem of coffee seedlings (Posada et al., 2007); in opium poppy Papaver somniferum cv. nigrum (QuesadaMoraga et al., 2006) and also in the in vitro culture of banana Musa spp. with an additional detrimental effect on larval survivorship of the banana weevil Cosmopolites sordidus (Akello et al., 2008) while in tomato and cotton seedlings, Beauveria bassiana conferred protection against the plant pathogens Rhizoctonia solani and Pyhtium myriotylum (Ownley et al., 2008).

The soil-inhabiting insect pathogenic fungi Metarhizium brunneum Petch (Ascomycota: Hypocreales: Clavicipitaceae) has so far been found to be endophytic in wheat (Triticum aestivum), switchgrass (Panicum vigratum) soybean (Glycine max) and haricot bean (Phaseolus vulgaris) (Behie and Bidochka, 2014). Seed inoculations with Metarhizium spp. enhanced plant protection against the pathogen Fusarium culmorum and the endophyte was able to move towards the roots and maintain its pathogenicity against Tenebrio molitor larvae (Keyser et al., 2014, 2015). Additional evidence with regard to the ability of Metarhizium sp. to colonize endophytically plant tissues has been reported for Phaseolus vulgaris plants that in benefit from the endophytic association also exhibited a faster root growth (Sasan and Bidochka, 2012). 
The plant pathogen biocontrol agent, Trichoderma koningiopsis has been tested against Fusarium oxysporum in tomato plants, resulting in an induced systemic resistance against this pathogen and also showed to up-regulate genes involved in jasmonic acid and ethylene transduction pathways (Jaimes et al., 2009)

Endophytic colonization is thought to enhance resistance against insect herbivores, may be due to a modulation of plant defense responses that accompany the colonization process (Dicke et al., 2009; Pieterse et al., 2013; Poelman et al., 2012) or by a change in the nutritional quality of the plant (Thakur et al., 2013).

Indirect effects of endophytes on plant parameters such as plant volatile profiles, temperature, leaf chlorophyll content or plant growth among others may influence the host acceptability by insects as well. Endophytes are among the ecological interactions that affect the plant volatile bouquet above and belowground (Clavijo McCormick et al., 2012; Dicke et al., 2009; Dicke and Baldwin, 2010; Heil, 2008; Pineda et al., 2010) and some plant volatiles act as chemical cues for associated insect species (Bruce et al., 2005; Mann et al., 2012; Metcalf and Metcalf, 1991; Sasso et al., 2009; van Dam et al., 2010). Nevertheless, plant volatiles are dynamic and plants can change their chemical composition in response to different biotic stress (Dicke et al., 2009).

Some endophytic fungal infections may promote plant growth, stress tolerance and also resistance to plant pathogens and herbivory (Jaber and Vidal, 2010). Horizontally transmitted endophytes which are able to colonize roots, stems, and leaves and are also known to increase the host shoot and/or root biomass (Rodriguez et al., 2009).

Leaf chlorophyll content, for instance, is an indicator parameter that provides information about the general health conditions of the plants, since it is an indirect sign of chloroplasts development and their photosynthetic capacity as well as the nitrogen content. The amount of chlorophyll in leaf tissue can be influenced by different abiotic factors such as nutrient availability or environmental stresses caused by salinity, temperatures or water supply (Palta, 1990). Nevertheless, biotic factors are also important in the chlorophyll content of plants. For instance, plant - endophyte interactions have demonstrated to be in detriment of the plant photosynthetic capacity in some cases, mainly related to fungal endophytes that confer protection against plant pathogens. Such is the case of the impact caused by Colletotrichum musae and Fusarium moniliforme that affects the photosynthetic activity of banana and maize plants, respectively (Costa Pinto et al., 2000), being maize plants reduced in the chlorophyll 
content and in consequence in their photosynthetic activity closely related to the endophytic infection.

The model evaluated here was composed by the three fungal endophytes Beauveria bassiana, Trichoderma koningiopsis and Metarhizium brunneum, the tomato plant Solanum lycopersicon (Mill.) as the host and two different insect herbivores, the aphid Myzus persicae and the polyphagous moth Helicoverpa armigera.

\section{Chapter 1. PCR based method for fungal endophytes detection in tomato plant tissues}

The aim of this study was (i) to determine if the fungal species Beauveria bassiana and Trichoderma koningiopsis are able to colonize endophytically tomato plants Solanum lycopersicon with different inoculation methods i.e. root inoculation and seed soaking; (ii) to determine whether the fungal endophytic colonization of tomato plant tissues moves along within the plant from, starting from the initial inoculation site, and (iii) whether the inoculation and growth of the fungi in the plants changes their biomass compared to non-inoculated plants. We hypothesize that i) the fungal endophytic colonization of plant tissues will differ among fungal strains depending on whether the isolate is a soil living microorganism or from an entomopathogen origin, thus, we expect that entomopathogenic fungi colonizes aboveground plant tissues in a higher proportion than the plant pathogen biocontrol agent Trichoderma koningiopsis, and iii) plants differ in their response towards different isolates and this would translate into differences in biomass allocations.

\section{Chapter 2. Fungal endophytic colonization influences tomato plant volatile emissions and aphid behavior}

The present research evaluated the effect of three different strains of Beauveria bassiana and Trichoderma koningiopsis in tomato plant (Solanum lycopersicon Mill.) volatile organic compound profiles and its consequent manipulation of plant-insect interactions, compared to changes induced by a endophytic plant pathogen biocontrol agent (Trichoderma koningiopsis Th003). Simultaneously, we analyzed the headspace of tomato plants that were induced first with the mentioned fungal inoculations and followed by the stimuli of a sap soaking insect attack, the aphid Myzus persicae. Our hypotheses were i) that endophytic fungi manipulate plant metabolism unique to each fungal isolate, ii) that insect herbivores are able to discriminate between endophytically colonized plants and endophyte-free plants and iii) that plant parameters changes may be to the detriment of the herbivores. 


\section{Chapter 3: Endophyte mediated host plant selection by Helicoverpa armigera}

Here we addressed two questions concerning the response of tomato plants Solanum lycopersicon to fungal endophytic inoculations and behavioral response of Helicoverpa armigera adults on tomato plants treated with different endophytes. First, we evaluated to what extent a fungal endophytic colonization of tomato plants influences plant traits such as leaf chlorophyll content, plant temperature, and plant biomass. Second, we investigated whether oviposition by Helicoverpa armigera adult females differs on entomopathogenic endophyte inoculated tomato plants compared to non-inoculated plants.

Based on our previous results about the colonization pattern of B. bassiana and T. koningiopsis presented in chapter 1, we hypothesize that i) endophytic colonization of soil born fungi might be higher in belowground than in aboveground plant tissues and this pattern may be the opposite for the fungi of entomopathogenic origin ii) tomato plant traits remain unaffected by fungal endophytic infection confirming its symptomless presence in the plant and iii) entomopathogenic fungal infection of tomato plant tissues may have repellent effect of the insect herbivore by reducing the preference of adult females to lay eggs on infected plants compared to plants infected with non-entomopathogenic fungi. 


\section{$\underline{\text { References }}$}

Akello, J., Dubois, T., Coyne, D., and Kyamanywa, S. (2008). Endophytic Beauveria bassiana in banana (Musa spp.) reduces banana weevil (Cosmopolites sordidus) fitness and damage. Crop Prot. 27, 1437-1441. doi:10.1016/j.cropro.2008.07.003.

Behie, S. W., and Bidochka, M. J. (2014). Ubiquity of insect-derived nitrogen transfer to plants by endophytic insect-pathogenic fungi: an additional branch of the soil nitrogen cycle. Appl. Environ. Microbiol. 80, 1553-60. doi:10.1128/AEM.03338-13.

Bruce, T. J. A., Wadhams, L. J., and Woodcock, C. M. (2005). Insect host location: A volatile situation. Trends Plant Sci. 10, 269-274. doi:10.1016/j.tplants.2005.04.003.

Clavijo McCormick, A., Unsicker, S. B., and Gershenzon, J. (2012). The specificity of herbivore-induced plant volatiles in attracting herbivore enemies. Trends Plant Sci. 17, 303-310. doi:10.1016/j.tplants.2012.03.012.

Costa Pinto, L., Azevedo, J. L., Pereira, J. O., Carneiro Vieira, M. L., and Labate, C. A. A. (2000). Symptomless infection of banana and maize by endophytic fungi impairs photosynthetic efficiency. New Phytol. 147, 609-615. doi:10.1046/j.14698137.2000.00722.x.

Dicke, M., and Baldwin, I. T. (2010). The evolutionary context for herbivore-induced plant volatiles: beyond the "cry for help". Trends Plant Sci. 15, 167-75. doi:10.1016/j.tplants.2009.12.002.

Dicke, M., van Loon, J. J. a, and Soler, R. (2009). Chemical complexity of volatiles from plants induced by multiple attack. Nat. Chem. Biol. 5, 317-324.

doi:10.1038/nchembio.169.

Heil, M. (2008). Indirect defence via tritrophic interactions. New Phytol. 178, 41-61. doi:10.1111/j.1469-8137.2007.02330.x.

Jaber, L. R., and Vidal, S. (2010). Fungal endophyte negative effects on herbivory are enhanced on intact plants and maintained in a subsequent generation. Ecol. Entomol. 35, 25-36. doi:10.1111/j.1365-2311.2009.01152.x.

Jaimes, Y. Y., Moreno, C. A., and Cotes, A. M. (2009). Induced systemic resistance against Fusarium oxysporum in tomato by Trichoderma koningiopsis Th003. Acta Biológica Colomb. 14, 111-120.

Keyser, C. A., Jensen, B., and Meyling, N. V (2015). Dual effects of Metarhizium spp. and Clonostachys rosea against an insect and a seed-borne pathogen in wheat. Pest Manag. Sci. 72, 517-526. Available at: http://www1.bio.ku.dk/forskning/oe/cse/gml_sider/mere_formidling.../Keyser_2014_Fun gal_Ecology.pdf [Accessed March 15, 2016].

Keyser, C. A., Thorup-Kristensen, K., and Meyling, N. V. (2014). Metarhizium seed treatment mediates fungal dispersal via roots and induces infections in insects. Fungal Ecol. 11, 122-131. doi:10.1016/j.funeco.2014.05.005.

Mann, R. S., Ali, J. G., Hermann, S. L., Tiwari, S., Pelz-Stelinski, K. S., Alborn, H. T., et al. 
(2012). Induced release of a plant-defense volatile "Deceptively" attracts insect vectors to plants infected with a bacterial pathogen. PLoS Pathog 8, e1002610.

doi:10.1371/journal.ppat.1002610.

Metcalf, R. L., and Metcalf, E. R. (1991). Plant kairomones in insect ecology and control. First edit. , eds. R. L. Metcalf and E. R. Metcalf New york: Chapman and Hall.

Ownley, B. H., Griffin, M. R., Klingeman, W. E., Gwinn, K. D., Moulton, J. K., and Pereira, R. M. (2008). Beauveria bassiana: endophytic colonization and plant disease control. $J$. Invertebr. Pathol. 98, 267-270. doi:10.1016/j.jip.2008.01.010.

Ownley, B. H., Gwinn, K. D., and Vega, F. E. (2010). Endophytic fungal entomopathogens with activity against plant pathogens: Ecology and evolution. BioControl 55, 113-128. doi:10.1007/s10526-009-9241-x.

Palta, P. J. (1990). Leaf chlorophyll content. Remote Sens. Rev., 207-213. Available at: http://www.tandfonline.com/doi/pdf/10.1080/02757259009532129 [Accessed March 10, 2016].

Parsa, S., Ortiz, V., and Vega, F. E. (2013). Establishing Fungal Entomopathogens as Endophytes: Towards Endophytic Biological Control. J. Vis. Exp. doi:10.3791/50360.

Pieterse, C. M. J., Poelman, E. H., Van Wees, S. C. M., and Dicke, M. (2013). Induced plant responses to microbes and insects. Front. Plant Sci. 4, 475. doi:10.3389/fpls.2013.00475.

Pineda, A., Zheng, S.-J., van Loon, J. J. a, Pieterse, C. M. J., and Dicke, M. (2010). Helping plants to deal with insects: the role of beneficial soil-borne microbes. Trends Plant Sci. 15, 507-14. doi:10.1016/j.tplants.2010.05.007.

Poelman, E. H., Bruinsma, M., Zhu, F., Weldegergis, B. T., Boursault, A. E., Jongema, Y., et al. (2012). Hyperparasitoids use herbivore-induced plant volatiles to locate their parasitoid host. PLoS Biol 10, e1001435. doi:10.1371/journal.pbio.1001435.

Posada, F., Aime, M. C., Peterson, S. W., Rehner, S. A., and Vega, F. E. (2007). Inoculation of coffee plants with the fungal entomopathogen Beauveria bassiana (Ascomycota: Hypocreales). Mycol. Res. 111, 748-757. doi:10.1016/j.mycres.2007.03.006.

Quesada-Moraga, E., Landa, B. B., Muñoz-Ledesma, J., Jiménez-Diáz, R. M., and SantiagoÁlvarez, C. (2006). Endophytic colonisation of opium poppy, Papaver somniferum, by an entomopathogenic Beauveria bassiana strain. Mycopathologia 161, 323-329. doi:10.1007/s11046-006-0014-0.

Rodriguez, R. J., White, J. F., Arnold, A. E., Redman, R. S., Jr, J. F. W., Arnold, A. E., et al. (2009). Fungal endophytes: diversity and functional roles. New Phytol. 182, 314-330. doi:10.1111/j.1469-8137.2009.02773.x.

Saikkonen, K., Faeth, S. H., Helander, M., and Sullivan, T. J. (1998). Fungal endophytes: A continuum of interactions with host plants. Annu. Rev. Ecol. Syst. 29, 319-343. doi:10.1146/annurev.ecolsys.29.1.319.

Sasan, R. K., and Bidochka, M. J. (2012). The insect-pathogenic fungus Metarhizium robertsii (Clavicipitaceae) is also an endophyte that stimulates plant root development. Am. J. Bot. 99, 101-107. doi:10.3732/ajb.1100136.

Sasso, R., Iodice, L., Woodcock, C. M., Pickett, J. a., and Guerrieri, E. (2009). 
Electrophysiological and behavioural responses of Aphidius ervi (Hymenoptera:

Braconidae) to tomato plant volatiles. Chemoecology 19, 195-201. doi:10.1007/s00049009-0023-9.

Stone, J. K., Bacon, C. W., and White Jr, J. F. (2000). “An overview of endophytic microbes: Endophytism defined," in Microbial endophyes, 4-5.

Thakur, A., Kaur, S., Kaur, A., and Singh, V. (2013). Enhanced resistance to Spodoptera litura in endophyte infected cauliflower plants. Environ. Entomol. 42, 240-6. doi:10.1603/EN12001.

van Dam, N. M., Qiu, B.-L., Hordijk, C. A., Vet, L. E. M., and Jansen, J. J. (2010). Identification of biologically relevant compounds in aboveground and belowground induced volatile blends. J. Chem. Ecol. 36, 1006-1016. doi:10.1007/s10886-010-9844-9.

Vega, F. E., Posada, F., Aime, M. C., Pava-Ripoll, M., Infante, F., and Rehner, S. A. (2008). Entomopathogenic fungal endophytes. Biol. Control 46, 72-82. doi:10.1016/j.biocontrol.2008.01.008. 


\title{
Fungal endophytes detection in tomato plant tissues
}

\author{
Aragón, S..$^{1,2 *}$, Vidal, S. $^{2}$ \\ ${ }^{1}$ Colombian Corporation for Agricultural Research. Biological Control Laboratory. \\ Mosquera, Colombia. \\ ${ }^{2}$ University of Göttingen. Department of Crop Sciences, Göttingen, Germany \\ * Corresponding author: saragon@ corpoica.org.co
}




\title{
Fungal endophytes detection in tomato plant tissues
}

\author{
Aragón, S. ${ }^{1,2 *}$, Vidal, S. ${ }^{2}$ \\ ${ }^{1}$ Colombian Corporation for Agricultural Research. Biological Control Laboratory. Mosquera, \\ Colombia. \\ ${ }^{2}$ University of Göttingen. Department of Crop Sciences, Göttingen, Germany \\ * Corresponding author: saragon@ corpoica.org.co
}

\begin{abstract}
Traditional methods to detect fungal endophytes in plant tissues are successful to determine the presence of fungal structures when they are cultured in appropriate medium. Nevertheless, when the aim of the research deals with the correlation of the amount of fungal DNA and the modulation of metabolic attributes of their plant hosts, the knowledge of appropriate methods that allow the detection of the fungi internally in a rapid and accurate way regardless the reproductive stage of the fungus, became valuable to determine quantitative differences among treatments. The aim of this study was to establish endophytically the fungi Beauveria bassiana and Trichoderma koningiopsis in tomato plant tissues Solanum lycopersicon Mill. and determine the ability of those fungi to migrate from the inoculation site along the plant tissues. Two different methods for fungal inoculation were tested, first the seed inoculation by soaking the surface sterilized seeds into the spores suspension and second the root inoculation made directly by immersing the clean root system in the spores suspension. The growing of the fungi inside the plant was determined four weeks post inoculation by fugal re-isolation in selective medium for each species and the colonization frequency was determined. Treated plants were also tested for fungal endophytic growing by molecular detection of fungal DNA with real time polymerase chain reaction with specific primers. The migration ability of tested fungal endophytes will be discussed.
\end{abstract}

Keywords: Real-time PCR, Fungal endophytes, Solanum lycopersicon, Trichoderma koningiopsis, Beauveria bassiana. 


\section{Introduction}

Plants are colonized by different endophytic microorganisms that cause no disease symptoms (Schulz and Boyle, 2006). Nevertheless the use of fungal endophytes with potential to be applied in the management of plant pathogens or insect herbivores has been only recently addressed. For instance, Ownley et al. (2010), reviewed the potential of the entomopathogenic endophytic fungi Beauveria bassiana to control pest and pathogens in different crop systems as well as the biocontrol agent Trichoderma koningiopsis in the control of plant pathogens such as Botrytis spp and Plasmotara spp. The detection of fungal endophytes in plant tissues has been done in general by re isolation methods as proposed by Parsa et al. (2013) for the artificial establishment of B. bassiana in bean plants Phaseolus vulgaris towards and application in the biological control of insect pest, obtaining higher colonization percentage when the conidia were sprayed in the leaves.

In other studies, Quesada-Moraga et al. (2006) found that Beauveria bassiana strains isolated from Timapsis papaveris (Hymenoptera:Cynipidae) had also the ability to colonize endophytically poppy plants where the determination of endophytic colonization was done with microbiological, molecular and electron microscopy techniques. In addition to confer plant protection against insects and pathogens, fungal endophytes are also known to promote plant growth as reported by Lopez and Sword (2015), who found that Beauveria bassiana was enhanced cotton growth as well as confers protection against Helicoverpa zea.

The aim of this study was first to determine if the fungal species Beauveria bassiana and Trichoderma koningiopsis are able to colonize endophytically tomato plants Solanum lycopersicon with different inoculation methods i.e. root inoculation and seed soaking. Second, to determine to what extent does fungal endophytic colonization of tomato plants moves along the plant from the initial inoculation site, and third, to determine if inoculated plants are affected in their biomass compared to non-inoculated plants.

\section{$2 \quad$ Materials and methods}

\subsection{Plant material}

Establishment of fungal endophytes was tested on tomato plants Solanum lycopersicon Mill. var Ruthje (Rein Saat ${ }^{\circledR}$, Austria ). Before use, seeds were surface sterilized by submerging them in $2 \%$ sodium hypochlorite for $3 \mathrm{~min}$ followed by $2 \mathrm{~min}$ immersion in ethanol $75 \%$ and three consecutive rinses in autoclaved water. Treated seeds were allowed to dry in the clean bench for 20minutes and then transferred to growing containers filled with an autoclaved mixture 3:1 soil (Fruhstorfer Erde Typ 25, Hawita Gruppe $\mathrm{GmbH}$, peat fine structure with volcanic clay, pH: 5.7-6.3, Fertilization of 200-300mg $\mathrm{N})$ and one part of $0.3 \mathrm{~mm}$ sand. The plants were maintained in the greenhouse conditions $\left(21 \pm 2^{\circ} \mathrm{C}, 70\right.$ $80 \% \mathrm{RH}$ and $12 \mathrm{~h}$ photoperiod) up to the development of the second true leaf. Plantlets were then removed from the substrate and their roots were carefully washed with tap water for root inoculation 
with the corresponding fungal endophyte, transplanted into an autoclaved soil mixture mentioned above and maintained in greenhouse for three weeks. Plants were fertilized once a week with Hakaphos $2 \mathrm{~g} / \mathrm{L}$ $\left(15 \% \mathrm{~N}, 11 \% \mathrm{P}_{2} \mathrm{O}_{5}, 15 \% \mathrm{~K}_{2} \mathrm{O}, 1 \% \mathrm{Mg}, 0.1 \% \mathrm{Fe}, 0.1 \% \mathrm{Mn}, 0.04 \% \mathrm{Cu}, 0.025 \% \mathrm{~B}\right.$ and $0.005 \% \mathrm{Mo}$ ).

\subsection{Fungal material}

Two different fungal endophytes were tested, one entomopathogenic fungi Beauveria bassiana strain Bv 061 provided by the germplasm bank of the Biological Control Laboratory at Colombian Corporation of Agricultural Research -Corpoica - in Colombia, Beauveria bassiana strain Bb1022 and EABb 04/01 -Tip come from the fungal collection of the Agricultural Entomology Laboratory at the University of Göttingen, Germany and the plant pathogen biocontrol agent Trichoderma koningiopsis strain Th003, kindly delivered by the company Prophyta (Biologischer Pflanzenschutz GmbH, Germany), the origin of the isolates is detailed in Table 1. The isolates were grown in potato dextrose agar (PDA) at $24 \pm 2{ }^{\circ} \mathrm{C}$ in dark conditions during two weeks to obtain enough spores for the suspension.

Petri dishes with the corresponding fungal growth were placed in sterile bench and $3 \mathrm{ml}$ of $0.01 \%$ Tween 20 were added to a single plate to re-suspend the spores. The growing media surface was scratched with a Drigalski spatula and the spores were finally suspended in $97 \mathrm{ml}$ of sterile deionized water. Spores concentration was determined with a counting chamber Thoma (Marienfeld, Germany) and adjusted to $1 \times 10^{6}$ conidia $/ \mathrm{ml}$.

Table 1. Fungal strains used for inoculation of tomato plants Solanum lycopersicon Mill.

\begin{tabular}{|c|c|c|c|c|c|c|}
\hline \multicolumn{7}{|c|}{ Endophytic fungi isolate screened for insect attraction and oviposition behavior } \\
\hline Fungi & Strain & $\begin{array}{l}\text { Geographic } \\
\text { origin }\end{array}$ & Insect host & Plant host & $\begin{array}{l}\text { Pathogen } \\
\text { Biocontrol }\end{array}$ & Reference \\
\hline $\begin{array}{l}\text { Beauveria } \\
\text { bassiana }\end{array}$ & $\begin{array}{l}\text { EABb } \\
\text { 04/01 -Tip }\end{array}$ & Spain & $\begin{array}{l}\text { Stem- borer } \\
\text { Timaspis } \\
\text { papaveris } \\
\text { (Kieffer) }\end{array}$ & $\begin{array}{l}\text { Opium } \\
\text { puppy } \\
\text { Papaver } \\
\text { somniferum } \\
\text { L. }\end{array}$ & & $\begin{array}{l}\text { (Quesada- } \\
\text { Moraga et } \\
\text { al., 2009) }\end{array}$ \\
\hline $\begin{array}{l}\text { Beauveria } \\
\text { bassiana }\end{array}$ & Bv 061 & Colombia & $\begin{array}{l}\text { Sweetpotato } \\
\text { whitefly } \\
\text { Bemisia tabaci } \\
\text { (Gennadius) }\end{array}$ & $\begin{array}{l}\text { Cotton } \\
\text { Gossypium } \\
\text { hirsutum L. }\end{array}$ & & $\begin{array}{l}\text { (Espinel et } \\
\text { al., 2008) }\end{array}$ \\
\hline $\begin{array}{l}\text { Beauveria } \\
\text { bassiana }\end{array}$ & $\mathrm{Bb} 1022$ & Canada & $\begin{array}{l}\text { Pine shoots } \\
\text { moth } \\
\text { Rhyacionia } \\
\text { buliana (Schiff.) }\end{array}$ & & & \\
\hline $\begin{array}{l}\text { Trichoderma } \\
\text { koningiopsis }\end{array}$ & Th003 & Colombia & Agricultural soil & $\begin{array}{l}\text { Tomato } \\
\text { Solanum } \\
\text { lycipersicon } \\
\text { Mill. }\end{array}$ & $\begin{array}{l}\text { Fusarium } \\
\text { oxysporum f. } \\
\text { sp. } \\
\text { lycopersici }\end{array}$ & $\begin{array}{l}\text { (Jaimes et } \\
\text { al., 2009) }\end{array}$ \\
\hline
\end{tabular}




\subsubsection{Root inoculations}

Two weeks after transplant, tomato seedlings were removed from the soil substrate and the roots were carefully washed with tap water. Clean roots were immersed in the final conidial suspension for $20 \mathrm{~min}$ and then transferred to plastic pots of $\mathrm{L} 11 \times \mathrm{W} 11 \times \mathrm{H} 12 \mathrm{~cm}$ filled with the soil mixture described in plant material section 2.1 and placed in greenhouse conditions.

\subsubsection{Seed inoculation}

Following the procedure explained in section 2.1, a total of 60 seeds were surface sterilized and immersed in the corresponding conidial suspension for $20 \mathrm{~min}$. Control seeds were treated only with $0.01 \%$ tween 20 and then transferred separately to plastic pots of L11 x W11 x H12 cm filled with the soil mixture described in plant material section and placed in greenhouse conditions.

\subsection{Determination of endophytic colonization of tomato plant tissues via re-isolation in selective medium}

For the plants inoculated in the roots, the colonization frequency obtained from B. bassiana and $T$. koningiopsis was evaluated 20 days post inoculation (dpi). Seedlings were carefully removed from the substrate and the roots were gently washed with tap water. The samples were placed in a sterile bench where each plant was sectioned into three different groups: Leaves, stems and roots. To determine the migration of the fungi along the plant tissues, samples of each tissue were taken from the different levels of the plant as detailed in Table 2.

Table 2. Sampling of tomato tissues for the re-isolation of fungal endophytes. The stem was divided into three sections $a, b$ and $c$ from the bottom to the top of the plant. The leaves were sampled complete, and the leaf discs were obtained at random avoiding the veins.

\begin{tabular}{lll}
\hline Distance from the soil & Stem & Leaf $^{* *}$ \\
\hline $0-10 \mathrm{~cm}$ & A & $1^{\text {st }}$ \\
$11-20 \mathrm{~cm}$ & B & $3^{\text {rd }}$ \\
$21-30 \mathrm{~cm}$ & C & $5^{\text {th }}$ \\
\hline
\end{tabular}

"The distance from the soil is approximate. Each stem section was surface sterilized separately, and the fragments used for the re-isolation were located in the middle of the stem section, to avoid the use of dead tissue due to the surface sterilization. ${ }^{* *}$ The first leaf was located closest to the soil, and numbers were assigned in the same order as they were present in the stem from the bottom to the top of the plant. 
A surface sterilization of the collected material with sodium hypochlorite $0.2 \%$ for twomin followed by a two minutes immersion in $70 \%$ ethanol and finished by three rinses with sterile distilled water. The samples were placed in autoclaved filter paper and allowed to dry. Five leaf disks of $6 \mathrm{~mm} \emptyset$, five stem segments of $5 \mathrm{~mm}$ length and five roots sections were placed into Petri dishes with the corresponding selective medium for Beauveria bassiana used by Quesada-Moraga et al. (2006) and for T. koningiopsis we used the selective media proposed by Elad and Chet (1983). Positive or negative fungal growth was recorded after 10 days of incubation at $25^{\circ} \mathrm{C}$ in darkness. A total of ten plants per treatment were evaluated. The colonization is presented as frequencies:

$$
\text { Colonization frequency }=\frac{\text { Number of plants colonized }}{\text { Total number of plant pieces }} \times 100
$$

\subsection{Determination of endophytic fungal colonization of tomato plant tissues via real time PCR}

\subsubsection{DNA extractions from pure cultures}

Endophytic colonization was confirmed by real-time polymerase chain reaction (RT-PCR). The positive PCR amplification was achieved from genomic DNA of each fungal strain obtained from actively growing mycelium in Potato Dextrose Broth (PDB) cultures incubated for five days at $25^{\circ} \mathrm{C}$ in the dark with a constant shake. The medium was filtered with a vacuum pump, and the filtrated mycelium was collected and lyophilized. The dry material was grinded, homogenized and stored at $-20^{\circ} \mathrm{C}$ until used.

The DNA quality was observed by electrophoresis in $0,8 \%$ agarose gel (w/v) prepared in TAE buffer (40mM Tris, $1 \mathrm{mM}$ EDTA, $\mathrm{pH}$ set to 8.5 with acetic acid), with $4 \mathrm{~V} / \mathrm{cm}$ for $60 \mathrm{mins}$ and ethidium bromide was used to stain the double stranded DNA with a final rinse with distilled water for 30min A digital imagen of the gel was used to quantify the fungal DNA and the final quantity was compared by densitometry with the values of diluted Lambda DNA (methylated, from Escherichia coli host strain W3110). Densitometry analysis was made with a Multi Analist Software (Bio Rad, Hercules, CA, USA).

\subsubsection{DNA extractions from inoculated plant material}

Four weeks after inoculation, the plant samples from root or seed inoculated treatments were collected and kept under $-83^{\circ} \mathrm{C}$ until lyophylization procedure. The plant material was packed into plastic ziplock bags separately, leafs, stems and roots. For fungal and plant DNA extraction we used the cetyl trimethylammonium bromide (CTAB) method, where a mixture of $1 \mathrm{ml}$ of CTAB buffer, $2 \mu 1$ mercaptoethanol and $1 \mu \mathrm{l}$ of Proteinase $\mathrm{K}$ was added to 50mg of fine powder, mixed thoroughly and incubated for $10 \mathrm{~min}$ at $42^{\circ} \mathrm{C}$, then increased the temperature to $65^{\circ} \mathrm{C}$ and incubated for $10 \mathrm{~min}$ more. After adding $800 \mu \mathrm{l}$ of chloroform/isoamylalcohol and incubation on ice for $10 \mathrm{~min}$, the extract was centrifuged at $8000 \mathrm{rp}$ for $10 \mathrm{~min}$. The supernatant was transferred to a new tube and added with $100 \mu 15 \mathrm{M} \mathrm{NaCl}$ and $200 \mu \mathrm{l}$ of $30 \% \mathrm{PEG}$, and incubated for $5 \mathrm{~min}$ at room temperature, followed by a 
spinning at $14000 \mathrm{rpm}$ for $15 \mathrm{~min}$. The supernatant was discarded and the pellet was washed two times

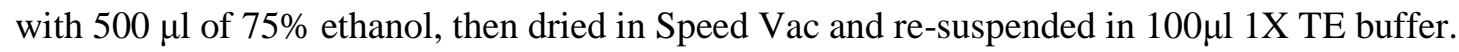

\subsubsection{Real time PCR conditions}

Following the protocol proposed by Brandfass and Karlovsky (2008), for each fungal DNA extracted in numeral 2.4.1 one standard curve was needed. A dilution series $(1.23 \mathrm{pg}, 3.70 \mathrm{pg}, 11.1 \mathrm{pg}, 33.3 \mathrm{pg}$ and $100 \mathrm{pg}$ ) of Beauveria bassiana and Trichoderma koningiopsis DNA was prepared separately. In order to quantify the unknown fungal DNA amount in the plant samples, each RT-PCR plate set up must contain the standards, a negative template control $\left(\mathrm{NTC}, \mathrm{ddH}_{2} \mathrm{O}\right)$ and a positive template control of plant samples containing the fungal DNA to be quantified. A 1:10 dilution of the DNA samples was used for the PCR. Two replicates were used per each standard and NTC, PTC and unknowns. Ten biological replicates were analyzed simultaneously.

\subsubsection{Beauveria bassiana}

Using the primers Bsn1-2 forward 5'-3' GCGTCAAGGTGCTCGAAGACAG' and reverse 3'-5' TCTGGGCGGCATCCCTATTGT for Beauveria bassiana with a product size of $231 \mathrm{bp}$ and melting temperature of $55^{\circ} \mathrm{C}$ with increments of $0.5^{\circ} \mathrm{C}$ for $5 \mathrm{~s}$. The qPCR amplifications were performed in a total volume of $10 \mu 1$ using the iCycler System (CFX384 Real time system, Bio-Rad, Hercules, CA, USA). The reaction mixtures contained a final concentration of $2 \mu \mathrm{l} 5 \mathrm{x}$ Buffer (Bioline, Luckenwalde, Germany), $1 \mu 1$ of $25 \mathrm{mM} \mathrm{MgCl} 2$ (Bioline, Luckenwalde, Germany), $0.4 \mu 1$ of $2.5 \mathrm{mM} \mathrm{dNTP}$ (Bioline, Luckenwalde, Germany), $0.3 \mu 1$ of $10 \mu \mathrm{M}$ each primers (Invitrogen, Karlsruhe, Germany), $0.1 \mu 1$ of

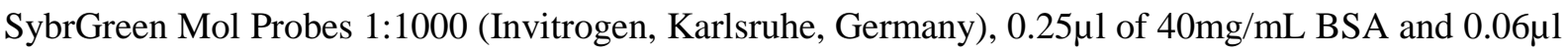
of 5U/ $\mu 1$ Hot Start Taq Polymerase (Bioline, Luckenwalde, Germany), $4.59 \mu 1$ of sterile water and $1 \mu 1$ of sample DNA. Thermal cycling conditions for amplification (iCycler System CFX Real time system, Bio-Rad, Hercules, CA, USA): started with an initial denaturation steps for $3 \mathrm{~min}$ at $94^{\circ} \mathrm{C}$, followed by 36 cycles each consisting of a denaturation step for $30 \mathrm{~s}$ at $94^{\circ} \mathrm{C}$, annealing for $20 \mathrm{~s}$ at $60^{\circ} \mathrm{C}$, extension for $30 \mathrm{~s}$ at $72^{\circ} \mathrm{C}$ and a plate read at the end of each cycle. This was followed by a final extension for $5 \mathrm{~min}$ at $72^{\circ} \mathrm{C}$ and a final melting curve from $55^{\circ} \mathrm{C}$ to $95^{\circ} \mathrm{C}$ in $0.5^{\circ} \mathrm{C}$ increments held for $5 \mathrm{~s}$ at each temperature and a plate read at each temperature, which was used to determine the purity of the reaction products.

\subsubsection{Trichoderma koningiopsis}

Specific primers (forward: 5'-TACAACTCCCAAACCCAATGTGA-3', reverse: 5'CCGTTGTTGAAAGTTTTGATTCATTT-3') for Trichoderma spp. designed by (López-Mondéjar et al., 2010) were used for the quantification. The qPCR amplifications were performed in a total volume of $10 \mu 1$ using the iCycler System (CFX384 Real time system, Bio-Rad, Hercules, CA, USA). The reaction mixtures followed the same proportions as those reported for B. bassiana. The thermal cycling 
conditions used for amplification: started with an initial denaturation steps for $3 \mathrm{~min}$ at $95^{\circ} \mathrm{C}$, followed by 35 cycles each consisting of a denaturation step for $5 \mathrm{~s}$ at $95^{\circ} \mathrm{C}$, annealing for $15 \mathrm{~s}$ at $64^{\circ} \mathrm{C}$, extension for $15 \mathrm{~s}$ at $72^{\circ} \mathrm{C}$ and a plate read at the end of each cycle. This was followed by a final extension for $5 \mathrm{~min}$ at $72^{\circ} \mathrm{C}$ and a melting curve from $55^{\circ} \mathrm{C}$ to $95^{\circ} \mathrm{C}$ in $0.5^{\circ} \mathrm{C}$ increments held for $5 \mathrm{~s}$ at each temperature and a plate read at each temperature, which was used to determine the purity of the reaction products.

\subsection{Effect of fungal endophytic colonization in plant length}

Before the evaluations of fungal colonization frequencies, the length of the stems of each treated plant was measured in situ from the basal part of the plant at the level of the soil, until the top of the stem where the new leaves were developing.

\subsection{Statistical analysis}

All data sets were analyzed with the statistical program SigmaPlot v. 11.0 (Systat Software Inc., 2016) using one-way ANOVA after checking the assumptions for normality and the homogeneity of variance via Kolmogorov-Smirnov test. No transformation was needed. A post hoc test was then performed using Tukey's Honestly Significant Difference (HSD) to identify which differences were significant and to determine the groups.

\section{Results}

\subsection{Determination of endophytic colonization of tomato plant tissues via re-isolation in selective medium}

The first aim of this experiment was to confirm the endophytic development of Beauveria bassiana and Trichoderma koningiopsis into tomato plant tissues. The fungal colonization of tomato plant tissues was studied in the selective medium corresponding to each species, for Beauveria bassiana, positive recordings of mycelial growth were registered when the white hyphae emerged from the edge of the tissue sample. In the figure 1, the endophytic colonization frequencies of treated plants are shown. Positive growth of fungal endophytes from leaf samples was achieved for all the treatments, it is also evident that the colonization frequency is higher for the basal leaves that for the new developed leaves. Plant samples treated with Beauveria bassiana $\mathrm{Bb}^{2}$ showed the highest frequencies of endophytic colonization along the three levels. In contrast, strains $\mathrm{Bb}^{1}$ and $\mathrm{Bb}^{3}$ did not succeed in colonizing new developed leaves. In addition, Trichoderma koningiopsis was also found colonizing leaf samples in all the levels. 


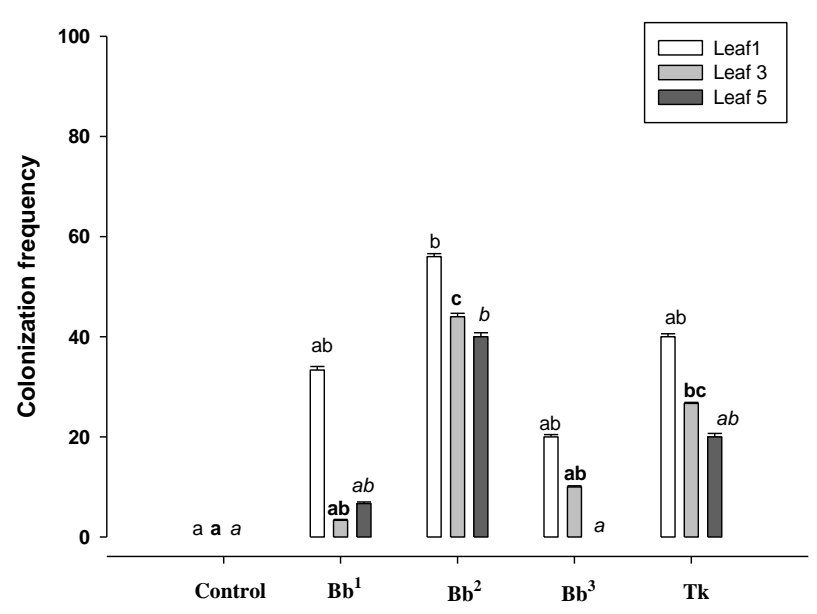

Figure 1. Colonization frequencies of the fungal endophytes in leaf tissues. A one-way analysis of variances ANOVA was developed per each level of leaf L1, L3, and L5. Significant differences were observed in all levels, for Leaf 1 (White bars) Error between $\mathrm{MS}=1.5889, \mathrm{df}=24$, Leaf 3 (light grey bars) the error between MS $=0.51944$, $\mathrm{df}=24$ and for the Leaf 5 (dark grey bars) error between $\mathrm{MS}=1,222, \mathrm{df}=24$. Beauveria bassiana $\mathrm{Bb}^{2}$ and Trichoderma koningiopsis are the endophytes that can approach leaves at each level of the plant indicating the ability of those fungi to move systemically.

The colonization frequencies achieved in the different stem sections (a, b, and c) is shown in Figure 2. For stem samples, no significant differences were obtained after the analysis of variances. Nevertheless, positive growth was registered for all treatments.

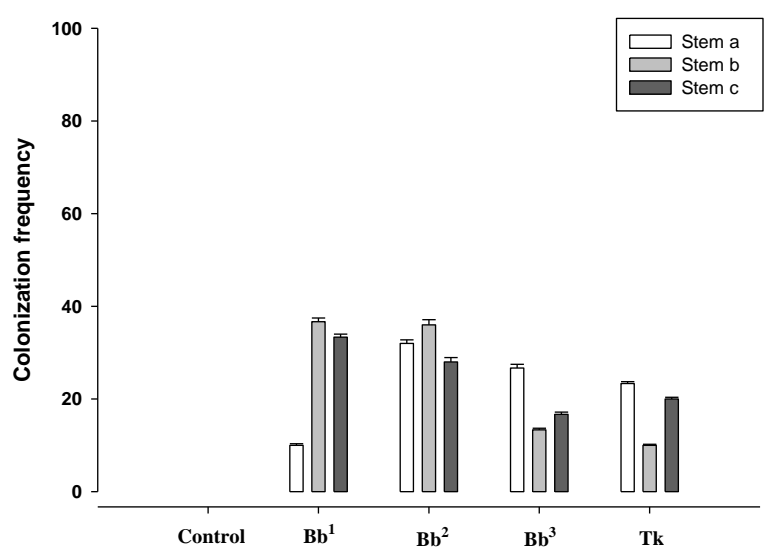

Figure 2. Colonization frequencies of the fungal endophytes in the stem. A one-way analysis of variances ANOVA was developed per each level $\mathrm{a}, \mathrm{b}$ and $\mathrm{c}$. We observed that the endophytes colonized the stem tissue, even in the higher sections of the stem with no significant differences among the levels or treatments. 
Finally, we observed the colonization frequencies of the root samples and only the roots from plants treated with Trichoderma koningiopsis showed positive growth in the selective medium (Figure 3).

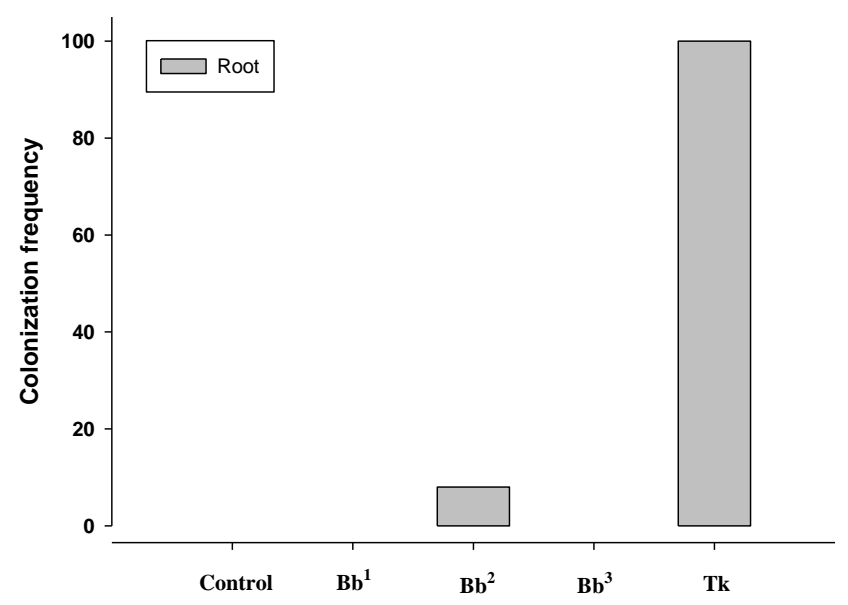

Figure 3. Colonization frequencies of the fungal endophytes in the roots. We observed that the fungi Trichoderma koningiopsis was reisolated from $100 \%$ of the samples and almost no sample resulted positive for Beauveria bassiana in the roots.

\subsection{Molecular detection of fungal DNA}

The amount of endophyte found in the samples ranged from 0 to $0.1 \mathrm{pg} / \mu$ l of DNA sample according to the extrapolated quantification values obtained with the program CFX Manager. Since our standard curves were established from 1.3 to $100 \mathrm{pg} / \mu \mathrm{l}$ of DNA for all the species, no appropriate measurement of the fungal DNA amount was achieved in this section. As it is observed in the Figures 4 and 5 the fungal DNA recovered from the samples is not among the quantitative standard. Nevertheless, the observations are still useful to determine presence or absence of the endophyte in the samples. 


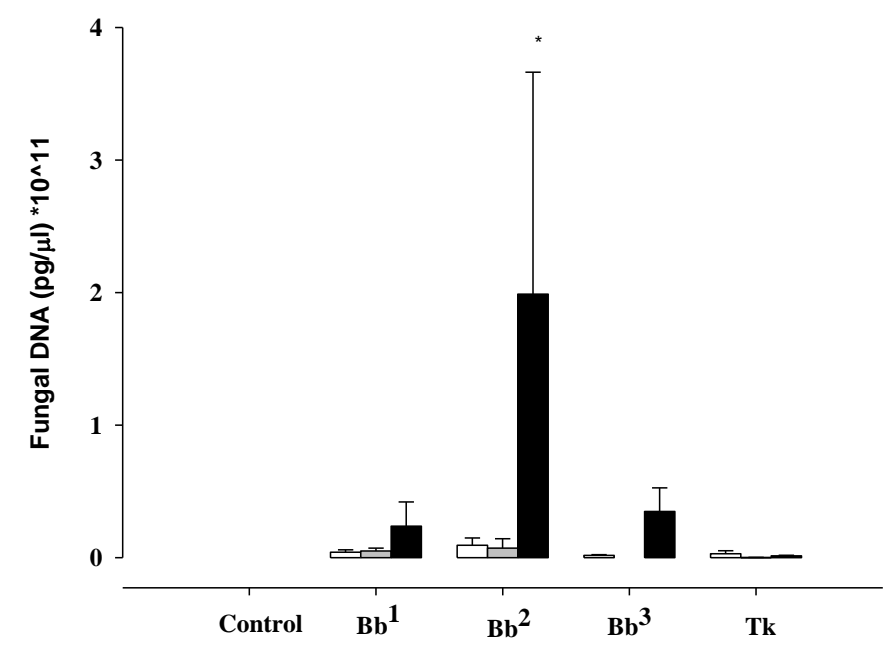

Figure 4. Endophytic fungal DNA quantified from root inoculated tomato plant samples. White bars show the amount quantified from leaves; gray bars show the results of stem samples and black bars are the root samples. The Raw data passed the normality test Kolmogorov-Smirnov $(\mathrm{P}=0,614)$ as well as the equality of variances $(\mathrm{P}=0,386)$. The ANOVA test performed per organ leaf, stem or root comparing among treatments showed significant differences between treatments $(\mathrm{P}<0.001 ; \mathrm{F}=6.818 ; \mathrm{DF}=4)$. An All Pairwise Multiple Comparison Tukey Test was developed to determine the groups.

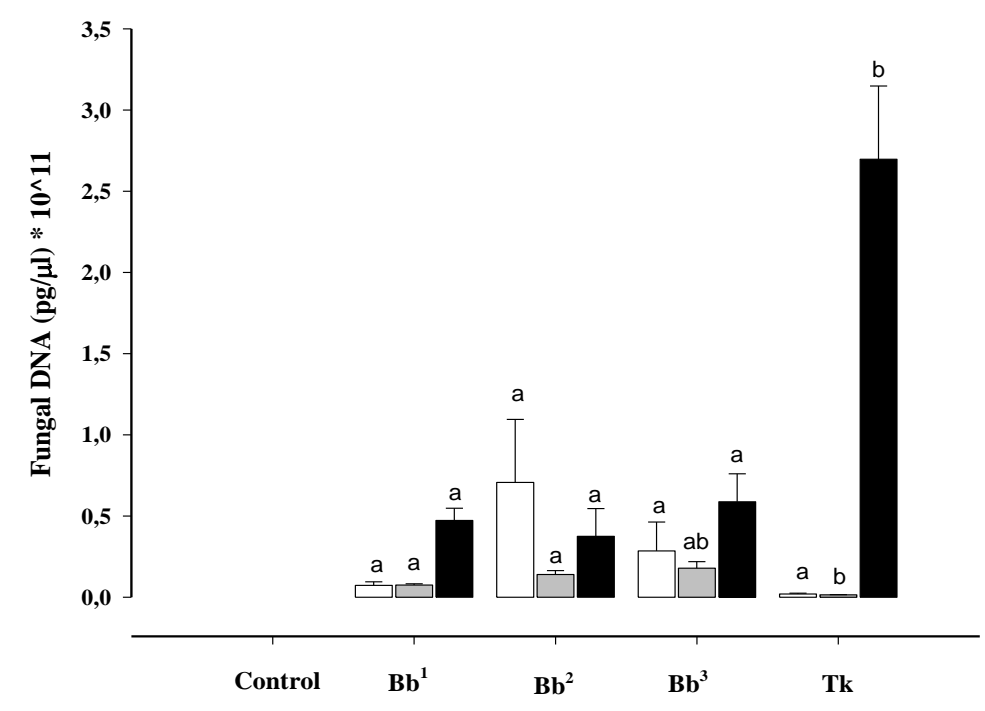

Figure 5. Endophytic fungal DNA quantified from seed inoculated tomato plant samples. White bars show the amount quantified from leaves; gray bars show the results of stem samples and black bars are the root samples. One way analysis of variance for seed inoculated samples. Raw data passed the normality test Kolmogorov-Smirnov $(\mathrm{P}=0,247)$ as well as the equality of variances $(\mathrm{P}=0,171)$. The ANOVA showed differences between the treatments $(\mathrm{P}=0.003, \mathrm{~F}=4.668, \mathrm{DF}=4)$, the test was performed per organ, leaf, stem or root comparing among treatments. The groups were determined based on a multiple comparisons of means Tukey contrast. 


\subsection{Effect of fungal endophytic colonization in plant length}

A comparison of the stem length of tomato plants infected via root and seed inoculation methods is showed in Figure 6. Plants that were root inoculated with Trichoderma koningiopsis showed significantly higher stem length than other treatments. Seed inoculated plants showed significant differences only from plants treated with Beauveria bassiana $\mathrm{Bb}^{2}$, which were smaller than plants from other treatments.

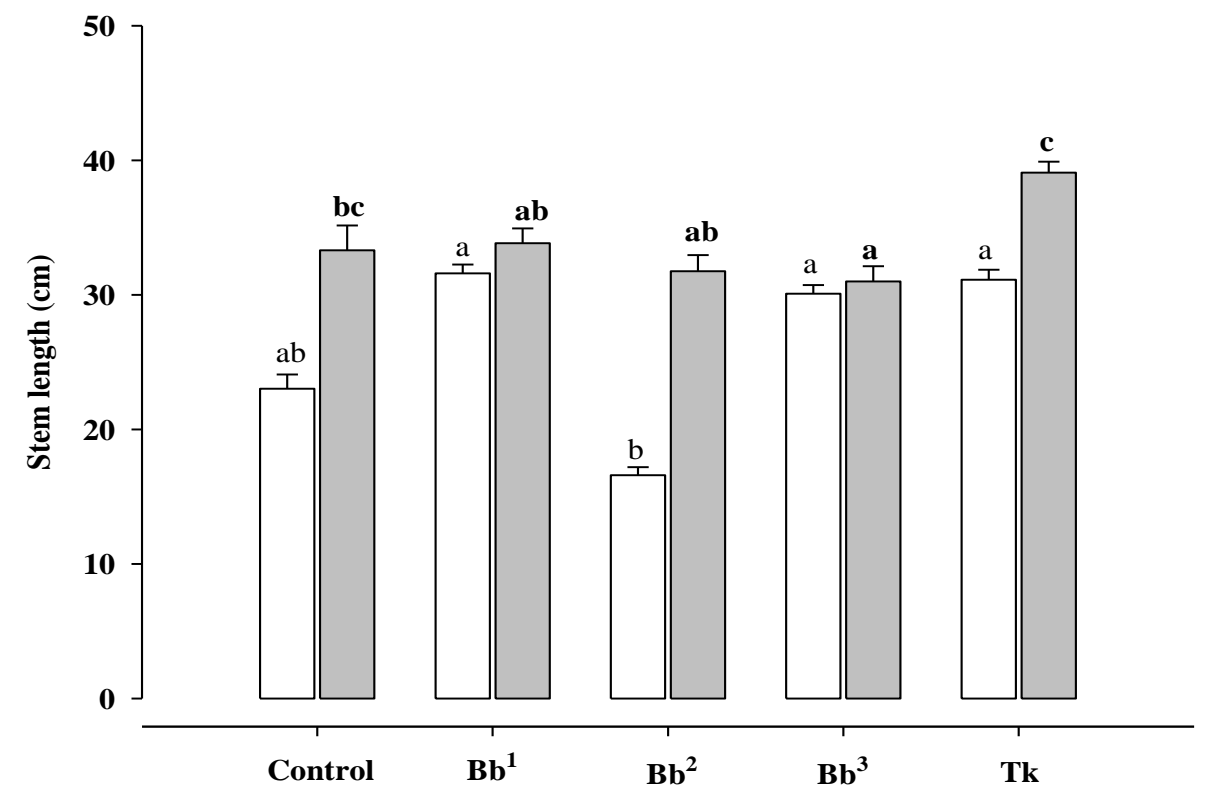

Figure 6. Effect of fungal endophytic colonization on the stem length of tomato plants. White bars are the seed inoculated plants, that showed a significant difference among treatments (ANOVA, $\mathrm{DF}=4, \mathrm{~F}=4.668, \mathrm{P}=0.003$ ). Seed inoculated samples demonstrate a strain-specific effect of the endophytic fungi Beauveria bassiana, where $\mathrm{Bb}^{2}$ delays the growth rate of tomato seedlings compared to other treatments. Grey bars are the root inoculated plants, that presented significant differences among treatments (ANOVA, $\mathrm{DF}=4, \mathrm{~F}=6.818, \mathrm{P} \leq 0.001$ ) and showed the plant growth promotion effect of Trichoderma koningiopsis and no significant effect of Beauveria bassiana treated plants. The groups were determined based on a multiple comparison of means Tukey contrast.

\section{Discussion}

In our research we successfully achieved the establishment of the fungal entomopathogen Beauveria bassiana and the biocontrol agent Trichoderma koningiopsis in tomato plants with two different inoculation methods, seed and root inoculation. The monitoring of the fungal growth in the different plant organs as well as along the plant tissues via selective medium re-isolation or via real time PCR was also successfully achieved. Unfortunately, no quantification was successfully achieved for the 
studied samples, but the molecular protocol allows us to determine the presence or absence of fungal DNA in the sample. The colonization of plant parts by Beauveria bassiana was found to be higher in the leaves than in the stems, and almost no positive records of B. bassiana were found in the roots when evaluated with selective medium re-isolation neither with RT-PCR technique. Likewise, Biswas et al. (2012) reported a higher endophytic colonization of jute plants with B. bassiana in the leaves and stems but they could not detect endophytic colonization in roots neither with selective medium method nor with the PCR technique.

Despite the colonization method, Beauveria bassiana has been reported in different plant systems colonizing endophytically stems and leaves(Greenfield et al., 2016; Landa et al., 2013; Posada et al., 2007; Quesada-Moraga et al., 2014). For instance, Parsa et al. (2013) reported the ability of this fungal entomopathogen to colonize Phaseolus vulgaris tissues and reported a lower colonization rate in the root system of this plant. Nevertheless, they suggest that higher colonization might be obtained if the samples were analyzed with molecular techniques such as PCR. In contrast, we found that the results observed with the re-isolation method were confirmed by PCR techniques and did not resulted in additional positive traces of the fungi in plant sections that showed negative results with the selective medium technique. Beauveria bassiana has been artificially induced to colonize endophytically sorghum plants by Tefera and Vidal (2009) resulting as well in a positive growth in leaves and stem, but no positive infections were obtained in roots.

The results obtained with the seed soaking inoculation method, showed that the fungal DNA was present in a higher frequency in the root tissues probably due to a contact of the root primordia with the external cover of the seed that probably contained viable spores. Interestingly, there was no significant difference among the fungal strains of $B$. bassiana indicating that all the strains were equally able to survive in the plant while the germination process occur despite the different origin.

For Trichoderma koningiopsis, we observed that the colonization in the roots was strong in but very weak to approach different plant organs far from the inoculation site, which is in concordance with the nature of this soil microorganism. In our experiments, we found Trichoderma koningiopsis colonizing stems of tomato plants, similar to the observations reported by Samuels et al. (2006) when isolated Trichoderma koningiopsis from freshly exposed, living sap-wood of trunks of Theobroma cacao plants in Brazil, Ecuador and Peru but failed to obtain it from apical meristems. However, to our knowledge, no reports are available about Trichoderma koningiopsis isolated as endophyte from Solanaceae plant family, which indicates that our findings might be considered as one of the first reports of this species colonizing endophytically tomato plant tissues. Furthermore, our finding may contribute to the potential use of this endophyte to protect plants against insect herbivores and plant pathogens in integrated pest management strategies. 
The amount of the detected fungal DNA in the sampled material is highly variable, indicating that there is no direct correlation between the initial spores concentration used for the infection and the final amount quantified by PCR. The protocol tested in our study for the molecular detection of endophytic fungal DNA was successful to determine the presence or absence of the endophyte in the samples. Nevertheless, to use this method for fungal DNA quantification, more detailed improvements are needed. We suggest obtaining standard curves with lower limit of quantification of the pure fungal DNA than the ones obtained in this research.

Finally, in our study we also wanted to observe to what extend may the fungal inoculation method influence the plant growth? As we expected, Trichoderma koningiopsis inoculated plants were positively affected by the presence of the endophyte, despite the inoculation method, the stem length was significantly higher when inoculated with this endophyte. In contrast, plants that were infected with the entomopathogenic fungi Beauveria bassiana showed no significant differences among the strains neither compared to the control plants. It was even observed that when the plants were seed inoculated with the strain $\mathrm{Bb}^{2}$ there was a delay in the growth compared to non-treated plants.

\section{$5 \quad$ References}

Biswas, C., Dey, P., Satpathy, S., and Satya, P. (2012). Establishment of the fungal entomopathogen Beauveria bassiana as a season long endophyte in jute (Corchorus olitorius) and its rapid detection using SCAR marker. BioControl 57, 565-571. doi:10.1007/s10526-011-9424-0.

Brandfass, C., and Karlovsky, P. (2008). Upscaled CTAB-based DNA extraction and real-time PCR assays for Fusarium culmorum and F. graminearum DNA in plant material with reduced sampling error. Int. J. Mol. Sci. 9, 2306-21. doi:10.3390/ijms9112306.

Elad, Y., and Chet, I. (1983). Improved selective media for isolation ofTrichoderma spp. orFusarium spp. Phytoparasitica 11, 55-58. doi:10.1007/BF02980712.

Espinel, C., Torres, L., and Grijalba, E. (2008). Preformulados para control de la mosca blanca Bemisia tabaci (Hemiptera: Aleyrodidae) en condiciones de laboratorio. Rev. Colomb. ... 34, 22-27. Available at: http://www.scielo.org.co/pdf/rcen/v34n1/v34n1a02.pdf [Accessed March 25, 2015].

Greenfield, M., Gómez-Jiménez, M. I., Ortiz, V., Vega, F. E., Kramer, M., and Parsa, S. (2016). Beauveria bassiana and Metarhizium anisopliae endophytically colonize cassava roots following soil drench inoculation. Biol. Control 95, 40-48. doi:10.1016/j.biocontrol.2016.01.002.

Jaimes, Y. Y., Moreno, C. A., and Cotes, A. M. (2009). Induced systemic resistance against 
Fusarium oxysporum in tomato by Trichoderma koningiopsis Th003. Acta Biológica Colomb. 14, 111-120.

Landa, B. B., López-Díaz, C., Jiménez-Fernández, D., Montes-Borrego, M., Muñoz-Ledesma, F. J., Ortiz-Urquiza, A., et al. (2013). In-planta detection and monitorization of endophytic colonization by a Beauveria bassiana strain using a new-developed nested and quantitative PCR-based assay and confocal laser scanning microscopy. J. Invertebr. Pathol. 114, 128138. doi:10.1016/j.jip.2013.06.007.

López-Mondéjar, R., Antón, A., Raidl, S., Ros, M., and Pascual, J. A. (2010). Quantification of the biocontrol agent Trichoderma harzianum with real-time TaqMan PCR and its potential extrapolation to the hyphal biomass. Bioresour. Technol. 101, 2888-91. doi:10.1016/j.biortech.2009.10.019.

Lopez, D. C., and Sword, G. A. (2015). The endophytic fungal entomopathogens Beauveria bassiana and Purpureocillium lilacinum enhance the growth of cultivated cotton (Gossypium hirsutum) and negatively affect survival of the cotton bollworm (Helicoverpa zea). Biol. Control 89, 53-60. doi:10.1016/j.biocontrol.2015.03.010.

Ownley, B. H., Gwinn, K. D., and Vega, F. E. (2010). Endophytic fungal entomopathogens with activity against plant pathogens: Ecology and evolution. BioControl 55, 113-128. doi:10.1007/s10526-009-9241-x.

Parsa, S., Ortiz, V., and Vega, F. E. (2013). Establishing Fungal Entomopathogens as Endophytes: Towards Endophytic Biological Control. J. Vis. Exp. doi:10.3791/50360.

Posada, F., Aime, M. C., Peterson, S. W., Rehner, S. A., and Vega, F. E. (2007). Inoculation of coffee plants with the fungal entomopathogen Beauveria bassiana (Ascomycota: Hypocreales). Mycol. Res. 111, 748-757. doi:10.1016/j.mycres.2007.03.006.

Quesada-Moraga, E., Landa, B. B., Muñoz-Ledesma, J., Jiménez-Diáz, R. M., and SantiagoÁlvarez, C. (2006). Endophytic colonisation of opium poppy, Papaver somniferum, by an entomopathogenic Beauveria bassiana strain. Mycopathologia 161, 323-329. doi:10.1007/s11046-006-0014-0.

Quesada-Moraga, E., López-Díaz, C., and Landa, B. B. (2014). The hidden habit of the entomopathogenic fungus Beauveria bassiana: First demonstration of vertical plant transmission. PLoS One 9, e89278. doi:10.1371/journal.pone.0089278.

Quesada-Moraga, E., Muñoz-Ledesma, F. J., and Santiago-Alvarez, C. (2009). Systemic protection of Papaver somniferum L. against Iraella luteipes (Hymenoptera: Cynipidae) by an endophytic strain of Beauveria bassiana (Ascomycota: Hypocreales). Environ. Entomol. 38, 723-730. doi:10.1603/022.038.0324.

Samuels, G. J., Dodd, S. L., Lu, B.-S., Petrini, O., Schroers, H.-J., and Druzhinina, I. S. (2006). The Trichoderma koningii aggregate species. Stud. Mycol. 56, 67-133. doi:10.3114/sim.2006.56.03. 
Schulz, B., and Boyle, C. (2006). What are Endophytes? Soil Biol. 9, 1-14. doi:10.1007/3-54033526-9.

Systat Software Inc. (2016). SigmaPlot V.11.0. Available at: www.systatsoftware.com.

Tefera, T., and Vidal, S. (2009). Effect of inoculation method and plant growth medium on endophytic colonization of sorghum by the entomopathogenic fungus Beauveria bassiana. BioControl 54, 663-669. doi:10.1007/s10526-009-9216-y. 


\section{Fungal endophytic colonization influences tomato plant volatile emissions and aphid behavior}

Aragón, S. ${ }^{1,2 *}$;Cotes A.M. ${ }^{1}$ Schütz, S. ${ }^{3}$; Vidal, S. ${ }^{2}$

${ }^{1}$ Colombian Corporation for Agricultural Research. Biological Control Laboratory.

Mosquera, Colombia.

${ }^{2}$ University of Göttingen. Department of Crop Sciences, Göttingen, Germany

${ }^{3}$ University of Göttingen. Buesgen-Institute, Department of Forest Zoology and Forest Conservation, Göttingen, Germany.

* Corresponding author: saragon@ corpoica.org.co 


\title{
Fungal endophytic colonization influences tomato plant volatile emissions and aphid behavior
}

\author{
Aragón, S. ${ }^{12^{*}}$; Cotes, A.M. ${ }^{1}$ Schütz, S. ${ }^{3}$; Vidal, S. ${ }^{2}$ \\ ${ }^{1}$ Colombian Corporation for Agricultural Research. Biological Control Laboratory. Mosquera, Colombia. \\ ${ }^{2}$ University of Göttingen. Department of Crop Sciences, Göttingen, Germany. * saragon@ corpoica.org.co \\ ${ }^{3}$ University of Göttingen. Buesgen-Institute, Department of Forest Zoology and Forest Conservation, Göttingen, \\ Germany.
}

\begin{abstract}
Tomato plants release a bouquet of volatiles that is involved in different biotic interactions potentially applicable in biological control of crop pests. Additionally, tomato plants host multiple microbes colonizing plant tissues endophytically without causing symptoms of infection. Here we studied the ability of horizontally transmitted fungal endophytes to modulate plant volatile organic compounds emitted by tomato plants (Solanum lycopersicon Mill) aboveground. Specifically, we analyzed the effect of an endophytic colonization by three different strains of the entomopathogenic endophytic fungi Beauveria bassiana: $\mathrm{Bv}$ 061, EABb 04/01- Tip and Bb1022 on the emissions of volatile organic compounds. These bouquets were compared with those of plants inoculated with the biocontrol agent Trichoderma koningiopsis Th003 used to protect plants from fungal infections. The tomato headspace bouquet was also analyzed following a combined infection by an endophytic fungus and an infestation by the aphid Myzus persicae. We hypothesize that fungal inoculations of tomato plants can lead to an endophytic colonization of plant tissues that alters the volatile organic compounds bouquet emitted by tomato plants and that those changes might be recognized by aphids modulating the insect herbivore attraction to inoculated plants. Based on analytical, molecular and behavioral methods we demonstrate i) that all fungal isolates successfully colonized tomato plant tissues endophytically; ii) that the headspace of tomato plants can be grouped into three distinct groups, i.e. non-treated plants, endophytically colonized plants, and plants treated simultaneously with aphids and endophytic fungi and iii) that Myzus persicae was able to discriminate between treated and non-treated tomato plants with more specimens attracted to blends emitted by tomato plants treated with the entomopathogenic endophytic fungi compared to the non-treated plants. Our findings contribute to a better understanding of plant-insect chemical communication mediated by endophytic fungi, which might potentially be used in the development of pest control strategies by introducing microorganisms traditionally applied to protect different crops in biological control strategies, using for example "lure and kill management". Nevertheless, in this paper, we focus on the interaction cascade from the endophytic infection until the insect attraction. Further studies are necessary to clarify if the higher attraction to plants inoculated with entomopathogenic fungi can cause pathogenicity in the attracted insects and potentially be used to manage crop pests.
\end{abstract}

Keywords: Volatile Organic Compounds, Fungal endophyte, Beauveria bassiana, Trichoderma koningiopsis, Insect attraction 


\section{Introduction}

Tomato plants (Solanum lycopersicon Mill) release a complex blend of volatile organic compounds (Proffit et al., 2011), which can be used as chemical clues in the detection of plant infection with pathogens of economic impact (Schütz et al. 1999, Hussaini et al., 2011; Jansen et al., 2009). In addition, plant volatiles can act as chemical attractants for associated insects. For instance Jallow et al. (2008) observed that variations in the amount of some compounds emitted by tomato plants consistently influences the decision made by a polyphagous moth Helicoverpa armigera (Hübner). A similar behavior was observed by Proffit et al. (2011), who observed that tomato plants release different volatile organic compounds depending on the cultivar and that those differences even of minor compounds can be detected by Tuta absoluta when choosing the host plant. Bruce and Pickett, (2011) reviewed the highly sensitive olfactory system that allows the insects to locate suitable host plants, and how the compound ratio in volatile blends can influence in the host selection.

Nevertheless, plant volatiles is dynamic and can be modulated in response to different biotic stress, affecting, in consequence, some inter-species interactions (Dicke et al., 2009). Many reviews summarize interactions that affect the plant volatile bouquet above and belowground (Clavijo McCormick et al., 2012; Dicke et al., 2009; Dicke and Baldwin, 2010; Heil, 2008; Pineda et al., 2010). Among the interactions that can influence the plant volatile bouquet are the ones caused by endophytes, commonly defined as microorganisms able to live for all or part of their life cycle inside tissues of living plants without causing any apparent symptom of disease or negative effect in the host plant (Rodriguez et al., 2009; Saikkonen et al., 1998; Schulz and Boyle, 2006).

Most of the studies involving the effect of fungal endophytes on multitrophic interactions have been conducted with grass endophytes (Li et al., 2014; Saikkonen et al., 2013) and, horizontally transmitted endophytes remain poorly explored (Rodriguez et al., 2009). Nevertheless, Jallow et al., (2008) report the ability of the root-colonizing microorganism Beauveria bassiana to induce changes in the volatile organic compounds profile of tomato plant species. According to Schausberger et al., (2012) the fungal endophyte Beauveria bassiana, was also able to modify the compound profile of cabbage plants depending on the fungal density. Similarly, it has been reported that tomato plants inoculated with the root endophyte Trichoderma longibrachiatum showed significant differences in the quantity of some volatile organic compounds. 
In order to contribute to a better understanding of plant-insect chemical communication mediated by endophytic fungi, we addressed the hypothesis that fungal inoculations of tomato plants can lead to an endophytic colonization of plant tissues that alters the volatile organic compounds bouquet emitted by tomato plants that subsequently might be detected by aphids, modulating the insect herbivore attraction to inoculated plants.

The present research evaluated the effect of three different strains of Beauveria bassiana and Trichoderma koningiopsis in tomato plant (Solanum lycopersicon Mill.) on volatile organic compound profiles and resulting manipulation of plant-insect interaction. Additionally, this effect was compared with the changes when the endophyte was a plant pathogen biocontrol agent Trichoderma koningiopsis Th003. Simultaneously, we analyzed the headspace of tomato plants induced firstly by the mentioned fungal inoculations and followed by the stimulus of a sap-sucking insect attack, the aphid Myzus persicae. We demonstrate that i) all fungal isolates of this model successfully colonize tomato plant tissues endophytically; ii) the headspace of tomato plants can be grouped into three distinct groups, i.e. non-treated plants, endophytically colonized plants, and plants treated simultaneously with aphids and endophytic fungi and iii) the aphid Myzus persicae is able to discriminate between treated and non-treated tomato plants with more specimens attracted to blends emitted by tomato plants treated with the entomopathogenic endophytic fungi compared to the non-treated plants.

Nevertheless, in this paper, we focus on the interaction cascade from the endophytic infection until the insect attraction, and further studies are necessary to clarify if the higher attraction to plants inoculated with entomopathogenic fungi can cause pathogenicity in the attracted insects and can potentially be used to manage crop pests.

\section{Materials and Methods}

\subsection{Plant material}

Seeds of Solanum lycopersicon var. Ruthje (Rein Saat ${ }^{\circledR}$ ) were sown in an autoclaved mixture of 3:1 soil (Fruhstorfer Erde Typ 25, Hawita Gruppe GmbH, peat fine structure with volcanic clay, pH: 5.7-6.3, fertilization of 200-300mg N) and one part of $0.3 \mathrm{~mm}$ sand. After 10 days of germination, seedlings were transplanted into $11 \mathrm{~cm}$ pots and placed in the greenhouse of the Department of Crop Sciences at the University of Göttingen, Germany. The temperature was in a range of $18-25^{\circ} \mathrm{C}$ and light in a photoperiod of $18 \mathrm{~L}: 6 \mathrm{D}$. Plants were fertilized once a week 
with Hakaphos $2 \mathrm{~g} / \mathrm{L}\left(15 \% \mathrm{~N}, 11 \% \mathrm{P}_{2} \mathrm{O}_{5}, 15 \% \mathrm{~K}_{2} \mathrm{O}, 1 \% \mathrm{Mg}, 0.1 \% \mathrm{Fe}, 0.1 \% \mathrm{Mn}, 0.04 \% \mathrm{Cu}\right.$, $0.025 \% \mathrm{~B}$ and $0.005 \% \mathrm{Mo})$.

\subsection{Insect rearing}

Myzus persicae aphids were collected from greenhouse plant material and reared on Brassica oleracea plants under laboratory conditions $23 \pm 2^{\circ} \mathrm{C}$ and a $16 \mathrm{~L}: 8 \mathrm{D}$ photoperiod and $60 \%$ R.H. The individuals used for behavior experiments were maintained in L60 x W60 x H60 cm insect rearing tents (BugDorm-2120, Bug Dorm Store, Taiwan) with two side panels made of polyester netting mesh size $680 \mu \mathrm{m}$ opening. Only winged aphids were taken from the rearing cage with an aspirator to be released in the experimental cages for behavior experiments.

\subsection{Fungal material}

Beauveria bassiana strains Bb 1022 and Bb EABb 04/01- Tip were supplied by the microbial collection of the Entomology laboratory at Göttingen University, while the strain Bv 061 was obtained from the germplasm bank of the Biological Control Laboratory at Corpoica, Colombia. Trichoderma koningiopsis Th003 was delivered by the company Prophyta (Biologischer Pflanzenschutz GmbH, Germany).

The fungal material was grown on Potato Dextrose Agar at $25^{\circ} \mathrm{C} \pm 2$ for a period of three weeks until they developed an abundant amount of spores. Then a spore suspension was prepared by adding $3 \mathrm{ml}$ of $0.01 \%$ Tween 20 in the Petri dish and spores were removed with a Drigalski spatula and re-suspended in $97 \mathrm{ml}$ of distilled autoclaved water. The suspension was filtered and the concentration was determined and adjusted to $1 \times 10^{7}$ conidia/ml.

\subsection{Root inoculation}

Four weeks old seedlings were root cleaned with tap water until the substrate was completely removed. Clean roots were immersed into the corresponding fungal treatment: $\mathrm{Bb}^{1}, \mathrm{Bb}^{2}, \mathrm{Bb}^{3}$ or Tk and the control group $(\mathrm{C})$ were immersed in a mixture of autoclaved distilled water $+0.01 \%$ Tween 20. After 20min in the suspension, the seedlings were transplanted into plastic pots filled with autoclaved soil and placed into a climatic room at $25^{\circ} \mathrm{C} \pm 2,70 \%$ R.H. and a photoperiod of 18L:6D. Each treatment was evaluated with 10 plants for inoculation success and 6 plants for volatile profiles, half treated only with endophytes and the other half treated with a combination of a fungal inoculation followed by the aphid induction three weeks after the root treatment. 


\subsection{Test for endophytic colonization}

\subsubsection{Re-isolation of endophytes from plant tissue}

Plant material was evaluated after three weeks post inoculation. Six plants per treatment were screened by carefully washing each of them with tap water until the roots were completely free of soil. Leaves, roots, and stems were collected and surface sterilized by soaking the samples in $70 \%$ Ethanol for two minutes, followed by a two minutes immersion in sodium hypochlorite $0.2 \%$ and finished with three rinses with sterile distilled water. The samples were dried in the extraction hood. After that, five leaf disks of $6 \mathrm{~mm} \varnothing$, five stem segments of $5 \mathrm{~mm}$ length and five roots sections were placed into Petri dishes with the corresponding selective medium for Beauveria bassiana (Quesada-Moraga et al., 2006) and for T. koningiopsis (Elad and Chet, 1983). Fungal growth was recorded after 10 days of incubation at $25^{\circ} \mathrm{C}$ in darkness. Endophytic colonization (presence/absence) was confirmed by real-time polymerase chain reaction (RTPCR) to avoid false positives following the protocols described in chapter 1 (Data not shown).

\subsection{Treatments and experimental design}

The experimental design included an endophyte-free control (C), an aphid infested control (A) and four endophyte treatments (E): Beauveria bassiana cv. EABb 04/01 -Tip $\left(\mathrm{Bb}^{1}\right)$, B. bassiana cv. Bv $061\left(\mathrm{Bb}^{2}\right)$, B. bassiana Bb1022 (Bb3 $)$, Trichoderma koningiopsis cv. Th 003 (Tk) as well as the combination of $(\mathrm{E})$ and $(\mathrm{A}):\left(\mathrm{Bb}^{1}+\mathrm{A}\right),\left(\mathrm{Bb}^{2}+\mathrm{A}\right),\left(\mathrm{Bb}^{3}+\mathrm{A}\right)$ and $(\mathrm{Tk}+\mathrm{A})$. In a randomized complete block design, two separate benches were assigned as blocks. Fifteen replicate plants per treatment were grown in each bench for a total of 150 plants. We tested two hypotheses: (i) Endophytic inoculations with $B$. bassiana alter differentially the aboveground headspace volatile profile of tomato plants in comparison with the plant pathogen biocontrol agent Trichoderma koningiopsis and Myzus persicae attack; (ii) Inoculation with B. bassiana might decrease the attraction of winged aphids of the species $M$. persicae to tomato plants more than those inoculated with T. koningiopsis.

\subsection{Experiment I: Plant volatile profiles in response to fungal endophytic inoculation}

\subsubsection{Sampling of volatile organic compounds}

The objective of this experiment was to test the hypothesis that endophytic colonization of tomato plants Solanum lycopersicon with fungal endophytes alters the plant volatile organic compounds bouquet differentially depending on the fungal species. Therefore, samples of volatile organic compounds emitted by tomato plants of each treatment mentioned in detail in 
section 2.6 were taken in the greenhouse four weeks after root inoculation. Using a dynamic headspace collection system modified of "Push- pull" headspace collection described in Tholl et al. (2006), the plant sample was enclosed in a volatile free polyester foil (Toppits ${ }^{\circledR}$. Minden, Germany) and with a miniature pump (Faulhaber Miniature Device Systems, series 2233T012S, Germany) the air was forced to move out of the bag through the TDS tube (Thermal Desorption System, Gerstel) filled with a porous polymer based on 2.6-diphenyleneoxide (Tenax ® TA). Samples were collected during $25 \mathrm{~min}$ with a flow rate of $0.18 \mathrm{1} / \mathrm{min}$. The TDS tubes were processed immediately in the GC-MS.

\subsubsection{Chemical Analysis}

Samples were analyzed using a Gas Chromatograph directly coupled to a quadrupole mass selective detector (GC-MS Hewlett Packard HP6890N and 5973, Agilent Technologies, Santa Clara, USA ) with a non-polar column (30m length, $0.2 \mu \mathrm{m}$ ID, $0.25 \mu \mathrm{m}$ film thickness, HP5MS, Agilent Technologies, UK). The samples on TDS traps were thermodesorbed in a TDS A2 thermodesorption autosampler system (Gerstel, Mülheim, Germany) with an initial temperature of $20^{\circ} \mathrm{C}$ held for $30 \mathrm{~s}$ and increased by $60^{\circ} \mathrm{Cmin}^{-1}$ up to $280^{\circ} \mathrm{C}$ for $3 \mathrm{~min}$. Over a helium flow (purity 99.999\%), volatiles were carried from the TDS tube to a cold injection system where volatiles was cryo-focussed in a cold injection system CIS 4 (Gerstel) at $-75^{\circ} \mathrm{C}$. After 90s the split was opened and no volatiles could reach the cold injection system. Volatiles were heated with $12^{\circ} \mathrm{C} \mathrm{s}^{-1}$ to $260^{\circ} \mathrm{C}$ and transferred by a He-flow into the column. Oven temperature started at $40^{\circ} \mathrm{C}$ for $3 \mathrm{~min}$, then programmed at $7,5^{\circ} \mathrm{Cmin}^{-1}$ to $200^{\circ} \mathrm{C}$ and the final temperature was held for $5 \mathrm{~min}$. Temperature program lasted 29,33min.

The GC-MS chromatograms were analyzed using MSD ChemStation data analysis software (Agilent Technologies, 2011), and the automated mass spectral deconvolution and identification system AMDIS. The compounds reported are limited only to those compounds that fit with the following parameters: i) that were present during retention times after $6 \mathrm{~min}$ and no later than $24 \mathrm{~min}$; ;i) that the quality of the mass spectra identification match was higher than $70 \%$ and iii) that were present in all the replicates of at least one treatment. The final matrix with candidate compounds was processed by a non-metric multidimensional scaling (NMDS) analysis in order to detect similarities among samples (using the peak area of Total Ion Current).

Tentative peak identification of the compounds was based i) matching of the mass spectra with those of the mass spectral library of the National Institute of Standards and Trade (NIST 98 MS library, Gaithersburg, USA), ii) comparing the calculated Linear Retention Index (LRI) with 
data provided in the literature. The confirmation of the identity of the compounds by co-elution with authentic standards as well as the comparison of the LRI with the literature is still in progress.

Table 1. Standard $n$-alkanes (C8 -C19) applied in the calculation of the linear retention index (LRI) of the interesting compounds. The standards were analysed using a gas chromatograph directly coupled to a quadrupole mass selective detector (GC-MS Hewlett Packard HP6890N and 5973, Agilent Technologies, Santa Clara, USA ) with a non-polar column (30m length, $0.2 \mu \mathrm{m}$ ID, $0.25 \mu \mathrm{m}$ film thickness, HP-5MS, Agilent Technologies, UK).

\begin{tabular}{lll}
\hline $\boldsymbol{Z}$ & n-alkane & $\boldsymbol{t}_{\boldsymbol{R} \boldsymbol{Z}}^{T}$ \\
\hline 7 & Heptane & 5.37 \\
8 & Octane & 7.38 \\
9 & Nonane & 9.72 \\
10 & Decane & 12.03 \\
11 & Undecane & 14.20 \\
12 & Dodecane & 16.23 \\
13 & Tridecane & 18.13 \\
14 & Tetradecane & 19.91 \\
15 & Pentadecane & 21.59 \\
16 & Hexadecane & 23.18 \\
17 & Heptadecane & 24.69 \\
18 & Octadecane & 26.38 \\
19 & Nonadecane & 28.53 \\
\hline
\end{tabular}

The linear retention indices (LRI) were determined for all constituents by using homologous series of n-alkanes C8-C20 shown in Table 1 based on the equation proposed from van den Dool and Kratz (1963):

$$
I^{T}=100\left[z+\left(\frac{t_{R i}^{T}-t_{R z}^{T}}{t_{R(z+1)}^{T}-t_{R z}^{T}}\right)\right]
$$

Where $t_{R i}^{T}$ the retention time of the interesting is compound; $t_{R z}^{T}$ and $t_{R(z+1)}^{T}$ are the retention times (in minutes) of the two standard $n$-alkanes containing $z$ and $(z+1)$ carbon numbers, respectively (See Table 2). 
Table 2. Linear retention index (LRI ) calculated for the tentative identified compounds. Where $t_{R i}^{T}$ is the retention time of the interesting compound; $t_{R z}^{T}$ and $t_{R(z+1)}^{T}$ are the retention times (in minutes) of the two standard $n$-alkanes containing $z$ and $(z+1)$ carbon numbers.

\begin{tabular}{|c|c|c|c|c|c|c|c|c|}
\hline$\overline{\mathbf{N}^{0}}$ & $\begin{array}{l}\text { Compound } \\
\text { name }\end{array}$ & $t_{R i}^{T}$ & $\bar{Z}$ & $\overline{t_{R z}^{T}}$ & $t_{R(z+1)}^{T}$ & $I^{T}$ & Literature & $\begin{array}{l}10 \text { Largest } \\
\text { peaks }\end{array}$ \\
\hline 1 & $\alpha$-pinene & 6,25 & 7 & 5,37 & 7,38 & 743,62 & 922 & $\begin{array}{l}93-91-119-92-77- \\
18-79-28-134- \\
121\end{array}$ \\
\hline 2 & hexanal & 7,34 & 7 & 5,37 & 7,38 & 798,08 & 769 & $\begin{array}{l}28-44-56-18-41- \\
43-57-32-29-39\end{array}$ \\
\hline 3 & p-cymene & 8,59 & 8 & 7,38 & 9,72 & 851,63 & 1011 & $\begin{array}{l}119-117-91-134- \\
132-28-115-120- \\
77\end{array}$ \\
\hline 4 & trans-isolimonene & 9,16 & 8 & 7,38 & 9,72 & 875,87 & 974 & $\begin{array}{l}28-79-93-91-107- \\
136-121-77-18- \\
67\end{array}$ \\
\hline 5 & o-cymene & 9,47 & 8 & 7,38 & 9,72 & 889,40 & 1076 & $\begin{array}{l}28-119-18-32-91- \\
117-44-134-252- \\
132\end{array}$ \\
\hline 6 & m-cymene & 9,49 & 8 & 7,38 & 9,72 & 890,17 & 1013 & $\begin{array}{l}\text { 119-91-134-114- } \\
121-93-77-115- \\
120-136\end{array}$ \\
\hline 7 & $\beta$-phellandrene & 11,25 & 9 & 9,72 & 12,03 & 966,06 & 1030 & $\begin{array}{l}93-91-77-136-68- \\
79-67-94-92-121\end{array}$ \\
\hline 8 & $\alpha$-terpinene & 11,50 & 10 & 12,03 & 14,2 & 975,58 & 1008 & $\begin{array}{l}119-121-93-91- \\
136-134-77-79- \\
105-117\end{array}$ \\
\hline 9 & $\alpha$-phellandrene & 11,50 & 9 & 9,72 & 12,03 & 977,20 & 997 & $\begin{array}{l}93-91-77-119- \\
136-28-79-94- \\
105-92\end{array}$ \\
\hline 10 & trans-isolimonene & 11,81 & 9 & 9,72 & 12,03 & 990,62 & 974 & $\begin{array}{l}79-107-93-121- \\
139-68-67-58-41- \\
55\end{array}$ \\
\hline 11 & $\gamma$-terpinene & 12,18 & 10 & 12,03 & 14,2 & 1007,05 & 1047 & $\begin{array}{l}\text { 121-93-119-91- } \\
136-77-79-105- \\
134-117\end{array}$ \\
\hline 12 & 2-carene & 12,34 & 10 & 12,03 & 14,2 & 1014,33 & 996 & $\begin{array}{l}132-93-117-91- \\
121-136-115-77- \\
79-92\end{array}$ \\
\hline 13 & $\alpha$-terpinolene & 12,35 & 10 & 12,03 & 14,2 & 1014,94 & 1078 & $\begin{array}{l}\text { 119-121-93-91- } \\
136-134-77-79- \\
105-117\end{array}$ \\
\hline 14 & sabinene & 12,79 & 10 & 12,03 & 14,2 & 1035,01 & 964 & $\begin{array}{l}93-91-77-136-79- \\
94-92-68-121-67\end{array}$ \\
\hline 15 & 1,3,8-p-menthatriene & 14,54 & 11 & 14,2 & 16,23 & 1116,95 & 1085 & $\begin{array}{l}28-91-132-93- \\
117-119-32-18- \\
115-77\end{array}$ \\
\hline 16 & eucarvone & 15,42 & 11 & 14,2 & 16,23 & 1160,16 & 1287 & $\begin{array}{l}28-32-18-121-91- \\
135-77-119-93- \\
107\end{array}$ \\
\hline 17 & p-cumenol & 16,76 & 12 & 16,23 & 18,13 & 1227,90 & - & - \\
\hline 18 & cumaldehyde & 17,16 & 12 & 16,23 & 18,13 & 1249,07 & 1214 & $\begin{array}{l}133-148-28-105- \\
77-119-91-79- \\
103-32\end{array}$ \\
\hline 19 & $\begin{array}{l}\text { 2-methyl-3-phenyl- } \\
\text { propanal }\end{array}$ & 17,16 & 12 & 16,23 & 18,13 & 1249,08 & 1244 & $\begin{array}{l}133-148-28-105- \\
77-119-91-79- \\
103-32\end{array}$ \\
\hline
\end{tabular}




\begin{tabular}{|c|c|c|c|c|c|c|c|c|}
\hline 20 & ascaridol & 19,04 & 13 & 18,13 & 19,91 & 1351,12 & 1273 & $\begin{array}{l}28-32-18-135-91- \\
55-41-252-70-44\end{array}$ \\
\hline 21 & piperitone & 17,33 & 12 & 16,23 & 18,13 & 1266,11 & 1228 & $\begin{array}{l}28-82-110-32-95- \\
18-135-137-109- \\
41\end{array}$ \\
\hline 22 & carvacrol & 17,99 & 12 & 16,23 & 18,13 & 1292,82 & 1278 & $\begin{array}{l}28-235-150-32- \\
91-18-115-107- \\
77-105\end{array}$ \\
\hline 23 & cuminol & 18,03 & 12 & 16,23 & 18,13 & 1294,90 & 1271 & $\begin{array}{l}28-135-119-32- \\
91-18-150-105- \\
77-79\end{array}$ \\
\hline 24 & caryophyllene & 20,47 & 14 & 19,91 & 21,59 & 1433,54 & 1424 & $\begin{array}{l}93-133-91-28-79- \\
69-105-41-161- \\
107\end{array}$ \\
\hline 25 & $\alpha$-humulene & 21,11 & 14 & 19,91 & 21,59 & 1471,62 & 1456 & $\begin{array}{l}93-28-80-121-91- \\
147-79-77-107- \\
105\end{array}$ \\
\hline
\end{tabular}

For each sample, the peak area was calculated by integrating the peaks and the given results are based on the percentage of a compound according to the total peak area. The representative total ion chromatogram (TIC) of the tomato plants headspace is shown in Figure 1.

\subsection{Experiment II: Effect of endophytic fungal inoculations on Myzus persicae attraction}

The objective of this experiment was to determine whether winged aphids Myzus persicae are able to detect differences in volatile organic compound blends emitted by tomato plants treated with fungal endophytes when offered simultaneously with non-inoculated tomato plants. In the laboratory conditions $23 \pm 2{ }^{\circ} \mathrm{C}$ and a 16L:8D photoperiod and $60 \%$ R.H., five wood cages $(50 \mathrm{x}$ $30 \times 35 \mathrm{~cm}$ ), with sidewalls of nylon tissue (mesh size $<1 \mathrm{~mm}$ ) were placed. In each cage, the five different odor sources i.e. one plant per (E) treatment and one control plant (C) were randomly distributed, resulting in a total of five plants per cage. 


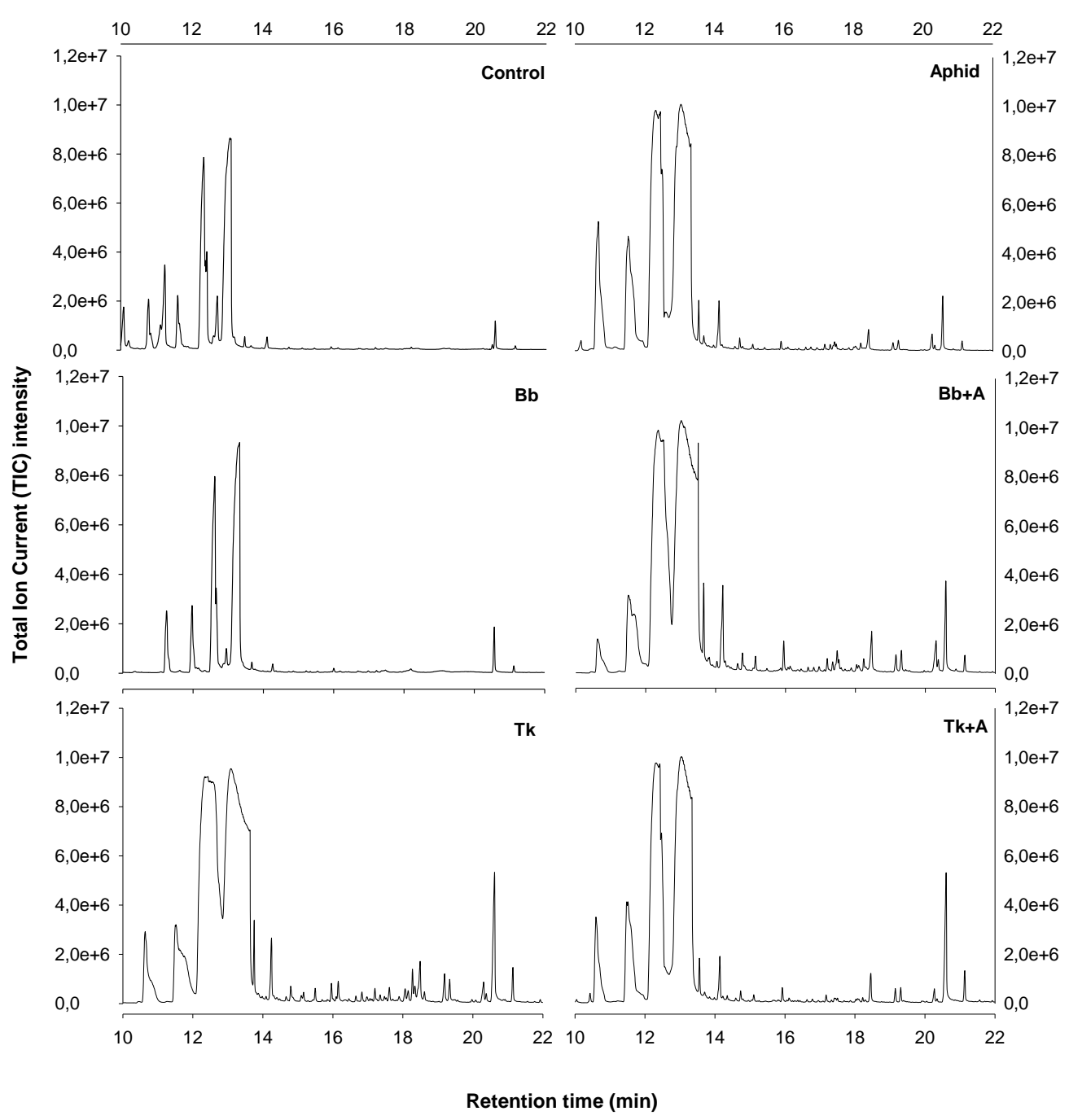

Figure 1. Representative total ion current (TIC) chromatograms showing abundance expressed as counts of ions present in a volatile organic compounds profile extracted from Solanum lycopersicon plants. On the left side, are the endophyte-free plants (Control), the inoculated with Beauveria bassiana $(\mathrm{Bb})$ and Trichoderma koningiopsis (Tk). Right-up are the aphid attacked plants (Aphid) followed by B. bassiana inoculated plants with aphid attack $(\mathrm{Bb}+\mathrm{A})$ and $T$. koningiopsis with aphid attack $(\mathrm{Tk}+\mathrm{A})$.

In the center of each cage, a group of 100 winged aphids was released and allowed tointeract with the plants for 24 hours. Then the host preference of insects registered as the number of recaptured individuals per treatment $(\mathrm{n}=100,5$ replicates). Additional observations were made under greenhouse conditions, during spring season 2014 a new group of four plants per treatment was randomly distributed in four benches in the greenhouse and the attracted insects were registered after 24 hours.

\subsection{Statistical Analysis}


The headspace composition among treatments was compared by multivariate analysis using the vegan package in $\mathrm{R}$ version 3.2.2 (R Core team, 2015), a non-metric multidimensional scaling (NMDS) analysis (Proffit et al., 2011) was done to detect similarities between the treatments. No transformations were applied to the relative amounts of the total peak area of each compound in each total ion chromatogram.

The effect of endophytic inoculation on tomato plants regarding the host plant selection by Myzus persicae was analyzed by means of a linear mixed effects model (r-package "lme4" and "Ime", $\mathrm{R}$ version 3.2.2). The amount of aphids recovered from the plants $(x)$ constituted the dependent variable $(n=100)$, the fixed effects were the different treatments, whereas each cage where the plants were grouped was considered as a block and represented the random effect in the model.

We plotted the residuals and observed a normal distribution of the data. The homogeneity of variances of the residues was confirmed with Shapiro -Wilk normality test for the greenhouse experiment $(\mathrm{P}=0.1542)$. For the laboratory assay the model showed a $\mathrm{P}$ value of 0.03839 , indicating the presence of significant differences, and the normality test of the residuals (Shapiro-Wilk) confirmed the assumption of normal distributed data $(\mathrm{P}=0.3876)$. The groups were determined based on multiple comparisons of means: Tukey contrast.

\section{Results}

\subsection{Endophytic colonization of tomato plant tissues}

Endophytic colonization of treated plants (E) was confirmed for all the strains in different organs of the plant: leaf, stem and root. Positive growth of fungal endophytes from leave samples was achieved in $100 \%$ of the sampled plants inoculated with $\mathrm{Bb}^{2}(\mathrm{n}=5)$ and $\mathrm{Tk}(\mathrm{n}=6)$, followed by a lower inoculation rate of $83 \%$ and $67 \%$ for $\mathrm{Bb}^{1}(\mathrm{n}=6)$ and $\mathrm{Bb}^{3}(\mathrm{n}=6)$ respectively. Stems were less successfully colonized by endophytes with a $96 \%$ of the $\mathrm{Bb}^{2}$ sampled plants, $80 \%$ of $\mathrm{Bb}^{1}$ and in the last place $\mathrm{Bb}^{3}$ and $\mathrm{Tk}$ with successful re-isolations of $57 \%$ and $53 \%$. For Tk treatment, $100 \%$ of selected tomato plants were positive for fungal colonization in roots, while only the treatment $\mathrm{Bb}^{2}$ showed presence of the endophyte in $8 \%$ of the sampled plants. Strains $\mathrm{Bb}^{1}$ and $\mathrm{Bb}^{3}$ were not found in root samples.

\subsection{Effect of inoculation by fungal endophytes on the volatile profile of tomato plants}


In order to determine the effects of fungal inoculations on the volatile organic profile of tomato plants, a total of 34 headspace samples were analyzed. The treatments Control, $\mathrm{Bb}^{1}, \mathrm{Bb}^{2}$, and $\mathrm{Tk}$ had a replicate number of four and $\mathrm{Bb}^{3}$, Aphid and all $(\mathrm{E}+$ Aphid) combinations had three biological replicates.

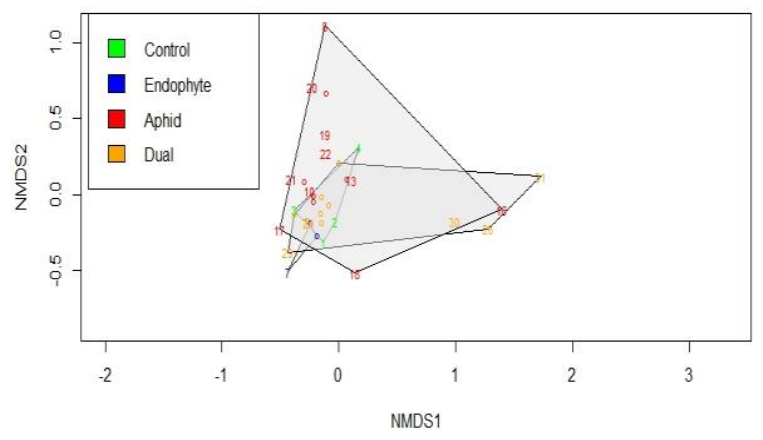

Figure 2. Non -metric multidimensional scaling (NMDS) plot visualizing the compounds of the tomato plants headspace based on similarity (Bray-Curtis distance), rotated by principal component, (stress $=0.068$ ). Compounds are grouped according to the treatment.

The polygons arranged the compounds into three major groups according to the treatments (Figure 2): Endophyte-free (C), endophytically inoculated (E) and in a third group showing almost no differences are the aphid infested plants (A) and the dual combination of aphid attack and endophyte $(\mathrm{A}+\mathrm{E})$. On the basis of the tentative identifications and semi-quantitative assessments of compound amounts by the relative peak area of the Total Ion Current, preliminary assignments of indicator compounds are suggested. For the first group, we could observe that one of the indicator compounds in the overall headspace composition of tomato plants $(\mathrm{C})$ is p-cymene. The second group that was obtained based on similarities is the group of endophytically inoculated tomato plants (E) which is characterized by the release of $\alpha$-pinene as the major indicator compound and trans-isolimonene. Finally, the third group $(\mathrm{A}+\mathrm{E})$ is characterized by compounds such as $\beta$-caryophyllene, ascaridole, and $\alpha$-thujone.

\subsection{Effect of fungal inoculations on host plant selection by the herbivorous insect Myzus} persicae 


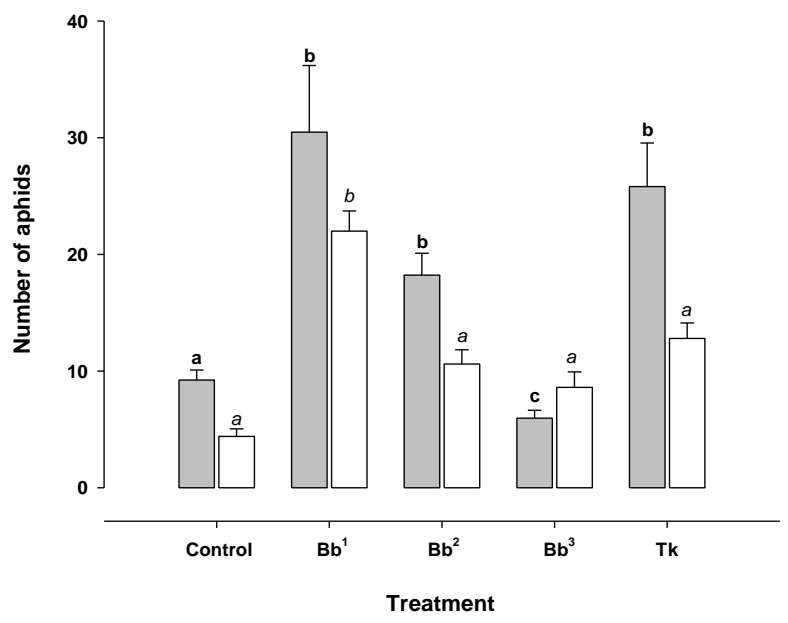

Figure 3. Host plant selection (mean $\pm \mathrm{SE}$ ) of winged aphids Myzus persicae in a multiple choice experiment, where five different treatments $\mathrm{C}, \mathrm{Bb}^{1} \mathrm{Bb}^{2} \mathrm{Bb}^{3}$ and $\mathrm{Tk}$ were evaluated for 24 hours. In laboratory conditions (gray bars), five tomato plants were introduced in each cage (one per treatment) and 100 aphids were placed in the center of the cage in a small petri dish and allowed to select the host plant during 24hours. The amount of aphids per plant was registered. Greenhouse host selection (white bars) where 4 plants per treatment were randomly distributed in four benches and the number of aphids that landed on each plant was registered. Bars with different letters indicate significant differences among treatments based linear mixed effect model with Tukey contrast $\mathrm{P}<0.05$. 
Table 3. Volatile organic compounds detected in the headspace of tomato plants from a dual treatment endophyte and aphid attack (E+A). The values represent relative TIC peak area \pm SE. The table contains only those compounds that were present in all replicates of at least one treatment. The retention time $\left(\mathrm{RT}^{*}\right)$ is an average of the retention times in which the compound was present in all the chromatograms.

\begin{tabular}{|c|c|c|c|c|c|c|c|c|c|c|c|c|c|c|c|c|c|c|c|}
\hline \multirow[b]{2}{*}{ RT* } & \multirow[b]{2}{*}{$\begin{array}{l}\text { Compound } \\
\text { name }\end{array}$} & \multicolumn{3}{|c|}{ Control } & \multicolumn{3}{|c|}{ Aphid } & \multicolumn{3}{|c|}{$\mathbf{B b}^{1}+\mathbf{A}$} & \multicolumn{3}{|c|}{$\mathbf{B b}^{2}+\mathbf{A}$} & \multicolumn{3}{|c|}{$\mathbf{B b}^{3}+\mathbf{A}$} & \multicolumn{3}{|c|}{$\mathbf{T k}+\mathbf{A}$} \\
\hline & & Mean & & SD & Mean & & SD & Mean & & SD & Mean & & SD & Mean & & SD & Mean & & SD \\
\hline 6,25 & $\alpha$-pinene & 2,46 & \pm & 1,98 & 4,30 & \pm & 1,00 & 2,66 & \pm & 3,05 & 2,91 & \pm & 1,93 & 0,70 & \pm & 0,45 & 3,37 & \pm & 1,18 \\
\hline 7,34 & Hexanal & 0,20 & \pm & 0,14 & 0,28 & \pm & 0,25 & 0,10 & \pm & 0,05 & 0,04 & \pm & 0,00 & 0,22 & \pm & 0,02 & 0,17 & \pm & 0,05 \\
\hline 8,59 & p-cymene & 0,20 & \pm & 0,16 & 0,07 & \pm & 0,00 & - & \pm & - & 0,68 & \pm & 0,00 & - & \pm & - & - & \pm & - \\
\hline 9,16 & $\begin{array}{l}(1 \mathrm{R})-(+)- \\
\text { Trans- } \\
\text { isolimonene }\end{array}$ & 0,25 & \pm & 0,09 & 0,22 & \pm & 0,00 & - & \pm & - & - & \pm & - & 0,15 & \pm & 0,00 & - & \pm & - \\
\hline 9,47 & o-cymene & 1,31 & \pm & 0,96 & - & \pm & - & - & \pm & - & 0,39 & \pm & 0,03 & 0,11 & \pm & 0,00 & - & \pm & - \\
\hline 9,49 & m-cymene & 2,75 & \pm & 2,03 & 5,05 & \pm & 1,94 & 3,38 & \pm & 3,64 & 2,58 & \pm & 1,97 & 1,78 & \pm & 1,18 & 4,94 & \pm & 1,93 \\
\hline 11,25 & $\beta$-phellandrene & 12,84 & \pm & 13,82 & 7,41 & \pm & 12,10 & 7,61 & \pm & 11,18 & 11,51 & \pm & 15,01 & 0,96 & \pm & 1,98 & 11,61 & \pm & 15,16 \\
\hline 11,30 & $\alpha$-terpinene & 9,82 & \pm & 10,29 & 8,32 & \pm & 7,49 & 8,24 & \pm & 5,74 & 4,55 & \pm & 6,74 & 9,26 & \pm & 12,02 & 10,40 & \pm & 8,18 \\
\hline 11,50 & $\alpha$-phellandrene & 3,40 & \pm & 1,25 & 2,87 & \pm & 0,00 & - & \pm & - & 3,90 & \pm & 0,22 & 0,04 & \pm & 0,00 & 4,39 & \pm & 0,57 \\
\hline 11,81 & $\begin{array}{l}\text { Trans- } \\
\text { isolimonene }\end{array}$ & 0,05 & \pm & 0,00 & 0,24 & \pm & 0,00 & 0,04 & \pm & 0,01 & - & \pm & - & - & \pm & - & 0,16 & \pm & 0,12 \\
\hline 12,18 & $\gamma$-terpinene & 0,26 & \pm & 0,26 & 5,69 & \pm & 15,77 & 0,86 & \pm & 1,91 & 0,44 & \pm & 0,32 & 7,31 & \pm & 13,98 & 1,11 & \pm & 1,92 \\
\hline 12,34 & 2-carene & 0,09 & \pm & 0,00 & 0,27 & \pm & 0,19 & 6,22 & \pm & 8,44 & 0,10 & \pm & 0,00 & 0,13 & \pm & 0,00 & 0,78 & \pm & 0,64 \\
\hline 12,35 & $\alpha$-terpinolene & 0,52 & \pm & 0,29 & 0,59 & \pm & 0,44 & 0,53 & \pm & 0,45 & 0,51 & \pm & 0,31 & 0,42 & \pm & 0,50 & 0,48 & \pm & 0,38 \\
\hline 12,79 & Sabinene & 2,71 & \pm & 0,66 & 4,80 & \pm & 1,31 & 8,02 & \pm & 6,54 & 3,56 & \pm & 3,12 & 2,01 & \pm & 0,00 & 2,63 & \pm & 0,00 \\
\hline 14,54 & $\begin{array}{l}1,3,8-\mathrm{p}- \\
\text { menthatriene }\end{array}$ & 0,06 & \pm & 0,02 & 0,06 & \pm & 0,02 & 0,08 & \pm & 0,01 & - & \pm & - & 0,11 & \pm & 0,00 & 0,07 & \pm & 0,01 \\
\hline 15,42 & Eucarvone & 0,05 & \pm & 0,00 & 0,03 & \pm & 0,00 & 0,05 & \pm & 0,00 & 0,04 & \pm & 0,00 & - & \pm & - & - & \pm & - \\
\hline 16,76 & p-cumenol & 0,06 & \pm & 0,01 & 0,04 & \pm & 0,00 & 0,05 & \pm & 0,01 & 0,04 & \pm & 0,00 & 0,05 & \pm & 0,00 & 0,04 & \pm & 0,00 \\
\hline 17,16 & Cumaldehyde & 0,10 & \pm & 0,00 & 0,13 & \pm & 0,00 & - & \pm & - & - & \pm & - & 0,08 & \pm & 0,05 & 0,09 & \pm & 0,00 \\
\hline 17,16 & $\begin{array}{l}\text { Propanal, 2- } \\
\text { methyl-3- } \\
\text { phenyl- }\end{array}$ & 0,07 & \pm & 0,01 & 0,07 & \pm & 0,01 & 0,07 & \pm & 0,01 & 0,06 & \pm & 0,01 & - & \pm & - & 0,07 & \pm & 0,00 \\
\hline 17,32 & Ascaridol & 0,03 & \pm & 0,00 & 0,09 & \pm & 0,02 & 0,17 & \pm & 0,09 & 0,04 & \pm & 0,01 & 0,19 & \pm & 0,08 & 0,08 & \pm & 0,03 \\
\hline 17,33 & Piperitone & 0,06 & \pm & 0,02 & 0,06 & \pm & 0,00 & 0,09 & \pm & 0,06 & 0,04 & \pm & 0,00 & 0,11 & \pm & 0,00 & 0,04 & \pm & 0,01 \\
\hline 17,99 & Carvacrol & 0,08 & \pm & 0,03 & 0,07 & \pm & 0,02 & 0,09 & \pm & 0,03 & 0,06 & \pm & 0,02 & 0,11 & \pm & 0,03 & 0,06 & \pm & 0,01 \\
\hline 18,03 & Cuminol & 0,05 & \pm & 0,01 & 0,05 & \pm & 0,03 & 0,06 & \pm & 0,00 & - & \pm & - & - & \pm & - & - & \pm & - \\
\hline 20,47 & Caryophyllene & 1,08 & \pm & 1,28 & 1,45 & \pm & 0,54 & 0,77 & \pm & 0,90 & 0,53 & \pm & 0,67 & 0,62 & \pm & 0,60 & 1,16 & \pm & 1,06 \\
\hline 21,11 & $\alpha$-humulene & 0,23 & \pm & 0,13 & 0,18 & \pm & 0,08 & 0,22 & \pm & 0,13 & - & \pm & - & - & \pm & - & 0,42 & \pm & 0,00 \\
\hline
\end{tabular}


Table 4. Volatile organic compounds detected in the headspace of tomato plants from endophyte treatments (E). The values represent relative TIC peak area \pm SE. The table contains only those compounds that were present in all replicates of at least one treatment. The retention time (RT*) is an average of the retention times in which the compound was present in all the chromatograms.

\begin{tabular}{|c|c|c|c|c|c|c|c|c|c|c|c|c|c|c|c|c|}
\hline \multirow[b]{2}{*}{ RT* } & \multirow[b]{2}{*}{ Compound name } & \multicolumn{3}{|c|}{ Control } & \multicolumn{3}{|c|}{$\mathrm{Bb}^{1}$} & \multicolumn{3}{|c|}{$\mathbf{B b}^{2}$} & \multicolumn{3}{|c|}{$\mathbf{B} \mathbf{b}^{3}$} & \multicolumn{3}{|c|}{ Tk } \\
\hline & & Mean & & SD & Mean & & SD & Mean & & SD & Mean & & SD & Mean & & SD \\
\hline 6,25 & $\alpha$-pinene & 2,46 & \pm & 1,98 & 4,97 & \pm & 1,55 & 1,93 & \pm & 1,43 & 2,02 & \pm & 1,30 & 0,65 & \pm & 0,84 \\
\hline 7,34 & hexanal & 0,20 & \pm & 0,14 & 0,17 & \pm & 0,08 & 0,07 & \pm & 0,03 & 0,06 & \pm & 0,01 & 0,10 & \pm & 0,09 \\
\hline 8,59 & p-cymene & 0,20 & \pm & 0,16 & 0,09 & \pm & 0,03 & 0,06 & \pm & 0,03 & - & \pm & - & 0,23 & \pm & 0,07 \\
\hline 9,16 & trans-isolimonene & 0,25 & \pm & 0,09 & - & \pm & - & 0,10 & \pm & 0,07 & 0,19 & \pm & 0,00 & - & \pm & - \\
\hline 9,47 & o-cymene & 1,31 & \pm & 0,96 & 0,09 & \pm & 0,00 & 0,04 & \pm & 0,01 & 0,05 & \pm & 0,00 & - & \pm & - \\
\hline 9,49 & m-cymene & 2,75 & \pm & 2,03 & 3,60 & \pm & 3,77 & 1,72 & \pm & 2,22 & 3,40 & \pm & 0,05 & 2,18 & \pm & 0,69 \\
\hline 11,25 & $\beta$-phellandrene & 12,84 & \pm & 13,82 & 9,30 & \pm & 13,77 & 10,35 & \pm & 12,06 & 18,61 & \pm & 17,01 & 7,47 & \pm & 11,16 \\
\hline 11,30 & $\alpha$-terpinene & 9,82 & \pm & 10,29 & 11,75 & \pm & 10,62 & 5,13 & \pm & 7,66 & 0,50 & \pm & 0,28 & 7,95 & \pm & 10,11 \\
\hline 11,50 & $\alpha$-phellandrene & 3,40 & \pm & 1,25 & 2,84 & \pm & 0,99 & 2,07 & \pm & 0,75 & 2,28 & \pm & 0,00 & 2,74 & \pm & 0,43 \\
\hline 11,81 & trans-isolimonene & 0,05 & \pm & 0,00 & 0,14 & \pm & 0,00 & 0,04 & \pm & 0,00 & 0,03 & \pm & 0,00 & 0,04 & \pm & 0,00 \\
\hline 12,18 & $\gamma$-terpinene & 0,26 & \pm & 0,26 & 0,33 & \pm & 0,26 & 0,28 & \pm & 0,31 & 0,25 & \pm & 0,26 & 0,24 & \pm & 0,24 \\
\hline 12,34 & 2-carene & 0,09 & \pm & 0,00 & 0,19 & \pm & 0,01 & - & \pm & - & 32,13 & \pm & 0,00 & - & \pm & - \\
\hline 12,35 & $\alpha$-terpinolene & 0,52 & \pm & 0,29 & 0,40 & \pm & 0,31 & 0,22 & \pm & 0,25 & 0,41 & \pm & 0,36 & 0,22 & \pm & 0,23 \\
\hline 12,79 & sabinene & 2,71 & \pm & 0,66 & 0,28 & \pm & 0,37 & 0,11 & \pm & 0,08 & 14,74 & \pm & 14,61 & 0,77 & \pm & 0,75 \\
\hline 14,54 & 1,3,8-p-menthatriene & 0,06 & \pm & 0,02 & 0,05 & \pm & 0,01 & 0,04 & \pm & 0,01 & - & \pm & - & 0,06 & \pm & 0,00 \\
\hline 15,42 & eucarvone & 0,05 & \pm & 0,00 & 0,08 & \pm & 0,03 & 0,05 & \pm & 0,01 & 0,06 & \pm & 0,02 & 0,13 & \pm & 0,00 \\
\hline 16,76 & p-cumenol & 0,06 & \pm & 0,01 & 0,06 & \pm & 0,01 & 0,05 & \pm & 0,00 & 0,09 & \pm & 0,00 & 0,10 & \pm & 0,00 \\
\hline 17,16 & cumaldehyde & 0,10 & \pm & 0,00 & - & \pm & - & - & \pm & - & 0,06 & \pm & 0,00 & - & \pm & - \\
\hline 17,16 & $\begin{array}{l}\text { 2-methyl-3-phenyl- } \\
\text { propanal }\end{array}$ & 0,07 & \pm & 0,01 & 0,11 & \pm & 0,04 & 0,05 & \pm & 0,01 & 0,13 & \pm & 0,00 & 0,06 & \pm & 0,05 \\
\hline 17,32 & ascaridol & 0,03 & \pm & 0,00 & 0,04 & \pm & 0,00 & 0,06 & \pm & 0,00 & 0,05 & \pm & 0,02 & - & \pm & - \\
\hline 17,33 & piperitone & 0,06 & \pm & 0,02 & 0,05 & \pm & 0,00 & 0,04 & \pm & 0,00 & 0,08 & \pm & 0,00 & - & \pm & - \\
\hline 17,99 & carvacrol & 0,08 & \pm & 0,03 & 0,10 & \pm & 0,04 & 0,08 & \pm & 0,03 & 0,09 & \pm & 0,04 & 0,13 & \pm & 0,11 \\
\hline 18,03 & cuminol & 0,05 & \pm & 0,01 & - & \pm & - & 0,02 & \pm & 0,00 & 0,13 & \pm & 0,00 & - & \pm & - \\
\hline 20,47 & caryophyllene & 1,08 & \pm & 1,28 & 1,25 & \pm & 1,39 & 1,18 & \pm & 0,82 & 1,69 & \pm & 0,31 & 1,36 & \pm & 0,57 \\
\hline 21,11 & $\alpha$-humulene & 0,23 & \pm & 0,13 & 0,06 & \pm & 0,01 & 0,25 & \pm & 0,06 & - & \pm & - & 0,20 & \pm & 0,02 \\
\hline
\end{tabular}

Fungal treatment (E) had a significant effect on the host plant selection by winged aphids Myzus persicae under laboratory and greenhouse conditions $(\mathrm{P}<0.05)$. In the laboratory experiment, winged aphids selected significantly more of those plants that were treated with $\mathrm{Bb}^{1}$ than the endophyte free plants; no significant differences were observed between the other treatments and the control. The strain $\mathrm{Bb}^{3}$ displayed the least attraction to the aphids. In the greenhouse trial aphids were more attracted to plants inoculated with $\mathrm{Bb}^{1}$ and $\mathrm{Tk}$. Plants inoculated with the strain $\mathrm{Bb}^{3}$ showed fewer attracted aphids even though this is not statistically different (Figure3). 


\section{Discussion}

Endophytic colonization is thought to enhance resistance against insect herbivores and some pathogens as well as to attract beneficial insects that can contribute to the biological control of several crop problems (Dicke et al., 2009; Pieterse et al., 2013; Poelman et al., 2012). This enhancement may be due to a modulation of plant defense responses that accompany the colonization process, which consequently can cause plant priming that may protect the plant against any subsequent attack by insect herbivores. Other authors suggest that the resistance to insect herbivory conferred by the endophytic colonization is mainly a result of the production of various alkaloid based defensive compounds in the plant tissues or even by affecting the nutritional quality of the plant (Li et al., 2014; Thakur et al., 2013). Some examples of positive results of fungal endophytic colonization against insect pests have been achieved mainly for grass endophytes (Ahlholm et al., 2002; Li et al., 2014; Saikkonen et al., 1998, 2013). With the endophytic entomopathogenic fungi Beauveria bassiana promising results in the management of plant-insect interaction are available for insect pests such as Cosmopolites spp., Aphis gossypii and Iraella luteipes (Akello et al., 2008; Gurulingappa et al., 2010, 2011; QuesadaMoraga et al., 2009).

Nevertheless, not all the endophytes result in a positive response of the plant against insect pests, but the opposite, they contribute to the attraction of insect herbivores such as Helicoverpa armigera (Jallow et al., 2008), which in turn can support the idea that changes in volatile profiles claim not only for plant protection or enhance plant defense but also "inform" other herbivorous insects about the suitability of the emitter of those chemical signals, becoming more apparent for herbivory (Halitschke et al., 2008). 
In our research, we found that aphids were more attracted to plants showing reduced emissions of p-cymene and $\alpha$-pinene, apparently as a response to the endophytic colonization with $B$. bassiana and T. koningiopsis. The ecological consequences of this plant - fungi interaction for the plant and other organisms is still far from being clarified. Nevertheless, it is known that greenhouse tomato Solanum lycopersicon Mill. releases volatile organic compounds such as $\beta$ phellandrene, 2-carene, $\alpha$-pinene and p-cymene that may contribute to the bumble bee pollination failure in some tomato greenhouses, since the insects apparently avoid plants that release mentioned compounds in higher amounts (Morse et al., 2012). The toxicity of p-cymene and its activity as an insect repellent has been addressed not only for tomato crops but also in other systems where this compound may contribute to the repellence against insect vectors of human viruses (Abdel-Sattar et al., 2010; Choi et al., 2002; Pitarokili et al., 2011)

The volatile profile of tomato plants Solanum lycopersicon cv. Ruthje showed that the highest TIC-peak areas in tomato headspace of non-treated plants are $\beta$-phellandrene, followed by $\alpha$ terpinene, $\alpha$-phellandrene, $\alpha$-pinene and p-cymene. These compounds are in concordance with the results reported by Jallow et al. (2008), Morse et al. (2012) and Proffit et al. (2011).

Once compared the headspace composition of treated plants against the control profiles, we observed that the TIC peak area ratios of several compounds, mostly sesquiterpenes, changed according to the treatment applied. Meanwhile, some other compounds such as p-cymene and $\alpha$-pinene significantly reduced their TIC peak area when the plant was inoculated with entomopathogenic fungi. p-cymene, which is naturally present in solanaceous plants, may play an important role in the protection against insect attack as reported by Bleeker et al. (2009) who observed that plants with lower amounts of p-cymene were more attacked by whiteflies. pcymene is an essential oil that has been reported to be toxic against western flower thrips Frankliniella occidentalis (Janmaat et al., 2002) .

Tomato volatile organic compounds headspace is composed of more than 400 compounds (Quayyum, 2010). Among the most common compounds reported for tomato plants are: 3methylbutanal, hexanal, (Z)-3-hexenal, (E)-2-hexenal, 3-methyl-1-butanol, 1-hexanol, (Z)-3hexen-1-ol, 1-penten-3-one, 6-methyl-5-hepten-2-one, 2-phenylethanol, methyl salicylate, pcymen-8-ol, (Quayyum, 2010; Tikunov et al., 2005). MeSA (Methyl Salicylate) in the control plants profile is expressed constitutively and induced systemically (Scutareanu et al., 2003) which mean that this is a constitutive compound, and is released in Lycopersicon spp. from the stored compound and not produced de novo (Tikunov et al., 2005) . 
Nevertheless, MeSA is known to be an induced defense volatile upon herbivory, which means that if the plant suffer from an insect attack (chewing insect) the emissions of MeSA will be upregulated (Ament et al., 2010) but there is no upregulation of MeSA in the profiles, in contrast, what we can see is a down-regulation of this compound when the plants are treated with fungal endophytes. The downregulation could suggest that the fungal endophytes are not undetectable by the plant metabolism and the Salicylic Acid (SA) pathway is upregulated, recognizing the endophytes as pathogens and due to the crosstalk between both pathways, the JA pathway is downregulated resulting in a reduction of MeSA until undetectable amounts.

The changes in the VOCs profiles migth interfere with the insect behavior since the theory says that the lower the MeSA, the higher the aphid attraction and the higher MeSA, the lower aphid attraction and higher natural enemies attracted. This is also evidenced in our results where the control tomato plants with higher levels of MeSA were less attractant for aphids than endophyte treated plants where the MeSA levels are lower. That does not mean that the endophytes are "stress reducers" that only explains the specific case of tomato plants and the interaction with aphid.

Our findings show that host plants inoculated with fungal endophytes used for biological control of plant pathogens or insect herbivores can influence the host selection. This may be advantageous for the fungi but in detriment to the plant and the insect.

Additional to the statistical differences we could observe a tendency in the attraction of the insect herbivores Myzus persicae to treated plants with different endophytes species. The strain that showed the highest attraction pattern was $\mathrm{Bb}^{1}$ for experiments in greenhouse and laboratory. The least attractive treatment were the plants inoculated with the strain $\mathrm{Bb}^{3}$ which highlights the strain- specificity of the responses in a multitrophic interaction.

In conclusion, our study has shown that fungal endophytes Beauveria bassiana and Trichoderma koningiopsis may modulate volatile organic compound profiles of tomato plants, and such responses can be strain dependent. Additionally, these results may contribute to understanding further implications of the use of fungal endophytes in integrated pest management.

Our results describe how fungal endophytically inoculated plants exhibit a profile of volatile organic compounds different from endophyte free plants, resulting in an increased attraction of 
insect herbivores. These results highlight the need to describe the ecological effect of entomopathogenic fungi when its life cycle is developed as an endophyte. Are the insects attracted with the final purpose of changing the fungi lifestyle from endophytic to an entomopathogenic style? However, in our system, it remains to be described which of the compounds released in the aboveground headspace of the plant are behaviorally active and whether their emission is caused by fungal colonization as endophyte or by the fungal mycelium.

\section{Funding}

This study was supported by The Colombian Corporation for Agricultural Research (Corpoica) and the Colombian Administrative Department of Science, Technology, and Innovation (Colciencias).

\section{References}

Abdel-Sattar, E., Zaitoun, A. A., Farag, M. A., Gayed, S. H. El, and Harraz, F. M. H. (2010). Chemical composition, insecticidal and insect repellent activity of Schinus molle L. leaf and fruit essential oils against Trogoderma granarium and Tribolium castaneum. Nat. Prod. Res. 24, 226-35. doi:10.1080/14786410802346223.

Agilent Technologies (2011). MSD ChemStation Data Analysis Software.

Ahlholm, J. U., Helander, M., Lehtimäki, S., Wäli, P., and Saikkonen, K. (2002). Vertically transmitted fungal endophytes: different responses of host-parasite systems to environmental conditions. Oikos 99, 173-183. doi:10.1034/j.1600-0706.2002.990118.x.

Akello, J., Dubois, T., Coyne, D., and Kyamanywa, S. (2008). Endophytic Beauveria bassiana in banana (Musa spp.) reduces banana weevil (Cosmopolites sordidus) fitness and damage. Crop Prot. 27, 1437-1441. doi:10.1016/j.cropro.2008.07.003.

Ament, K., Krasikov, V., Allmann, S., Rep, M., Takken, F. L. W., and Schuurink, R. C. (2010). Methyl salicylate production in tomato affects biotic interactions. Plant J. 62, 124-134.

Bleeker, P. M., Diergaarde, P. J., Ament, K., Guerra, J., Weidner, M., Schütz, S., et al. (2009). The role of specific tomato volatiles in tomato-whitefly interaction. Plant Physiol. 151, 925-35. doi:10.1104/pp.109.142661.

Bruce, T. J. a, and Pickett, J. a. (2011). Perception of plant volatile blends by herbivorous insects - Finding the right mix. Phytochemistry 72, 1605-1611. doi:10.1016/j.phytochem.2011.04.011.

Choi, W.-S., Park, B.-S., Ku, S.-K., and Lee, S.-E. (2002). Repellent activities of essential oils and monoterpenes against Culex pipiens pallens. J. Am. Mosq. Control Assoc. 18, 348-51. 
Available at: http://www.ncbi.nlm.nih.gov/pubmed/12542193 [Accessed March 2, 2016].

Clavijo McCormick, A., Unsicker, S. B., and Gershenzon, J. (2012). The specificity of herbivore-induced plant volatiles in attracting herbivore enemies. Trends Plant Sci. 17, 303-310. doi:10.1016/j.tplants.2012.03.012.

Dicke, M., and Baldwin, I. T. (2010). The evolutionary context for herbivore-induced plant volatiles: beyond the "cry for help". Trends Plant Sci. 15, 167-75. doi:10.1016/j.tplants.2009.12.002.

Dicke, M., van Loon, J. J. a, and Soler, R. (2009). Chemical complexity of volatiles from plants induced by multiple attack. Nat. Chem. Biol. 5, 317-324. doi:10.1038/nchembio.169.

Elad, Y., and Chet, I. (1983). Improved selective media for isolation ofTrichoderma spp. orFusarium spp. Phytoparasitica 11, 55-58. doi:10.1007/BF02980712.

Gurulingappa, P., McGee, P. A., and Sword, G. (2011). Endophytic Lecanicillium lecanii and Beauveria bassiana reduce the survival and fecundity of Aphis gossypii following contact with conidia and secondary metabolites. Crop Prot. 30, 349-353. doi:10.1016/j.cropro.2010.11.017.

Gurulingappa, P., Sword, G. A., Murdoch, G., and McGee, P. A. (2010). Colonization of crop plants by fungal entomopathogens and their effects on two insect pests when in planta. Biol. Control 55, 34-41. doi:10.1016/j.biocontrol.2010.06.011.

Halitschke, R., Stenberg, J. A., Kessler, D., Kessler, A., and Baldwin, I. T. (2008). Shared signals -'alarm calls' from plants increase apparency to herbivores and their enemies in nature. Ecol. Lett. 11, 24-34. doi:10.1111/j.1461-0248.2007.01123.x.

Heil, M. (2008). Indirect defence via tritrophic interactions. New Phytol. 178, 41-61. doi:10.1111/j.1469-8137.2007.02330.x.

Hussaini, H., Sani, A., and Aliero, A. A. (2011). Volatile metabolites profiling to discriminate diseases of tomato fruits inoculated with three toxigenic fungal pathogens. Res. Biotechnol. $2 . \quad$ Available at: http://researchinbiotechnology.com/index.php/rib/article/view/35 [Accessed March 3, 2014].

Jallow, M. F. a, Dugassa-Gobena, D., and Vidal, S. (2008). Influence of an endophytic fungus on host plant selection by a polyphagous moth via volatile spectrum changes. Arthropod. Plant. Interact. 2, 53-62. doi:10.1007/s 11829-008-9033-8.

Janmaat, A. F., de Kogel, W. J., and Woltering, E. J. (2002). Enhanced fumigant toxicity of pcymene against Frankliniella occidentalis by simultaneous application of elevated levels of carbon dioxide. Pest Manag. Sci. 58, 167-73. doi:10.1002/ps.432.

Jansen, R. M. C., Hofstee, J. W., Wildt, J., Verstappen, F. W. a, Bouwmeester, H. J., and van Henten, E. J. (2009). Induced plant volatiles allow sensitive monitoring of plant health status in greenhouses. Plant Signal. Behav. 4, 824-829. 
Li, T., Blande, J. D., Gundel, P. E., Helander, M., and Saikkonen, K. (2014). Epichloë endophytes alter inducible indirect defences in host grasses. PLoS One 9, e101331. doi:10.1371/journal.pone.0101331.

Morse, A., Kevan, P., Shipp, L., Khosla, S., and McGarvey, B. (2012). The Impact of Greenhouse Tomato (Solanales: Solanaceae) Floral Volatiles on Bumble Bee (Hymenoptera: Apidae) Pollination. Environ. Entomol. 41, 855-864.

Pieterse, C. M. J., Poelman, E. H., Van Wees, S. C. M., and Dicke, M. (2013). Induced plant responses to microbes and insects. Front. Plant Sci. 4, 475. doi:10.3389/fpls.2013.00475.

Pineda, A., Zheng, S.-J., van Loon, J. J. a, Pieterse, C. M. J., and Dicke, M. (2010). Helping plants to deal with insects: the role of beneficial soil-borne microbes. Trends Plant Sci. 15, 507-14. doi:10.1016/j.tplants.2010.05.007.

Pitarokili, D., Michaelakis, A., Koliopoulos, G., Giatropoulos, A., and Tzakou, O. (2011). Chemical composition, larvicidal evaluation, and adult repellency of endemic Greek Thymus essential oils against the mosquito vector of West Nile virus. Parasitol. Res. 109, 425-30. doi:10.1007/s00436-011-2271-1.

Poelman, E. H., Bruinsma, M., Zhu, F., Weldegergis, B. T., Boursault, A. E., Jongema, Y., et al. (2012). Hyperparasitoids use herbivore-induced plant volatiles to locate their parasitoid host. PLoS Biol 10, e1001435. doi:10.1371/journal.pbio.1001435.

Proffit, M., Birgersson, G., Bengtsson, M., Reis, R., Witzgall, P., and Lima, E. (2011). Attraction and Oviposition of Tuta absoluta Females in Response to Tomato Leaf Volatiles. J. Chem. Ecol. 37, 565-574. doi:10.1007/s10886-011-9961-0.

Quayyum, H. (2010). "Chemistry and biochemistry of some vegetables flavors," in HANDBOOK OF FRUIT AND VEGETABLE FLAVORS, eds. F. Chen, L. M. L. Nollet, Y. H. Hui, R. P. F. Guiné, M. I. Mínguez-Mosquera, F. L. P. Pessoa, et al. (Hooken, New Jersey: John Wiley \& Sons), 575.

Quesada-Moraga, E., Landa, B. B., Muñoz-Ledesma, J., Jiménez-Diáz, R. M., and SantiagoÁlvarez, C. (2006). Endophytic colonisation of opium poppy, Papaver somniferum, by an entomopathogenic Beauveria bassiana strain. Mycopathologia 161, 323-329. doi:10.1007/s11046-006-0014-0.

Quesada-Moraga, E., Muñoz-Ledesma, F. J., and Santiago-Alvarez, C. (2009). Systemic protection of Papaver somniferum L. against Iraella luteipes (Hymenoptera: Cynipidae) by an endophytic strain of Beauveria bassiana (Ascomycota: Hypocreales). Environ. Entomol. 38, 723-730. doi:10.1603/022.038.0324.

R Core team (2015). R Core Team. $R$ A Lang. Environ. Stat. Comput. R Found. Stat. Comput. , Vienna, Austria. ISBN 3-900051-07-0, URL http//www.R-project.org/.

Rodriguez, R. J., White, J. F., Arnold, A. E., Redman, R. S., Jr, J. F. W., Arnold, A. E., et al. (2009). Fungal endophytes: diversity and functional roles. New Phytol. 182, 314-330. 
doi:10.1111/j.1469-8137.2009.02773.x.

Saikkonen, K., Faeth, S. H., Helander, M., and Sullivan, T. J. (1998). Fungal endophytes: A continuum of interactions with host plants. Annu. Rev. Ecol. Syst. 29, 319-343. doi:10.1146/annurev.ecolsys.29.1.319.

Saikkonen, K., Gundel, P. E., and Helander, M. (2013). Chemical ecology mediated by fungal endophytes in grasses. J. Chem. Ecol. 39, 962-8. doi:10.1007/s10886-013-0310-3.

Schausberger, P., Peneder, S., Jürschik, S., and Hoffmann, D. (2012). Mycorrhiza changes plant volatiles to attract spider mite enemies. Funct. Ecol. 26, 441-449. doi:10.1111/j.13652435.2011.01947.x.

Schulz, B., and Boyle, C. (2006). What are Endophytes? Soil Biol. 9, 1-14. doi:10.1007/3-54033526-9.

Scutareanu, P., Bruin, J., Posthumus, M. A., and Drukker, B. (2003). Constitutive and herbivore-induced volatiles in pear, alder and hawthorn trees. Chemoecology 13, 63-74. doi:10.1007/s00049-002-0228-7.

Thakur, A., Kaur, S., Kaur, A., and Singh, V. (2013). Enhanced resistance to Spodoptera litura in endophyte infected cauliflower plants. Environ. Entomol. 42, 240-6. doi:10.1603/EN12001.

Tikunov, Y., Lommen, A., Ric De Vos, C. H., Verhoeven, H. A., Bino, R. J., Hall, R. D., et al. (2005). A Novel Approach for Nontargeted Data Analysis for Metabolomics. Large-Scale Profiling of Tomato Fruit Volatiles 1[w]. Plant Physiol. 139. doi:10.1104/pp.105.068130.

van den Dool, H., and Kratz, P. D. (1963). A generalization of the retention index system including linear temperature programmed gas-liquid partition chromatography. $J$. Chromatogr. 11, 463-471. Available at: http://ac.els-cdn.com/S002196730180947X/1s2.0-S002196730180947X-main.pdf?_tid=d9963662-0537-11e6-949a-

00000aab0f27\&acdnat=1460964991_68ebe5962fc238f96d9b1b8b9791eeeb [Accessed April 18, 2016]. 


\title{
Endophyte-mediated host plant selection by Helicoverpa armigera
}

\author{
Aragón, S..$^{1,2 *}$, Vidal, S. $^{2}$ \\ ${ }^{1}$ Colombian Corporation for Agricultural Research. Biological Control Laboratory. \\ Mosquera, Colombia. \\ ${ }^{2}$ University of Göttingen. Department of Crop Sciences, Göttingen, Germany \\ ${ }^{3}$ University of Göttingen. Buesgen-Institute, Department of Forest Zoology and Forest \\ Conservation, Göttingen, Germany.
}

* Corresponding author: saragon@ corpoica.org.co 


\title{
Endophyte-mediated host plant selection by Helicoverpa armigera
}

\author{
Aragón, S. ${ }^{1,2 *}$, Vidal, S. ${ }^{2}$ \\ ${ }^{1}$ Colombian Corporation for Agricultural Research. Biological Control Laboratory. Mosquera, Colombia. \\ ${ }^{2}$ University of Göttingen. Department of Crop Sciences, Göttingen, Germany \\ * Corresponding author: saragon@ corpoica.org.co
}

\begin{abstract}
Recent studies have been published about the ability of some fungal endophytes to protect crop plants against insect herbivory and plant pathogens. Nevertheless, the potential of fungal endophyte to modify plant parameters involved in plant - insect interactions remains poorly understood. Our aim was to evaluate the potential of three different species of fungal endophytes Beauveria bassiana, Metarhizium bruneum and Trichoderma koningiopsis to i) colonize endophytically tomato plant tissues, ii) affect plant attributes such as temperature, chlorophyll content and biomass iii) modulate host plant selection of Helicoverpa armigera for oviposition. Tomato seedlings were root inoculated to test the ability of the different fungal species to colonize tomato tissues and the establishment of the microorganism along the plant. We observed that all the isolates successfully colonized the root tissue of treated plants. Stem and leaf tissues were colonized in a lower proportion for all the isolated except Metarhizium brunneum. Plant temperature showed no significant differences between the treatments. In contrast, plants inoculated with Beauveria bassiana showed significant differences in leaf chlorophyll content. In a multiple choice experiment, we offered five different plants inoculated with fungal endophytes and one endophyte free plant to Helicoverpa armigera adults for oviposition preference and the resulting behavior was compared to the one obtained in a no-choice experiment. These results support our hypothesis that i) endophytic colonization might be higher belowground than in aboveground plant tissues and it is specific to each fungal isolate, ii) tomato plant traits remain unaffected by fungal endophytic infection confirming its symptomless presence in the plant and iii) entomopathogenic fungal infection of tomato plant tissues reduce the preference to lay eggs on infected plants compared to plants infected with non-entomopathogenic fungi.
\end{abstract}

Keywords: Multiple choice, Solanum lycopersicon, Oviposition preference, qPCRbased endophyte detection, Chlorophyll content, Plant growth, Near Infrared Spectroscopy (NIRS), Plant biomass. 


\section{Introduction}

The mechanisms that regulate the interaction between insect herbivores and host plants are mostly regulated by the chemical cues emitted by plants such as volatile organic compounds (VOCs) or secondary metabolites (Bruce and Pickett, 2011). For instance, Jallow et al. (2008) suggest that among other physiological attributes of tomato plants, quantitative variations in the emission of some VOCs influence the host selection made by the polyphagous moth Helicoverpa armigera (Hiibner) (Lepidoptera:Noctuidae) for oviposition. Nevertheless, host plant selection is also regulated by other plant physiological attributes closely related to the nutritional state of the plant, plant temperature range and phenological stage (Ramaswamy, 1988; Renwick, 1994). These parameters confer short distance cues to the insect that are complementary to the chemical cues followed from a long distance to find a suitable host for oviposition or mating (Renwick, 1994).

Biological interactions between fungal endophytes and plants have been reported to be symptomless (Schulz and Boyle, 2006). However, it is documented that these microbial associations with host plants might modulate the interaction between insect herbivores and plant hosts by conferring some fitness benefits and ecological adaptations to the colonized plant (Rodriguez et al., 2009). According to Rodriguez et al. (2009), the enhancement of plant biomass is one of the plant attributes that is most commonly reported to be acquired by the plants after a colonization with an ascomycota or basidiomycota endophyte normally found to infect roots, stems or leaves of their host. In turn, the endophyte may obtain nutrition for growth and reproduction. In addition to growth promotion, endophytes can confer other benefits to the host plant in terms of stress tolerance and resistance against plant pathogens and herbivory (Jaber and Vidal, 2010).

Here we addressed two questions concerning the response of tomato plants Solanum lycopersicon to endophytic fungi inoculations and the behavioral response of $H$. armigera adults to tomato plants treated with different endophytes. First, to what extent does endophytic fungi colonization of tomato plants influence traits such as leaf chlorophyll content, plant temperature, and plant biomass? Second, is there a reduction in oviposition on entomopathogenic endophyte-inoculated tomato plants by $H$. armigera adults compared to noninoculated plants? 


\section{Materials and methods}

\subsection{Plant material}

Tomato seeds Solanum lycopersicon Mill. var Ruthje (Rein Saat ${ }^{\circledR}$, Austria) were grown in a nursery in a 3:1 soil mixture: sand (soil: Fruhstorfer Erde Typ 25, Hawita Gruppe GmbH, peat fine structure with volcanic clay, pH: 5.7-6.3, Fertilization of 200-300mg N. Sand: $0.3 \mathrm{~mm}$ grain $\varnothing)$ and maintained under greenhouse conditions for two weeks with an average temperature of $24 \pm 2^{\circ} \mathrm{C}$, a relative humidity between $75-80 \%$ and $12 \mathrm{~L}: 12 \mathrm{D}$ photoperiod. When the seedlings developed the second true leaf, they were removed from the substrate and the roots were carefully washed with tap water and kept in a beaker with water in a laminar flow chamber to avoid dehydration until the root inoculation procedure. Once inoculated, plants were individually transplanted into $11 \times 11 \times 12 \mathrm{~cm}$ pots filled with the soil mixture mentioned above, moved to the greenhouse, watered regularly and fertilized once a week with Hakaphos $2 \mathrm{~g} / \mathrm{L}$ $\left(15 \% \mathrm{~N}, 11 \% \mathrm{P}_{2} \mathrm{O}_{5}, 15 \% \mathrm{~K}_{2} \mathrm{O}, 1 \% \mathrm{Mg}, 0.1 \% \mathrm{Fe}, 0.1 \% \mathrm{Mn}, 0.04 \% \mathrm{Cu}, 0.025 \% \mathrm{~B}\right.$ and $\left.0.005 \% \mathrm{Mo}\right)$ until four weeks post inoculation.

\subsection{Fungal inoculates}

Beauveria bassiana strain Bv 061 was provided by the germplasm bank of the Biological Control Laboratory at Colombian Corporation of Agricultural Research - Corpoica - in Colombia; B. bassiana strain Bb1022 and EABb 04/01 -Tip come from the fungal collection of the Agricultural Entomology Laboratory at the University of Göttingen, Germany. Metarhizium brunneum (Metschnikoff) Sorokin strain ART 2825 was provided by Fytovita spol. s.r.o. (Ostrozska Lhota, Czech Republic), originally isolated from A. obscurus in Switzerland (Kölliker et al., 2011). The plant pathogen biocontrol agent Trichoderma koningiopsis (formerly known as Trichoderma koningii) strain Th003 was delivered by the company Prophyta (Biologischer Pflanzenschutz GmbH, Germany).

The treatments included an endophyte-free control (C), five endophyte treatments (E): $B$. bassiana cv. EABb 04/01 -Tip $\left(\mathrm{Bb}^{1}\right)$, B. bassiana cv. Bv $061\left(\mathrm{Bb}^{2}\right)$, B. bassiana $\mathrm{Bb} 1022\left(\mathrm{Bb}^{3}\right)$, M. brunneum cv. ART $2825(\mathrm{Mb})$ and Trichoderma koningiopsis cv. Th 003 (Tk)

The isolates were grown in Potato Dextrose Agar (PDA) at $24 \pm 2^{\circ} \mathrm{C}$ in dark conditions during two weeks to obtain enough spores for the suspension. The spore suspension was prepared by adding $3 \mathrm{ml}$ of $0.01 \%$ Tween 20 on the growing media and the spores were removed with a 
Drigalski spatula and re-suspended in $97 \mathrm{ml}$ of distilled autoclaved water. The suspension was filtered and the concentration was determined with a Thoma counting chamber $(0.10 \mathrm{~mm}$ depth) and adjusted to $1 \times 10^{7}$ conidia/ml. Washed roots were soaked into the corresponding spore suspension for $20 \mathrm{~min}$. Roots from control plants were immersed in a solution of $0.01 \%$ tween $20+$ sterile deionized water during the same period. All treated plants were transplanted and maintained randomly distributed under greenhouse conditions for four weeks.

\subsection{Insect rearing}

Eggs from a laboratory rearing of Helicoverpa armigera were provided by Bayer Crop Science, Monheim, Germany, and kept in a climatic chamber at $23 \pm 2{ }^{\circ} \mathrm{C}, 60 \% \mathrm{RH}$ and $16 \mathrm{~L}: 8 \mathrm{D}$ photoperiod until they hatched. Larvae were transferred to an artificial diet (Cunningham et al., 1998) and maintained there up to the development of the third larval instar. Then they were individualized in $35 \mathrm{~mm} \varnothing$ Petri dishes filled with the diet until pupation to prevent cannibalism. Pupae were sexed according to Rincón and López-Ávila (2004) and maintained in groups of $10 \bigcirc: 10{ }^{\lambda}$ in plastic insect rearing cages of $30 \mathrm{~cm}^{3}$ until adult emergence. Adults were fed $\mathrm{ad}$ libitum with a $10 \%$ honey solution provided on dental cotton rolls saturated with the solution and inserted into a $2 \mathrm{ml}$ Eppendorf tube filled with the mixture.

\subsection{Detection of fungal endophytic colonization by real-time polymerase chain reaction}

Endophytic colonization (presence / absence) was confirmed by real-time polymerase chain reaction (RT-PCR). The positive PCR amplification was achieved from genomic DNA of each fungal strain obtained from actively growing mycelium in Potato Dextrose Broth (PDB) cultures incubated for five days at $25^{\circ} \mathrm{C}$ in the dark with a constant shake. The medium was filtered with a vacuum pump, and the filtrated mycelium was collected and lyophilized. The dry material was ground, homogenized and stored at $-20^{\circ} \mathrm{C}$ until used. The plant samples were conserved at $-80^{\circ} \mathrm{C}$ until lyophilization, and the dry material was ground and stored in $-20^{\circ} \mathrm{C}$ until the DNA extraction. For fungal and plant DNA extraction we used the cetyltrimethylammonium bromide (CTAB) method, where a mixture of $1 \mathrm{ml}$ of CTAB buffer, $2 \mu \mathrm{l}$ mercaptoethanol, and $1 \mu \mathrm{l}$ of Proteinase $\mathrm{K}$ was added to $50 \mathrm{mg}$ of fine powdered samples, mixed thoroughly and incubated for $10 \mathrm{~min}$ at $42^{\circ} \mathrm{C}$, then the temperature was increased to $65^{\circ} \mathrm{C}$ and incubated for 10min more. After adding $800 \mu \mathrm{l}$ of chloroform/isoamyl alcohol and incubation on ice for $10 \mathrm{~min}$, the extract was centrifuged at $8000 \mathrm{rpm}$ for $10 \mathrm{~min}$. The supernatant was transferred to a new tube and $100 \mu 15 \mathrm{M} \mathrm{NaCl}$ and $200 \mu \mathrm{l}$ of $30 \%$ of Polyethilene glycol 
(PEG) were added, and incubated for $5 \mathrm{~min}$ at room temperature, followed by a centrifugation at $14000 \mathrm{rpm}$ for $15 \mathrm{~min}$. The supernatant was discarded and the pellet was washed two times with $500 \mu \mathrm{l}$ of $75 \%$ ethanol, then dried in Speed Vac and re-suspended in $100 \mu 1$ 1X Tris EDTA (TE) buffer.

\subsubsection{Beauveria bassiana}

The qPCR amplifications were performed using the primers designed by Zhang (2014) Bsn1-2 forward 5'-3' GCGTCAAGGTGCTCGAAGACAG” and reverse 3'-5' TCTGGGCGGCATCCCTATTGT for Beauveria bassiana with a product size of $231 \mathrm{bp}$. The qPCR amplifications were performed in a total volume of $10 \mu 1$ using the iCycler System (CFX384 Real time system, Bio-Rad, Hercules, CA, USA). The reaction mixtures contained a final concentration of $2 \mu 15 x$ reaction buffer (Bioline, Luckenwalde, Germany), $1 \mu 1$ of $25 \mathrm{mM}$ $\mathrm{MgCl}_{2}$ (Bioline, Luckenwalde, Germany), $0.4 \mu 1$ of $2.5 \mathrm{mM}$ Deoxynucleoside triphosphates (dNTP) (Bioline, Luckenwalde, Germany), $0.3 \mu \mathrm{l}$ of $10 \mu \mathrm{M}$ each primer (Invitrogen, Karlsruhe, Germany), 0.1 $\mu 1$ of SybrGreen Mol Probes 1:1000 (Invitrogen, Karlsruhe, Germany), $0.25 \mu 1$ of 40mg/mL Bovine Serum Albumin (BSA) and $0.06 \mu 1$ of 5U/ $\mu 1$ Hot Start Taq Polymerase (Bioline, Luckenwalde, Germany), $4.59 \mu 1$ of sterile water and $1 \mu 1$ of sample DNA. Thermal cycling conditions for amplification: started with an initial denaturation step for $3 \mathrm{~min}$ at $94^{\circ} \mathrm{C}$, followed by 36 cycles, each consisting of a 30 s denaturation at $94^{\circ} \mathrm{C}$, annealing for $20 \mathrm{~s}$ at $60^{\circ} \mathrm{C}$, extension for $30 \mathrm{~s}$ at $72^{\circ} \mathrm{C}$ and a plate read at the end of each cycle. This was followed by a final extension for $5 \mathrm{~min}$ at $72^{\circ} \mathrm{C}$ and a final melting curve from $55^{\circ} \mathrm{C}$ to $95^{\circ} \mathrm{C}$ in $0.5^{\circ} \mathrm{C}$ increments held for $5 \mathrm{~s}$ at each temperature and a plate read at each temperature, which was used to determine the purity of the reaction products.

\subsubsection{Trichoderma koningiopsis}

Specific primers (forward: 5'-TACAACTCCCAAACCCAATGTGA-3', reverse: 5'CCGTTGTTGAAAGTTTTGATTCATTT-3') for Trichoderma spp. (López-Mondéjar et al., 2010) were used for the quantification. The qPCR amplifications were performed in a total volume of $10 \mu \mathrm{l}$ using the iCycler System (CFX384 Real time system, Bio-Rad, Hercules, CA, USA). The reaction mixture followed the same proportions as those reported for B. bassiana. The thermal cycling conditions used for amplification: started with an initial denaturation step for $3 \mathrm{~min}$ at $95^{\circ} \mathrm{C}$, followed by 35 cycles, each consisting of a denaturation step for $5 \mathrm{~s}$ at $95^{\circ} \mathrm{C}$, annealing for $15 \mathrm{~s}$ at $64^{\circ} \mathrm{C}$, extension for $15 \mathrm{~s}$ at $72^{\circ} \mathrm{C}$ and a plate read at the end of each cycle. 
This was followed by a final extension for $5 \mathrm{~min}$ at $72^{\circ} \mathrm{C}$ and a melting curve from $55^{\circ} \mathrm{C}$ to $95^{\circ} \mathrm{C}$ in $0.5^{\circ} \mathrm{C}$ increments held for $5 \mathrm{~s}$ at each temperature and a plate read at each temperature, which was used to determine the purity of the reaction products.

\subsubsection{Metarhizium brunneum}

Specific primers (Ma 1763: 5'-CCAACTCCCAACCCCTGTGAAT -3' and Ma 2079: 5'AAAACCAGCCTCGCCGAT-3') for Metarhizium spp. (Schneider et al., 2012) were used for the quantification. The qPCR amplifications were performed in a total volume of $10 \mu 1$ using the iCycler System (CFX384 Real time system, Bio-Rad, Hercules, CA, USA). The reaction mixtures contained a final concentration of $1 \mu 110 x$ reaction buffer (Bioline, Luckenwalde, Germany), $0.2 \mu 1$ of $25 \mathrm{mM} \mathrm{MgCl}_{2}$ (Bioline, Luckenwalde, Germany), $0.4 \mu 1$ of $2.5 \mathrm{mM} \mathrm{dNTP}$ (Bioline, Luckenwalde, Germany), $0.3 \mu \mathrm{l}$ of $10 \mu \mathrm{M}$ each primers (Invitrogen, Karlsruhe, Germany), 0.1 $\mu 1$ of SybrGreen Mol Probes 1:1000 (Invitrogen, Karlsruhe, Germany), 0.25 $\mu 1$ of $40 \mathrm{mg} / \mathrm{mL}$ BSA and $0.06 \mu 1$ of $5 \mathrm{U} / \mu 1$ BIOTaq DNA Polymerase (Bioline, Luckenwalde, Germany), $6.39 \mu 1$ of sterile water and $1 \mu 1$ of sample DNA. The thermal cycling conditions used for amplification: started with an initial denaturation step at $94{ }^{\circ} \mathrm{C}$ for $2 \mathrm{~min}$, followed by 39 cycles each consisting of a denaturation step for 40 s at $94^{\circ} \mathrm{C}$, annealing for $40 \mathrm{~s}$ at $65^{\circ} \mathrm{C}$, extension for $45 \mathrm{~s}$ at $72^{\circ} \mathrm{C}$ and a plate read at the end of each cycle. This was followed by a final extension for $5 \mathrm{~min}$ at $72^{\circ} \mathrm{C}$ and a melting curve from $55^{\circ} \mathrm{C}$ to $95^{\circ} \mathrm{C}$ in $0.5^{\circ} \mathrm{C}$ increments held for $5 \mathrm{~s}$ at each temperature and a plate read at each temperature, which was used to determine the purity of the reaction products.

\subsection{Effects of plant-fungal interaction on plant attributes}

Four weeks after fungal inoculation, the plants were moved to laboratory conditions (Temperature $20^{\circ} \mathrm{C} \pm 2$, RH 70\%, 16:8 light /dark conditions) where they were distributed according to the corresponding treatment into mesh cages. Plant parameters: temperature, length and chlorophyll content were measured as soon as the 24 hours of interaction between Helicoverpa armigera and the plants ended.

\subsubsection{Plant temperature measurements}

Each plant was removed from the mesh cage and placed on a thermally isolated surface. Thermal images were obtained using a heat sensing camera (FLIR T6xx systems, Danderyd, 
Sweden) that generates thermal infrared imaging with a sensitivity of $0.08^{\circ} \mathrm{C}$ and accuracy of $\pm 2^{\circ} \mathrm{C}$. Simultaneously, visible images were obtained with the digital image of the FLIR camera.

\subsubsection{Foliar chlorophyll content}

Fully expanded leaves per plant were used for chlorophyll measurements in planta. Five readings per plant using SPAD (SPAD 502 plus, Leaf Chlorophyll Meter, Minolta) were taken around the midpoint near the midrib of each leaf sample and averaged. A total of 360 measurements were taken.

\subsubsection{Near infrared spectroscopy}

Plant material was carefully transported to the Spectroscopy laboratory at the Division of Plant Breeding, at the University of Göttingen where the Near Infrared Spectroscopy (NIRS) (NIRS System 6500) scanning was performed at controlled temperature and humidity conditions. From each treatment, a leaf disc was obtained with a standard $20 \mathrm{~mm} \varnothing$ mold and packed manually in a sample capsule with a quartz glass cover. Each sample was scanned once. The spectral data were recorded as $\log 1 / \mathrm{R}$ (where $\mathrm{R}$ is reflectance) and the first and second derivatives of $\log 1 / \mathrm{R}$, one sample per plant was taken with 12 biological replicates per treatment.

\subsubsection{Plant biomass}

Plants were removed from the soil and washed off with tap water. Aboveground, and belowground parts were separated and gently blotted with paper towels to absorb any free surface moisture. Shoot length (SL) and root length (RL) were measured separately. For root length measurements, the fresh root system was expanded over a flat surface and kindly separated to measure the length of the longest root. The samples were then lyophilized and the dry weight of shoots (DWS) and the dry weight of roots (DWR) were recorded. The plant root - shoot ratio was calculated:

$$
\text { Root }- \text { Shoot ratio }=\frac{D W R}{D W S}
$$




\subsection{Helicoverpa armigera oviposition preference}

\subsubsection{No- choice bioassay}

One five days old female and one male moth were released in a mesh cage of $20 \times 20 \times 40 \mathrm{~cm}$, which contains one tomato plant treated with the corresponding endophyte or control plants. The insects interacted with the plants for 24 hours and were used only once for experiments. Laid eggs were counted and removed to avoid over counting. The experiment was replicated twice, under laboratory conditions with a temperature of $23 \pm 2{ }^{\circ} \mathrm{C}$ and a $16 \mathrm{~L}: 8 \mathrm{D}$ photoperiod, one plant per cage and eight plants per treatment were tested.

\subsubsection{Multiple choice bioassay}

For this experimental setup, five tomato plants (one per treatment) were distributed into a mesh house and in the center of the cage one five days old female and one male moth were released. After 24 hours the laid eggs were counted. This experiment was developed under laboratory conditions with a temperature of $23 \pm 2^{\circ} \mathrm{C}$ and a $16: 8 \mathrm{LD}$ photoperiod, one plant per treatment / cage and twelve replicates were tested.

\subsection{Statistical analysis}

A Pearson product moment correlation was made using Sigma Plot version 11.0 (Systat Software Inc., 2016) for each treatment to determine the relationship between the amounts of endophytic fungal DNA found in the plant tissues and the oviposition of $H$. armigera, plant temperature, leaf chlorophyll content and stem length.

\subsubsection{Detection of fungal endophytic colonization by real-time polymerase chain reaction}

The response of the endophyte in terms of fungal DNA found in the different tissues of the plant, roots, stems, and leaves was analyzed by means of linear mixed-effects model r-package "Ime4" (Bates et al., 2015), R version 3.2.2. (R Core team, 2015) (The amount of fungal DNA recover from the different plant tissues after the RT-PCR was named according to the name of the organ where it was recovered: "Stem", "Root" or "Leaf" and constituted the dependent variable $(n=12)$. Each cage where the plants were grouped was considered as a block named "block" in the model $(n=12)$ and considered as a random effect. The following formula was applied. 
Endophytic colonization $=\operatorname{lme}(a \sim$ Treatment, random $=\sim 1 \mid$ Block $)$

Where a, is the corresponding fungal DNA amount found in the organ analyzed: Stem, root or leaf. A normality test of the residuals (Shapiro-Wilk) was used to test the assumption of normally distributed data, and the groups were determined with Tukey multiple comparisons of means.

\subsubsection{Effects of plant-fungal interaction on plant attributes}

Fungal endophytic fungi effect on stem length of tomato plants. Data are shown in average length $(\mathrm{cm}) \pm$ SE. One way analysis of variance $(\mathrm{P}<0.001)$, Normality test KolmogorovSmirnov, passed with a $\mathrm{P}=0.316$, equal variance test passed $(\mathrm{P}=0.240)$. Tukey HSD test for the group definition.

\subsubsection{H. armigera oviposition preference}

The multiple choice oviposition data were not normal distributed; therefore, a generalized linear model (GLM) was used with a negative binomial distribution of errors with r-package "MASS" (Venables and Ripley, 2002), R version 3.2.2 (R Core team, 2015). The model formula used was:

$$
\text { model. } n b=\text { glm.nb (eggs Treatment })
$$

A Chi-square goodness of fit (GOF) test was applied

For the no-choice oviposition data, a one way analysis of variance ANOVA was used.

\section{Results}

A Pearson product moment correlation analysis showed no correlation between the measured parameters in the plants treated with the entomopathogenic fungi M. brunneum. For plants treated with $T$. koningiopsis, a positive correlation between the amount of fungal DNA in the stem and the number of laid eggs $(r=0.787, \mathrm{P} \leq 0.00236)$ was found. Similarly, among the leaf chlorophyll content and the plant length $(\mathrm{r}=0.733, \mathrm{P} \leq 0.00668)$. B. bassiana treated plants showed specific correlations according to the strain. For $\mathrm{Bb}^{1}$ treated plants, the number of laid eggs was positively correlated with the fungal DNA quantified from leaf tissues ( $\mathrm{r}=0.847$, $\mathrm{P} \leq 0.000511$ ), while the plant length was positively correlated with two parameters fungal DNA in root tissue and the chlorophyll content $(\mathrm{r}=0.598, \mathrm{P} \leq 0.0399$ and $\mathrm{r}=0.711, \mathrm{P} \leq 0.00949$ 
respectively). For the $\mathrm{Bb}^{2}$ treated plants, the chlorophyll content also positively correlates with the plant length $(\mathrm{r}=0.706, \mathrm{P} \leq 0.0103)$. Finally, the $\mathrm{Bb}^{3}$ treated plants showed a negative correlation between the amount of fungal DNA in the leaves and plant temperature $(r=-0.685$, $\mathrm{P} \leq 0.0416)$.

\subsection{Detection of fungal endophytic colonization by real-time polymerase chain reaction}

The fungal establishment success of each fungus in plant tissues is shown in figure 1. The colonization was higher in the roots for all the treatments with significant differences observed in the model $(\mathrm{F}=5.419$ on 5 and $64 \mathrm{df}, \mathrm{P} \leq 0.000345)$ when compared to the control. The amount of fungal DNA observed in tomato stem tissues of plants treated with T. koningiopsis Tk $(\mathrm{P} \leq 0.0033)$ and Beauveria bassiana $\mathrm{Bb}^{3}$ were significantly higher than the other strains studied $(\mathrm{P} \leq 0.0023)$. In the leaves, the amount of fungal DNA recovered was significantly different to the control plant in the samples from Beauveria bassiana $\mathrm{Bb}^{1}(\mathrm{P} \leq 0.0033)$, and Beauveria bassiana $\mathrm{Bb}^{3}(\mathrm{P} \leq 0.035)$.

\subsection{Effects of plant-fungal interaction on plant growth parameters}

\subsubsection{Plant temperature}

The plant temperature measured with FLIR thermal imaging registered in the multiple choice experiments was analyzed with a generalized linear model and showed no significant differences between the treatments $(\mathrm{P}=0.9001)$ (Figure 2a, 2b ). 


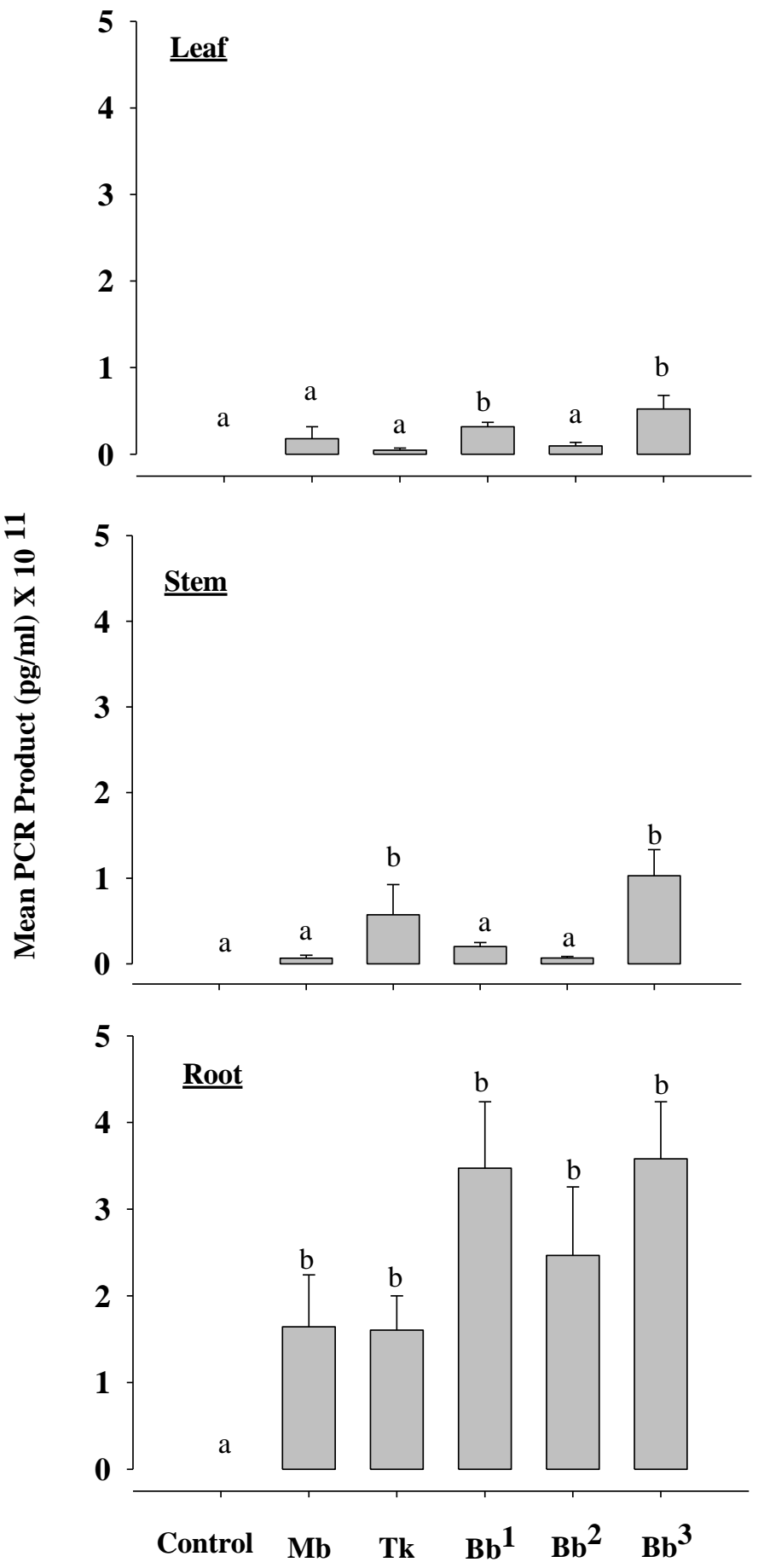

Figure 1. Fungal DNA detected with the qPCR technique in plant samples. 

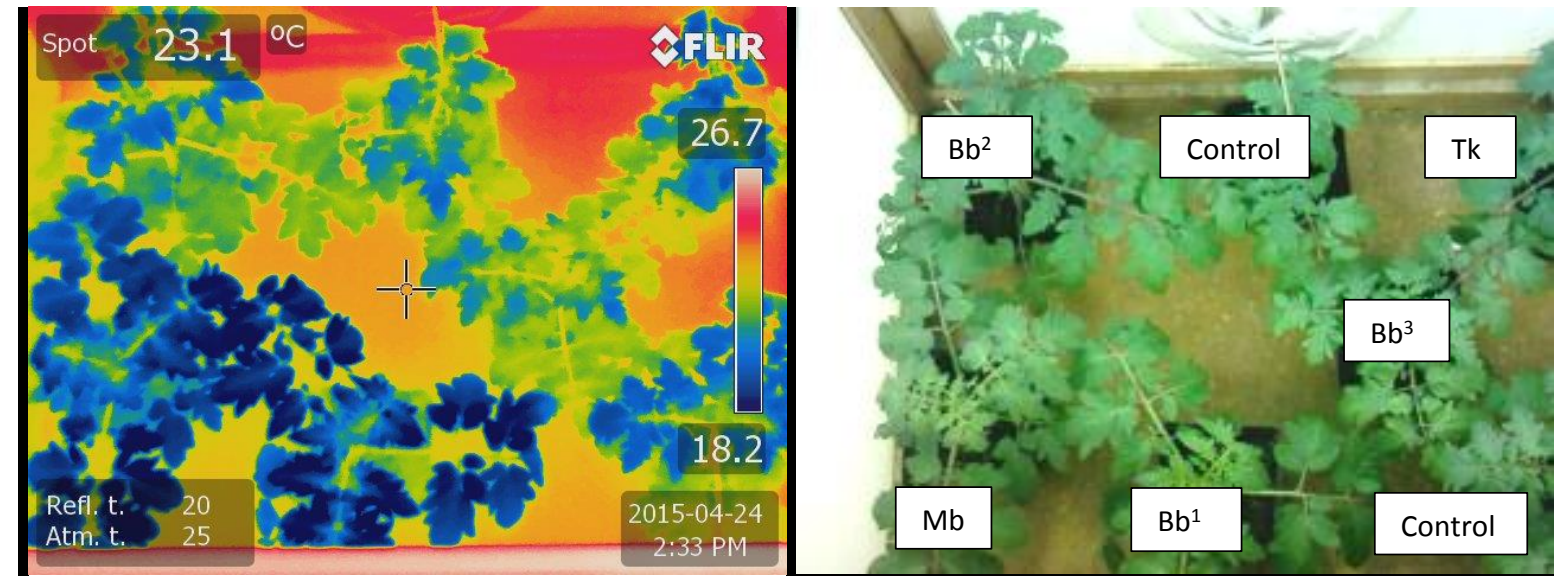

a.

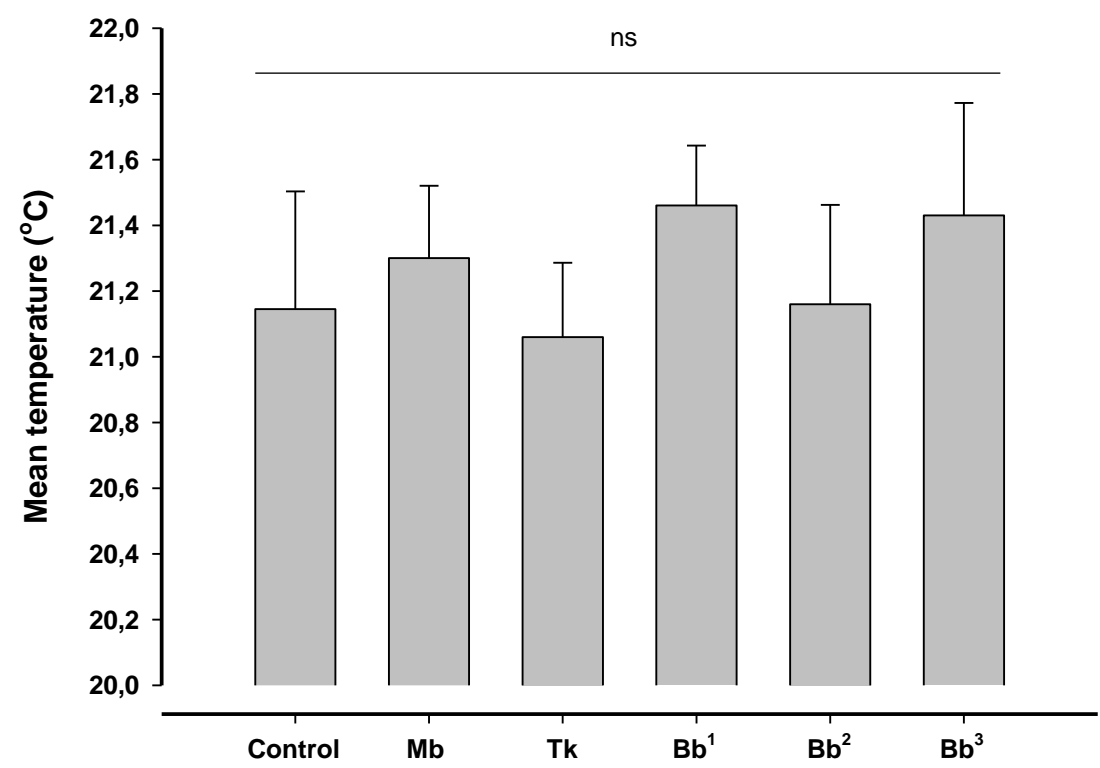

b.

Figure 2. a) Thermal images captured by the FLIR T6xx series. In the right side treatments distributions are presented. b) Plant temperature measured with FLIR thermal imaging registered in plants used for multiple choice experiments. Generalized linear model of the temperature showed no significant differences between the treatments $(P=0.9001)$

\subsubsection{Foliar chlorophyll content}

The foliar chlorophyll content data showed a normal distribution according to the normality test Kolmogorov - Smirnov $(\mathrm{P}=0.317)$ and passed the homogeneity of variances assumption $(\mathrm{P}=0.331)$. A one-way analysis of variance showed significant differences among treatments $(\mathrm{P}<0.001, \mathrm{~F}=12.420$, df $=5)$. All pairwise comparison Tukey test showed that Beauveria 
bassiana $\mathrm{Bb}^{1}, \mathrm{Bb}^{2}$ and $\mathrm{Bb}^{3}$ were significantly different compared to the control plants and no significant difference between T. koningiopsis and M. brunneum treated plants with the control were observed (Figure 3).

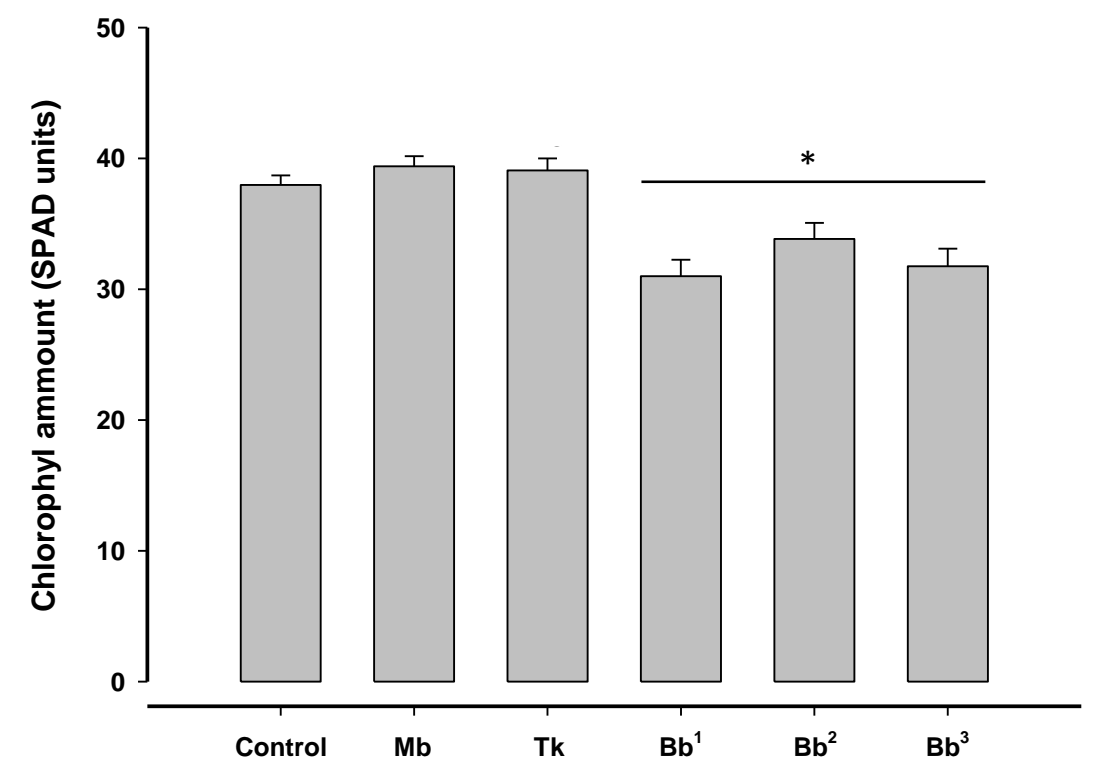

Figure 3. Chlorophyll content of tomato plants registered from five randomly selected leaves per plant (Average $\pm \mathrm{SE}$ ).

\subsubsection{Near-infrared spectroscopy (NIRS)}

The near infrared spectroscopy (NIRS) analysis showed no differences among the treatments in terms of absorbance.

\subsubsection{Plant biomass}

Plants treated with Tk endophyte, showed the higher total biomass, stem length and shoot biomass compared with all the treatments and control. No further variation was explained by other treatment. While the root biomass and the root:shoot ratio was not significantly different between the treatments (Figure 4). 

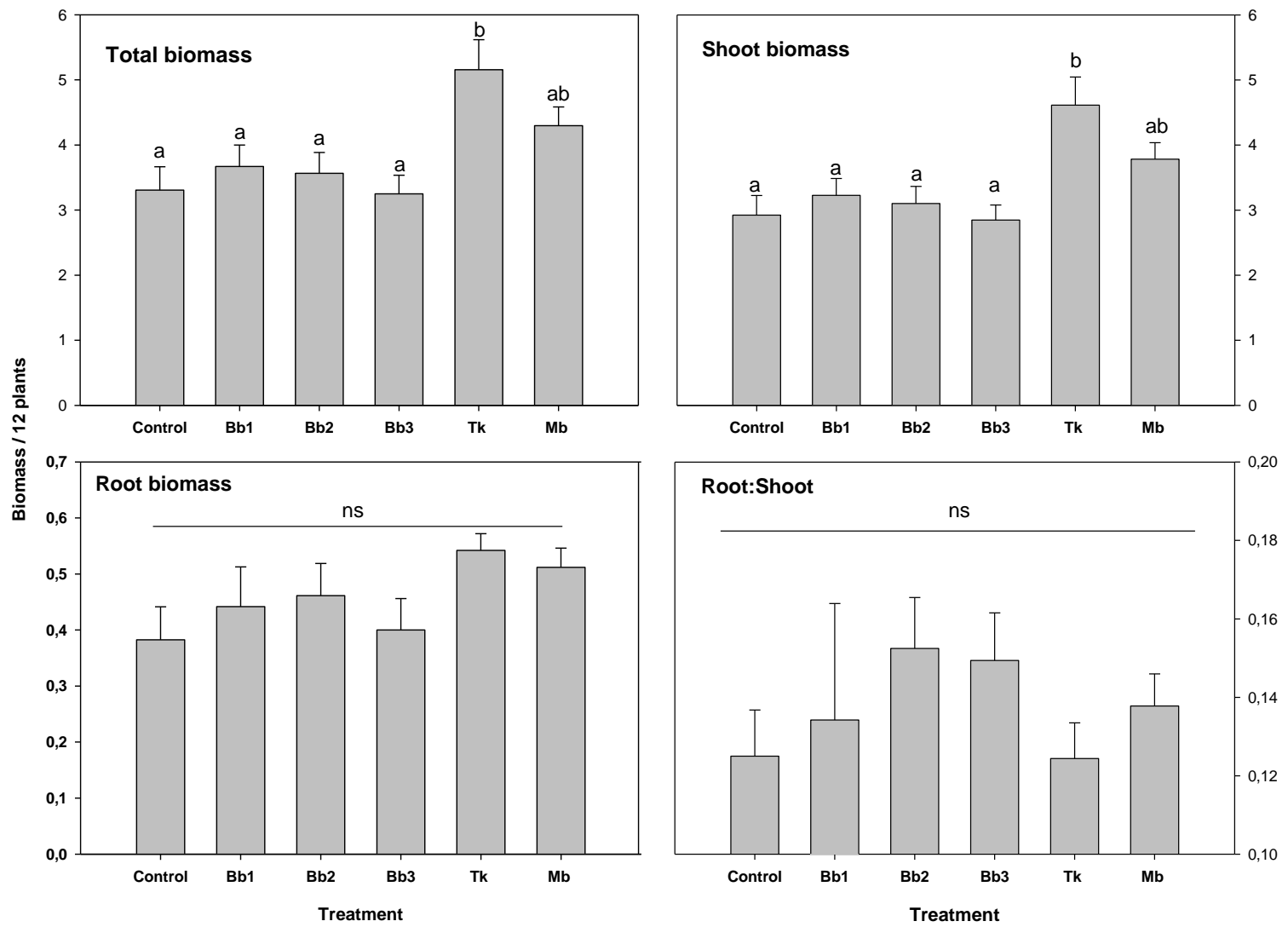

Figure 4. Effect of endophytic fungal colonization on tomato plant biomass. No significant differences were found in the root biomass between the treatments.

\subsection{Helicoverpa armigera oviposition preference}

\subsubsection{No- choice experiment}

The oviposition preference of $H$. armigera in a no-choice experimental setup showed no significant differences among treatments (ANOVA $\mathrm{P}=0.427, \mathrm{DF}=5, \mathrm{~F}=1.022$ ).

\subsubsection{Multiple choice experiment}

Data from the $H$. armigera oviposition preference in a multiple choice experiment fitted to a negative binomial distribution (Model information: $\mathrm{P}=0.315$, Link function: $\log , \mathrm{df}=71$, Akaike's information criterion $(\mathrm{AIC})=379.62$, Initial theta $=0.3057, \mathrm{SE}=0.0640, \mathrm{n}=12$ ). A significantly less preference to oviposit on those plants treated with $\mathrm{Bb}^{1}(\mathrm{P}=0.014)$ was observed. No further differences were observed. 


\section{Discussion}

In accordance with our hypothesis, we found that all tested fungal endophytes successfully colonized plant roots with no significant differences between the treatments. When observed the colonization of aboveground plant tissues, T. koningiopsis and B. bassiana $\mathrm{Bb}^{3}$ showed the highest levels of colonization in the stem, and finally only $B$. bassiana $\mathrm{Bb}^{3}$ showed significant differences in the colonization of leaves. Since our inoculation method involves only root treatment with the fungal suspension, finding traces of the fungal endophyte DNA in aboveground plant tissues indicate that B. bassiana strain $\mathrm{Bb}^{3}$ and $\mathrm{Tk}$ are able to mobilize systemically from the roots to the newly developed tissues and remain in the plant for at least four weeks after application. These results are in accordance with those reported by QuesadaMoraga et al. (2006) and Behie et al., (2015). The $\mathrm{Bb}^{3}$ was more efficient in approaching plant tissues far from the initial inoculation site. The mechanisms that allow this fungus to spread trroughout the plant tissues are not yet described, and future studies are needed to understand its ecological implications and potential applications in the biological control of tomato pests.

Similarly, T. koningiopsis was able to colonize stems of tomato plants in addition to its growing in roots. This observation is similar to that obtained by Samuels et al. (2006) who isolated $T$. koningiopsis from freshly exposed, living sapwood of trunks of Theobroma cacao plants in Brazil, Ecuador, and Peru but failed to obtain it from apical meristems. However, to our knowledge, no reports are available about $T$. koningiopsis being isolated as an endophyte in the Solanaceae plant family. As such, our finding may contribute to the potential use of this endophyte to protect plants against insect herbivores and plant pathogens in integrated crop management strategies.

In the case of M. brunneum, we found positive traces of this fungal DNA only in root tissues, indicating that this endophyte cannot spread throughout the plant and stays in the root system as observed by Greenfield et al. (2016) for Metarhizium anisopliae and Behie et al. (2015) who found that Metarhizium brunneum growth was restricted to the roots while B. bassiana was found along the plant.

We observed that tomato plants infected with fungal endophytes did not exhibit any significant difference among treatments in terms of plant temperature but, the leaf chlorophyll content and plant biomass were significantly affected by the endophytic treatment with $B$. bassiana and $T$. koningiopsis respectively. Similarly, Moreno et al. (2009) observed that T. koningiopsis Th003 
contributes to obtaining higher plants when inoculating tomato seedlings after a seed priming with the fungal suspension. Tomato shoot dry weight of $T$. koningiopsis treated plants was also significantly different compared to the control and other treatments. These results can be attributed to the ability of Trichoderma spp. to promote plant growth mainly reported for $T$. harzianum (Oskiera et al., 2015; Ownley et al., 2010) but also reported by Moreno et al. (2009) for T. koningiopsis Th003 in tomato plants.

Another plant response associated with endophyte treatment was observed for entomopathogenic endophyte $B$. bassiana, which significantly reduced the amount of leaf chlorophyll content registered for infected plants compared to the control and the fungal endophytes T.koningiopsis and M. brunneum. The lowest content of chlorophyll was observed in $B$. bassiana $\mathrm{Bb}^{1}$ treated plants. This trait is positively correlated with the oviposition of $H$. armigera, and with the stem length. The more chlorophyll, the longer the stem of tomato plants treated with $\mathrm{Bb}^{1}, \mathrm{Bb}^{2}$, and $\mathrm{Tk}$.

Leaf chlorophyll content of plants is a parameter that provides information about the general health conditions of plants since it is an indirect sign of chloroplasts development and their photosynthetic ability as well as of nitrogen content (Palta, 1990). The amount of chlorophyll in leaf tissue can be influenced by different abiotic factors such as nutrient availability or environmental stress caused by salinity, temperatures or water supply (Palta, 1990). Nevertheless, biotic factors are also important in the modulation of the chlorophyll content of plants. For instance, plant - endophyte interactions have been shown to be in detriment of the plant's photosynthetic capacity in some cases, mainly related to fungal endophytes that confer protection against plant pathogens (Azevedo et al., 2000; Singh et al., 2011). Such is the case of the impact caused by Colletotrichum musae and Fusarium moniliforme that has an effect on the photosynthetic activity of banana and maize plants respectively (Costa Pinto et al., 2000).

In our study, we found that, instead of the plant pathogen biocontrol agent Trichoderma koningiopsis, the main effect on chlorophyll content was observed in plants treated with the entomopathogenic fungi Beauveria bassiana.

Once we observed that the endophytic fungi affect some parameters in the plant odor (see chapter 2), plant chlorophyll content and biomass, the following step was to observe if there is a relation between those parameter of the plant and the insect behavior, specifically with the host plant selection of gravid females of Helicoverpa armigera. In that sense it has been 
reported that for many insect herbivores, olfactory cues play decisive roles when females search for a proper host plant for oviposition (Reisenman and Riffell, 2015). Nevertheless, not only the plant volatiles are involved in the plant selection for oviposition, once the plant is located by the chemical cues, the moths uses the chemical and visual cues given by the plant surface. For lepidopteran, the information perceived through antenna, tarsi and ovipositor are crucial for acceptance of a plant for oviposition (Juma et al.). We observed in our experiments, the higher eggs laid by $H$. armigera was observed in plants treated with $\mathrm{Mb}$ and $\mathrm{Bb}^{3}$, which are the same treatments that showed no effects in the chlorophyll content compared to the control.

It can be inferred from those results that, inoculations with entomopathogenic fungi B. bassiana and T. koningiopsis may contribute to the management of the population growth by decreasing the suitability of tomato leaves for potential offspring of $H$. armigera. Further studies are necessary to confirm if the chlorophyll content of tomato plants is a decision factor for selecting a proper oviposition site for gravid Helicoverpa armigera.

Some studies demonstrate that the specialist moth Euphydryas aurinia (Lepidoptera: Nymphalinae: Melitaeini) select the greenest leaves for oviposition, searching for a guaranty of suitable leaves for the new hatched larvae (Stefanescu et al., 2006).

We can conclude that under our study conditions the endophytic fungi Beauveria bassiana and Trichoderma koningiopsis are able to modulate plant traits of the tomato plant Solanum lycopersicon that positively affects the insect-plant interaction with the polyphagous moth Helicoverpa armigera. 


\section{Acknowledgements}

This study was supported by The Colombian Corporation for Agricultural Research (Corpoica) and the Colombian Administrative Department of Science, Technology, and Innovation (Colciencias).

\section{References}

Azevedo, J. L., Maccheroni Jr., W., Pereira, J. O., and De Araújo, W. L. (2000). Endophytic microorganisms: a review on insect control and recent advances on tropical plants. Electron. J. Biotechnol. 3, 0-0. doi:10.2225/vol3-issue1-fulltext-4.

Bates, D., Mächler, M., Bolker, B. M., and Walker, S. C. (2015). Fitting Linear Mixed-Effects Models Using lme4. JSS J. Stat. Softw. 67. doi:10.18637/jss.v067.i01.

Behie, S. W., Jones, S. J., and Bidochka, M. J. (2015). Plant tissue localization of the endophytic insect pathogenic fungi Metarhizium and Beauveria. Fungal Ecol. 13, 112-119. doi:10.1016/j.funeco.2014.08.001.

Bruce, T. J. a, and Pickett, J. a. (2011). Perception of plant volatile blends by herbivorous insects - Finding the right mix. Phytochemistry 72, 1605-1611. doi:10.1016/j.phytochem.2011.04.011.

Costa Pinto, L., Azevedo, J. L., Pereira, J. O., Carneiro Vieira, M. L., and Labate, C. A. A. (2000). Symptomless infection of banana and maize by endophytic fungi impairs photosynthetic efficiency. New Phytol. 147, 609-615. doi:10.1046/j.14698137.2000.00722.x.

Cunningham, J. P., Jallow, M. F. A., Wright, D. J., and Zalucki, M. P. (1998). Learning in host selection in Helicoverpa armigera ( $\mathrm{H} \bullet$ bner) (Lepidoptera: Noctuidae). Anim. Behav. 55, 227-234.

Greenfield, M., Gómez-Jiménez, M. I., Ortiz, V., Vega, F. E., Kramer, M., and Parsa, S. (2016). Beauveria bassiana and Metarhizium anisopliae endophytically colonize cassava roots following soil drench inoculation. Biol. Control 95, 40-48. doi:10.1016/j.biocontrol.2016.01.002.

Jaber, L. R., and Vidal, S. (2010). Fungal endophyte negative effects on herbivory are enhanced on intact plants and maintained in a subsequent generation. Ecol. Entomol. 35, 25-36. doi:10.1111/j.1365-2311.2009.01152.x.

Jallow, M. F. a, Dugassa-Gobena, D., and Vidal, S. (2008). Influence of an endophytic fungus on host plant selection by a polyphagous moth via volatile spectrum changes. Arthropod. Plant. Interact. 2, 53-62. doi:10.1007/s11829-008-9033-8. 
Juma, G., Clément, G., Ahuya, P., Hassanali, A., Derridj, S., Gaertner, C., et al. Influence of Host - Plant Surface Chemicals on the Oviposition of the Cereal Stemborer Busseola Fusca. doi:10.1007/s10886-016-0704-0.

Kölliker, U., Biasio, L., and Jossi, W. (2011). Potential control of Swiss wireworms with entomopathogenic fungi. IOBC/WPRS Bull. 66, 517-520.

López-Mondéjar, R., Antón, A., Raidl, S., Ros, M., and Pascual, J. A. (2010). Quantification of the biocontrol agent Trichoderma harzianum with real-time TaqMan PCR and its potential extrapolation to the hyphal biomass. Bioresour. Technol. 101, 2888-91. doi:10.1016/j.biortech.2009.10.019.

Moreno, C. A., Castillo, F., González, A., Bernal, D., Jaimes, Y., Chaparro, M., et al. (2009). Biological and molecular characterization of the response of tomato plants treated with Trichoderma koningiopsis - ArtculoenPhysiologicalandmolecularplantpathology.pdf. Physiol. Mol. Plant Pathol, $1-10 . \quad$ Available at: http://www.corpoica.org.co/sitioweb/Archivos/oferta/ArtculoenPhysiologicalandmolecul arplantpathology.pdf [Accessed January 8, 2015].

Oskiera, M., Szczech, M., and Bartoszewski, G. (2015). Molecular Identification Of Trichoderma Strains Collected To Develop Plant Growth-Promoting And Biocontrol Agents. J. Hortic. Res. 23, 75-86. doi:10.2478/johr-2015-0010.

Ownley, B. H., Gwinn, K. D., and Vega, F. E. (2010). Endophytic fungal entomopathogens with activity against plant pathogens: Ecology and evolution. BioControl 55, 113-128. doi:10.1007/s10526-009-9241-x.

Palta, P. J. (1990). Leaf chlorophyll content. Remote Sens. Rev., 207-213. Available at: http://www.tandfonline.com/doi/pdf/10.1080/02757259009532129 [Accessed March 10, 2016].

Quesada-Moraga, E., Landa, B. B., Muñoz-Ledesma, J., Jiménez-Diáz, R. M., and SantiagoÁlvarez, C. (2006). Endophytic colonisation of opium poppy, Papaver somniferum, by an entomopathogenic Beauveria bassiana strain. Mycopathologia 161, 323-329. doi:10.1007/s11046-006-0014-0.

R Core team (2015). R Core Team. $R$ A Lang. Environ. Stat. Comput. R Found. Stat. Comput. , Vienna, Austria. ISBN 3-900051-07-0, URL http//www.R-project.org/.

Ramaswamy, S. B. (1988). Host finding by moths: Sensory modalities and behaviours. J. Insect Physiol. 34, 235-249. doi:10.1016/0022-1910(88)90054-6.

Reisenman, C. E., and Riffell, J. A. (2015). The neural bases of host plant selection in a Neuroecology framework. Front. Physiol. 6, 229. doi:10.3389/fphys.2015.00229.

Renwick, J. A. A. (1994). Oviposition Behavior in Lepidoptera. Annu. Rev. Entomol., 377-400. Available http://www.annualreviews.org/doi/pdf/10.1146/annurev.en.39.010194.002113 [Accessed 
March 15, 2016].

Rincón, D. F., and López-Ávila, A. (2004). Dimorfismo sexual en pupas de Tecia solanivora (Povolný)(Lepidoptera: Gelechiidae). Rev. Corpoica 5, 41-42.

Rodriguez, R. J., White, J. F., Arnold, A. E., Redman, R. S., Jr, J. F. W., Arnold, A. E., et al. (2009). Fungal endophytes: diversity and functional roles. New Phytol. 182, 314-330. doi:10.1111/j.1469-8137.2009.02773.x.

Samuels, G. J., Dodd, S. L., Lu, B.-S., Petrini, O., Schroers, H.-J., and Druzhinina, I. S. (2006). The Trichoderma koningii aggregate species. Stud. Mycol. 56, 67-133. doi:10.3114/sim.2006.56.03.

Schneider, S., Widmer, F., Jacot, K., Kölliker, R., and Enkerli, J. (2012). Spatial distribution of Metarhizium clade 1 in agricultural landscapes with arable land and different semi-natural habitats. Appl. Soil Ecol. 52, 20-28. doi:10.1016/j.apsoil.2011.10.007.

Schulz, B., and Boyle, C. (2006). What are Endophytes? Soil Biol. 9, 1-14. doi:10.1007/3-54033526-9.

Singh, L. P., Gill, S. S., and Tuteja, N. (2011). Unraveling the role of fungal symbionts in plant abiotic stress tolerance. Plant Signal. Behav. 6, 175-91. Available at: http://www.pubmedcentral.nih.gov/articlerender.fcgi?artid=3121976\&tool=pmcentrez\&r endertype $=$ abstract [Accessed March 10, 2016].

Stefanescu, C., Peñuelas, J., Sardans, J., and Filella, I. (2006). Females of the specialist butterfly Euphydryas aurinia (Lepidoptera: Nymphalinae: Melitaeini) select the greenest leaves of Lonicera implexa (Caprifoliaceae) for oviposition. Eur. J. Entomol. 103, 569-574. doi:10.14411/eje.2006.077.

Systat Software Inc. (2016). SigmaPlot V.11.0. Available at: www.systatsoftware.com.

Venables, W. N., and Ripley, B. D. (2002). Modern Applied Statistics with S. Fourth. New york: Springer Available at: http://www.stats.ox.ac.uk/pub/MASS4.

Zhang, L. (2014). Colonization pattern of crop plants by endophytic fungi. 


\section{Acknowledgements}

I would like to express my sincere gratitude to my advisor Prof. Dr. Stefan Vidal for open me the doors of his research group and show me the marvelous world of fungal endophytes, his continuous support during my Ph.D. studies, motivation, and his wise advice in the improvement of my scientific writing. Thank you, Stefan, also for supporting my ideas and for allowing me to attend training courses and scientific meetings across Europe.

My sincere thanks also go to my advisor at Corpoica, Dr. Alba Marina Cotes, who gave me the opportunity to join her research team in the field of chemical ecology and biological control of pests and encouraged me to conduct my Ph.D. studies abroad.

I sincerely appreciate the continuous support of Prof. Dr. Stefan Schütz for giving me access to the laboratory facilities and supporting me with his wise in the field of identification of chemical compounds and his assistance in the edition of the document. Many thanks to Prof. Dr. Petr Karlovsky, for being always willing to teach me the "step by step" in the molecular detection of fungal endophytes and for allowing me to work in his Laboratory of Molecular Phytopathology and Mycotoxin Research. I also appreciate Assoc. Prof. Dariusz Piesik, who accepted the invitation to review my thesis and invest his time to give contributions to the research.

I would like to thank my lab fellows for the daily friendly working atmosphere and the helpful assistance of our laboratory technicians Dorothea Mennerich and Bianca Tappe. I also want to thank my friends Jhenny Salgado and Ariana Valdés for their stimulating discussions in the statistical analysis and $\mathrm{R}$ coding, and also for the exhaustive working days we were working together before the deadlines and for all the fun that came along with this.

I would also like to thank my sons Manuel and Sergio for their unconditional support during these years, for preparing the soil mixture with me, their company during the unforgettable watering duties and for their understanding during mama's long writing days. My deepest thanks to my husband who also pursued his Ph.D. studies and nevertheless supported me unconditionally, without his love, encouragement and scientific assistance I would not have finished this thesis.

This research would not have been possible without the financial support of the Colombian Administrative Department of Science, Technology and Innovation (Colciencias) that provided me with a scholarship from the program Francisco José de Caldas for Ph.D. studies abroad and The Colombian Corporation of Agricultural Research (Corpoica) for the study leave. 


\section{Curriculum vitae}

Personal details

Aragón Rodríguez, Sandra Milena

February $21^{\text {st }} 1982$ in Armenia, Colombia

e-mail: sandra.milena.aragon@gmail.com

University studies

2012-2016

Ph.D

International Ph.D. Program of Agriculture

Göttingen University

Göttingen, Germany

2005-2007

M.Sc. Applied Biology

Crop Protection

Militar Nueva Granada University

Bogotá, Colombia

1999-2004

\section{B.Sc. Applied Biology}

Biological control

Militar Nueva Granada University

Bogotá, Colombia

Professional experience

2010- 2016

Master Researcher.

Colombian Corporation of Agricultural Research (Corpoica).

Biological Control Laboratory

Mosquera, Colombia

2007-2009

General Biology Teacher.

British Gymnasium.

Chía, Colombia

$2005-2007$

Research Asistant.

Militar Nueva Granada University.

Sciences Faculty

Bogotá, Colombia

2002-2003 Internship.

Center for Agribusiness Research and Consultancies.

Jorge Tadeo Lozano University.

Chía, Colombia 
Training School "Isolation and characterization of fungal root endophytes". Leibniz-Institute of Vegetable and Ornamental Crops (IGZ).

Großbeeren, Germany 8-12 September 2014.

2013

Training School Characterization of biologically active secondary metabolites from endophytic fungi.

Helmholtz Center for Infection Research.

Braunschweig, Germany 2-6 Dec 2013.

2011

Ph.D. Course in insect chemical ecology. The impact of Semiochemicals on Insect Behavior.

Swedish University of Agricultural Sciences

Alnarp, Sweden, 7-18 June 2011.

2010

Internship

Swedish University of Agricultural Sciences.

Division of Chemical Ecology.

Alnarp, Sweden. Prof. Dr. Peter Witzgall.

\section{Abstracts in Scientific meetings}

Aragón, Sandra; Cotes, Alba Marina; Schütz, Stefan; Vidal, Stefan. Smells good, but ....? Herbivores and endophytic entomopathogenic fungal volatile bouquets. - Inbiosoil symposium - Strategies for a sustainable agriculture in Europe: innovative biocontrol options. Gottingen, Germany 29 - 03 December 2015

Aragón, Sandra; Cotes, Alba Marina; Schütz, Stefan; Vidal, Stefan. "Insects smell endophytes". International Microbe Assisted Crop Production - Oportunities, Challenges and needs - MiCROPe - 2015 symposium, 23-26th November 2015. Vienna, Austria.

Aragón, Sandra; Cotes, Alba Marina; Schütz, Stefan; Vidal, Stefan. Not visible, but highly effective: plant volatile manipulation by endophytic fungi and responses of herbivores. $31^{\text {st }}$. Conference of the International Society of Chemical Ecology. Stockholm, Sweden 29 - 04 July 2015

Aragón, Sandra; Cotes, Alba Marina; Schütz, Stefan; Vidal, Stefan. Endophytic fungal entomopathogens makes tomato plants more attractive to insect herbivory. Entomology Congress of the German Society for general and applied entomology. Goethe University. Frankfurt, Germany. 02 - 05 March 2015

Aragón, Sandra; Cotes, Alba Marina; Vidal, Stefan. Plant volatile organic compound manipulation by endophytic entomopathogenic fungi. 47 Congress of Society for Invertebrate Pathology. Mainz, Germany. 03-08 August 2014. 
Aragón, Sandra. Plant volatile organic compounds induced by entomopathogenic endophytic fungi. Leibniz-Institute of Vegetable and Ornamental Crops. Großbeeren, Germany.09 September 2014.

Aragón, Sandra; Vidal, Stefan; Cotes, Alba Marina. Different endophytic fungi change volatile organic compound emissions in tomato plants. 59 Deutschen Pflanzenschutztagung (German Conference of Plant Protection). Albert-Ludwigs-Universität Freiburg, Deutschland. 23-26 September 2014.

\section{Awards}

Best Poster Award. In recognition for the excellent performance at the international Microbe Assisted Crop Production - Oportunities, Challenges and needs - MiCROPe - 2015 symposium, for presenting the work with the title "Insects smell endophytes". 25th November 2015. Vienna, Austria.

Student travel award. From the International Society of Chemical Ecology, in recognition for the work titled "Not visible, but highly effective: plant volatile manipulation by endophytic fungi and responses of herbivores" presented in $\mathbf{2 9}^{\text {th }}$ of July 2015. Stockholm, Sweden.

Student travel award from the Fungi Division of the Society for Invertebrate Pathology, in recognition for the work titled "Plant volatile organic compound manipulation by endophytic entomopathogenic fungi" presented in $\quad \mathbf{0 7}^{\text {th }}$ of August 2014. Mainz, Germany.

Grant for Training School "Experimental Design and Statistical Data Analysis: Applications in R-software for endophyte-related data". University of Evora. Evora, Portugal. 20-24 October 2014. European Cooperation in Science and Technology, COST. Cost Action Food and Agriculture FA1103. Endophytes in Biotechnology and Agriculture

Grant for Training School "Isolation and characterization of fungal root endophytes" at the Leibniz-Institute of Vegetable and Ornamental Crops. Großbeeren, Germany. 08-12 September 2014. European Cooperation in Science and Technology, COST. Cost Action Food and Agriculture FA1103. Endophytes in Biotechnology and Agriculture

Grant for Training School "Characterization of biologically active secondary metabolites from endophytic fungi" at the Department Microbial Drugs, Helmholtz Centre for Infection Research. Braunschweig, Germany. 02-06.12.2013. European Cooperation in Science and Technology, COST. Cost Action Food and Agriculture FA1103. Endophytes in Biotechnology and Agriculture.

Scholarship for Doctoral studies abroad given by Colciencias. Colombian Administrative Department of Science, Technology, and Innovation (Colciencias). Colombia. 